Aus der Klinik für Neurologie

(Prof. Dr. med. M. Bähr)

der Medizinischen Fakultät der Universität Göttingen

\title{
Charakterisierung von Prädiktoren rapid-progressiver Verläufe des M. Alzheimer
}

\author{
INAUGURAL - DISSERTATION \\ zur Erlangung des Doktorgrades \\ der Medizinischen Fakultät der \\ Georg-August-Universität zu Göttingen
}

vorgelegt von

Thomas Bartlau

aus

Göttingen

Göttingen 2015 
Dekan:

Prof. Dr. rer. nat. H. K. Kroemer

I. Berichterstatterin: Prof. Dr. med. I. Zerr

II. Berichterstatter: $\quad$ Prof. Dr. rer. nat. R. Hilgers

III. Berichterstatter/in:

Tag der mündlichen Prüfung: $\quad$ 12.07.2016 


\section{Inhaltsverzeichnis}

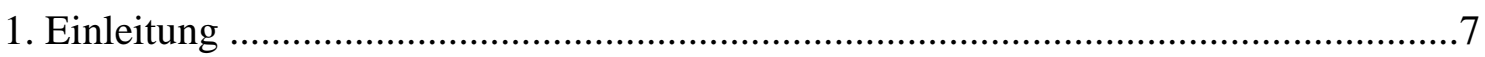

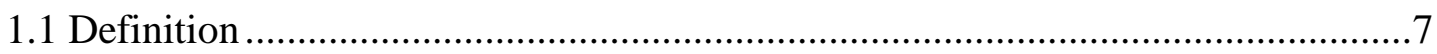

1.1.1 Alzheimer (Historischer Exkurs) ……………………………………………...

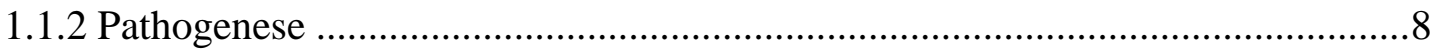

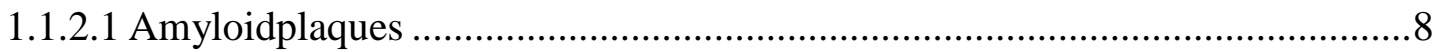

1.1.2.1.1 Nicht-amyloidogener Weg .................................................................

1.1.2.1.2 Amyloidogener Weg ................................................................................

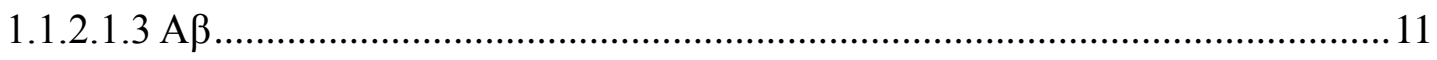

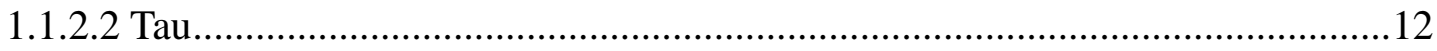

1.1.2.3 Inflammation ......................................................................................13

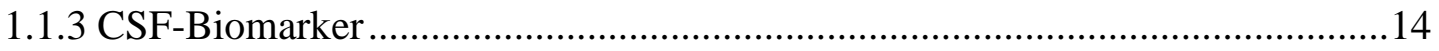

1.1.3.1 A

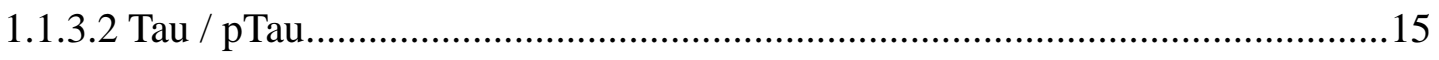

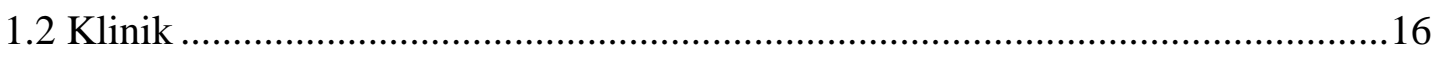

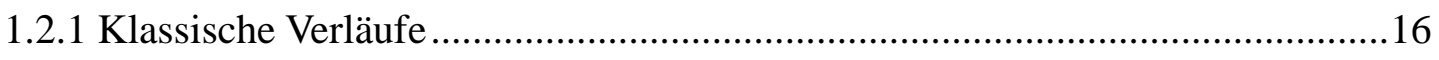

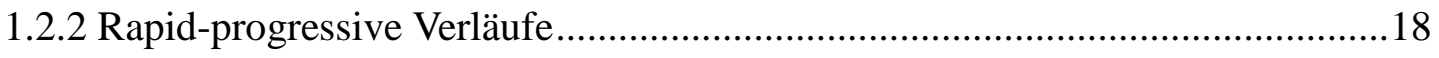

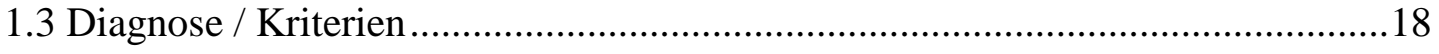

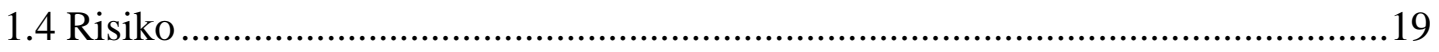

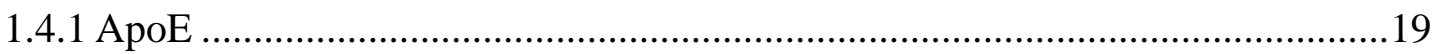

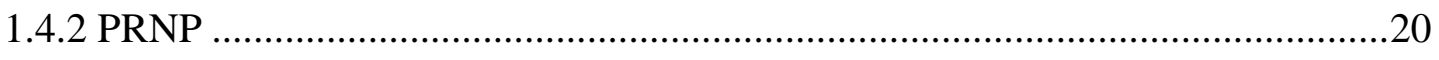

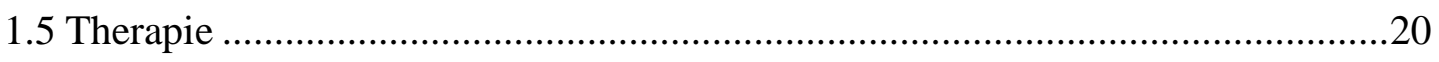

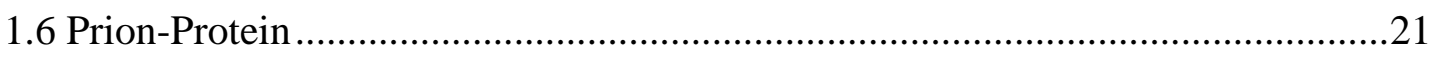

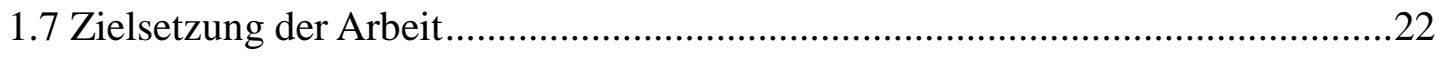

2. Material und Methoden .......................................................................................2

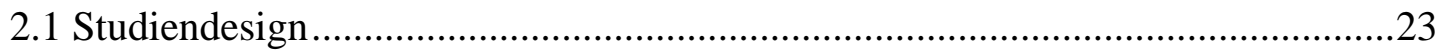

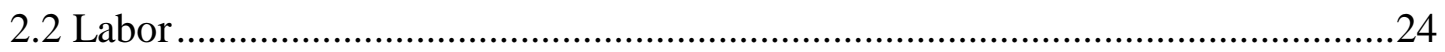

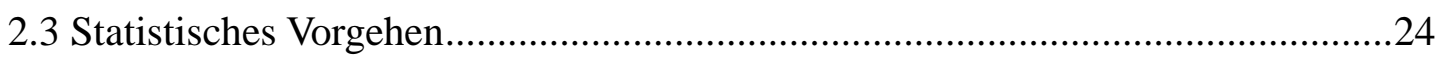

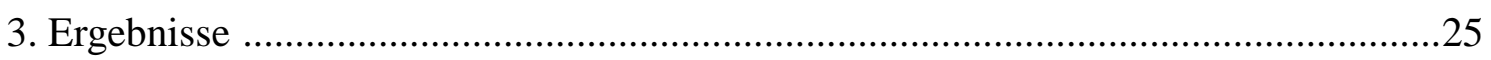

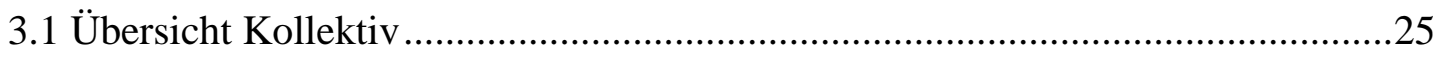

3.2 Verteilung der CSF-Parameter ......................................................................2

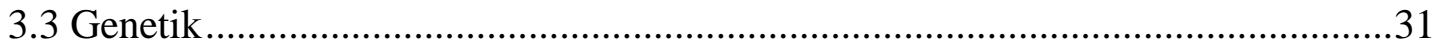

3.3.1 ApoE-Genetik ………………………………………………………....... 


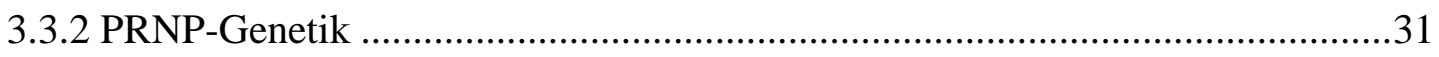

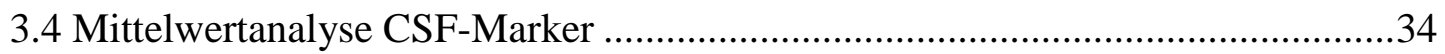

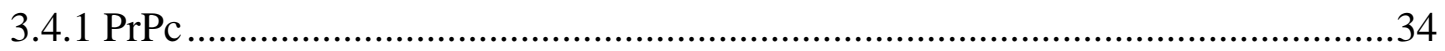

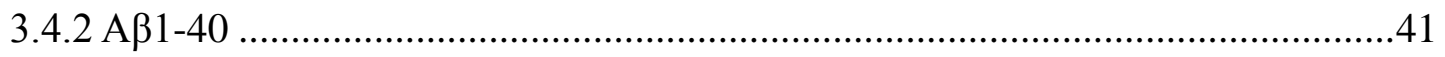

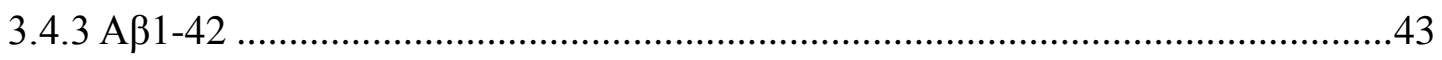

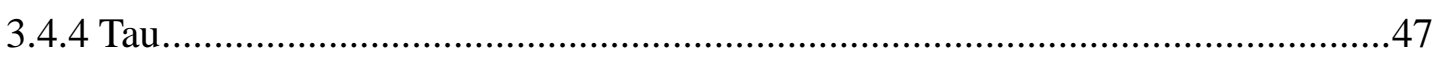

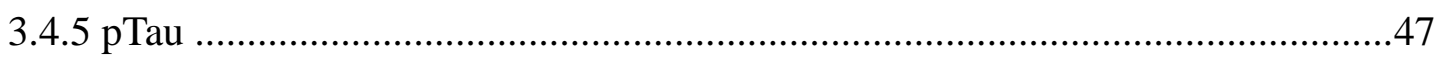

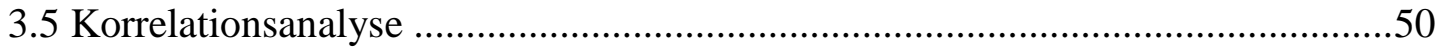

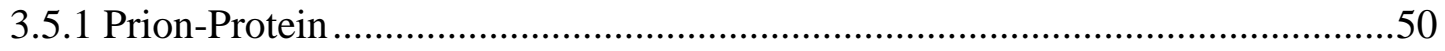

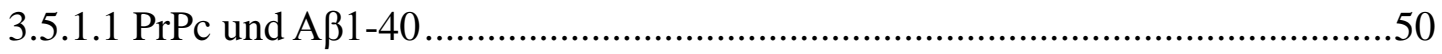

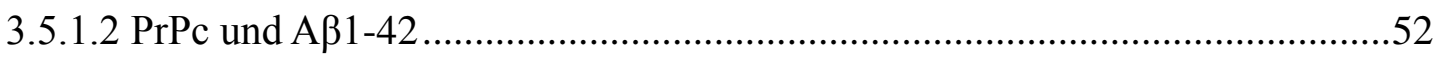

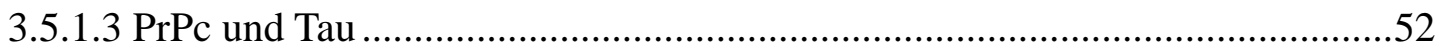

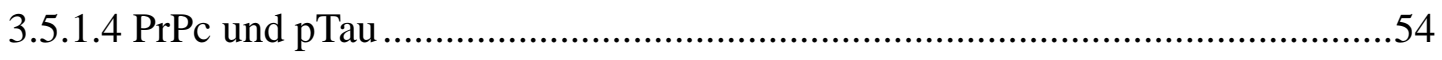

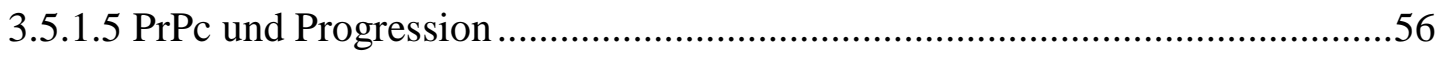

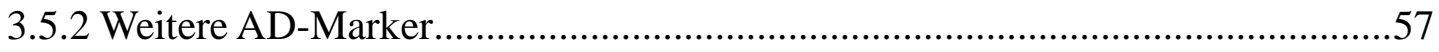

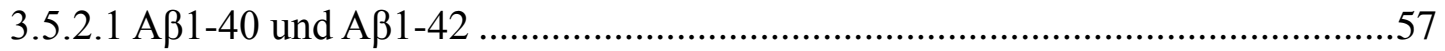

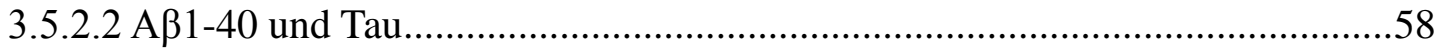

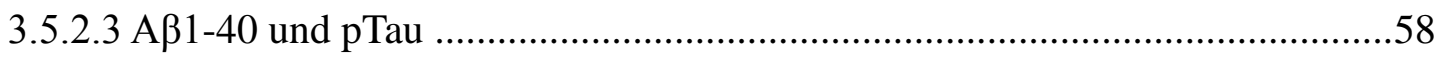

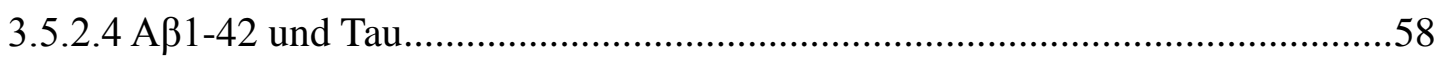

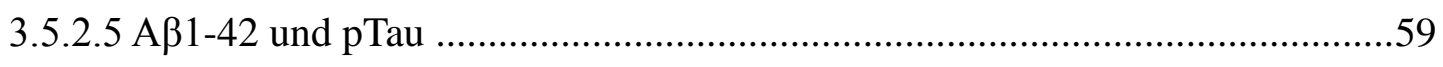

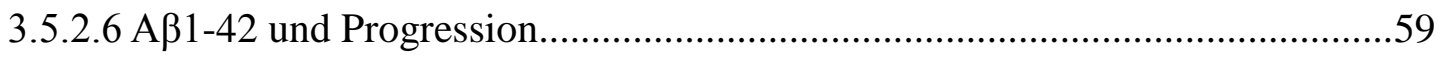

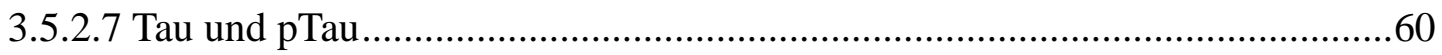

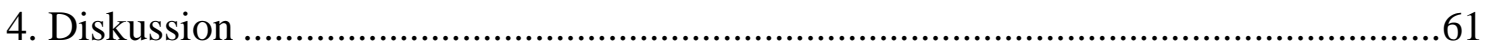

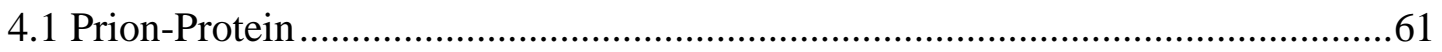

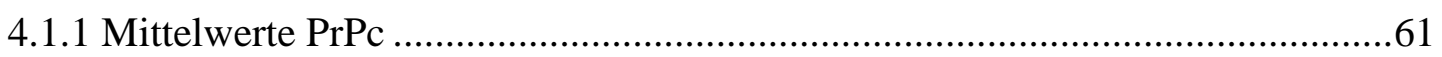

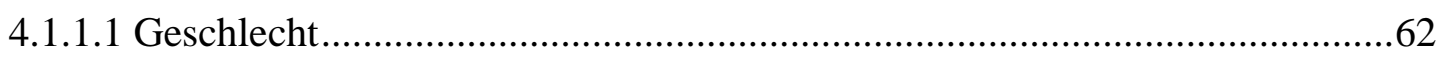

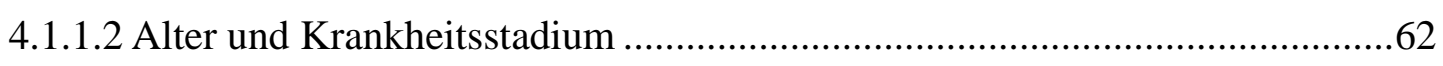

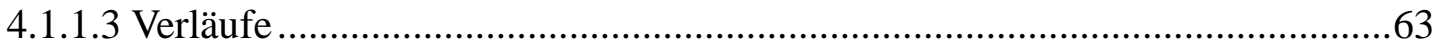

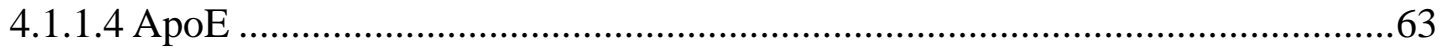

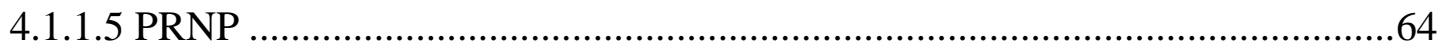

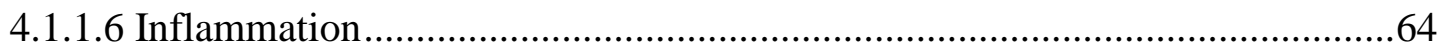

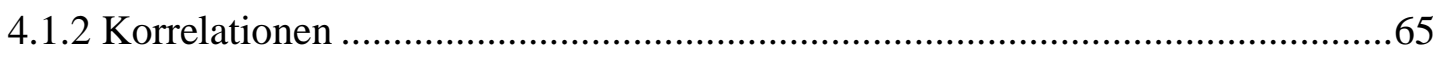

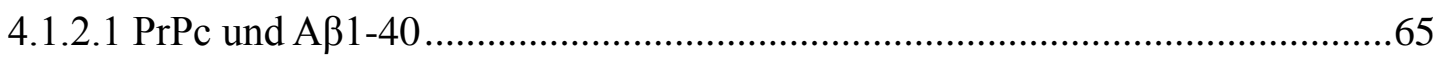

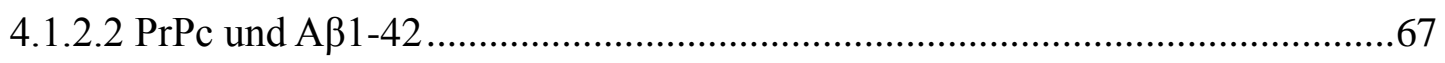

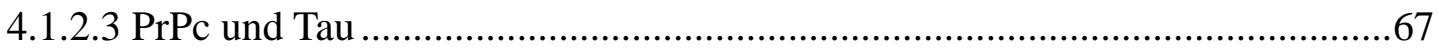




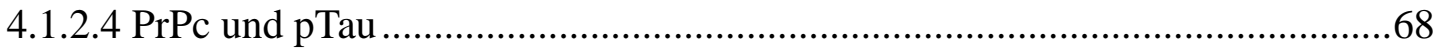

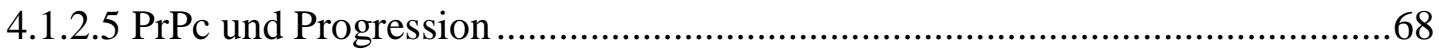

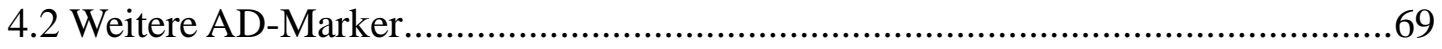

4.2.1 A

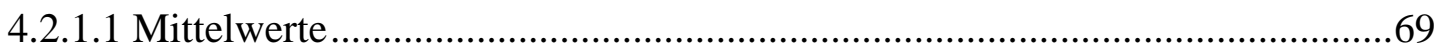

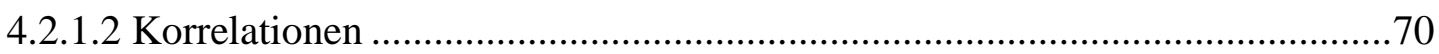

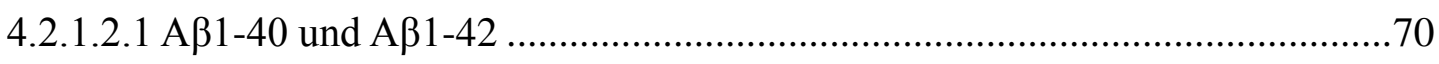

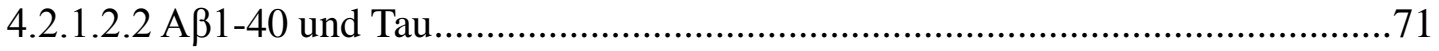

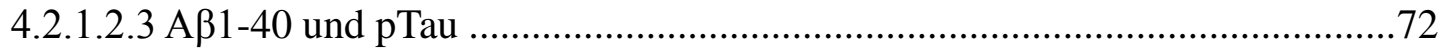

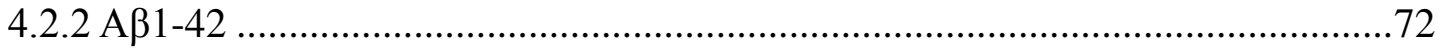

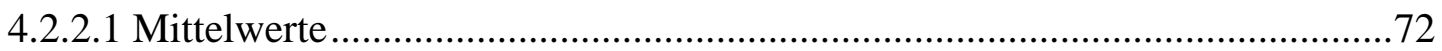

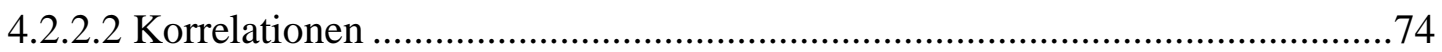

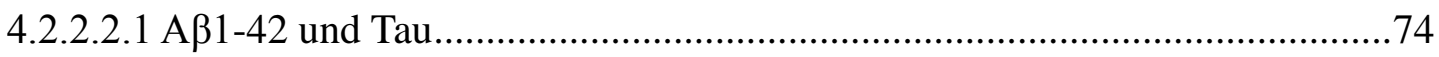

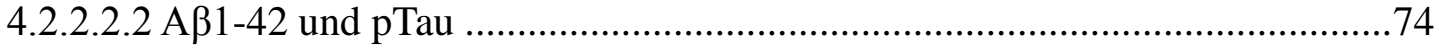

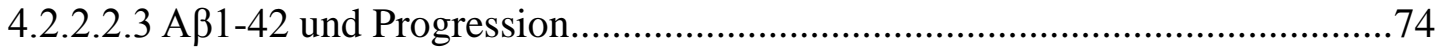

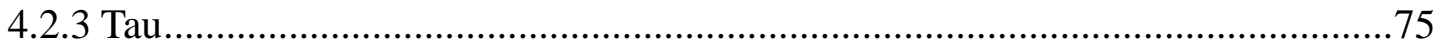

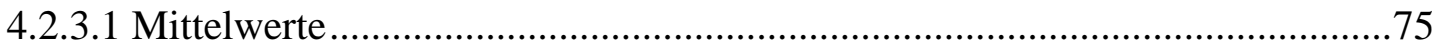

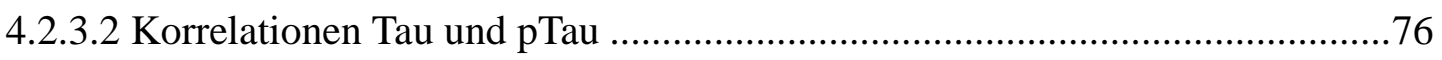

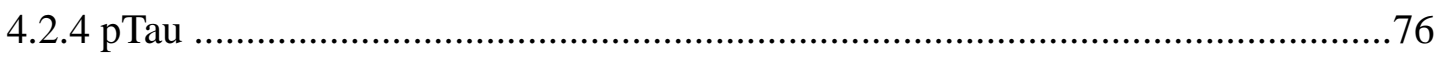

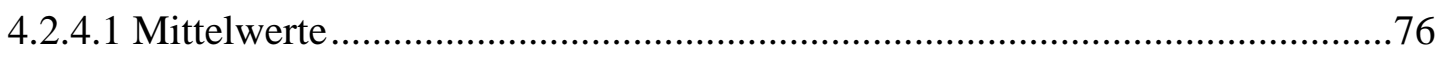

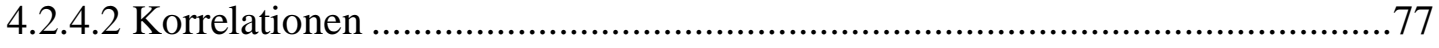

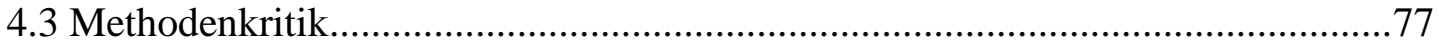

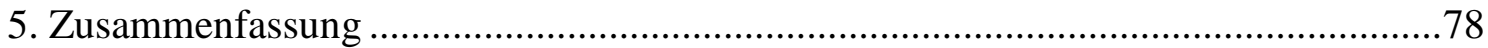

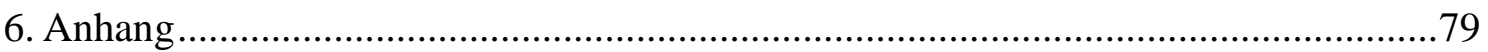

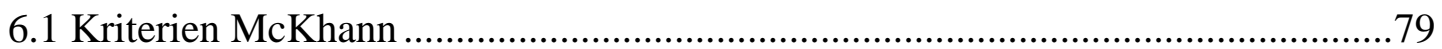

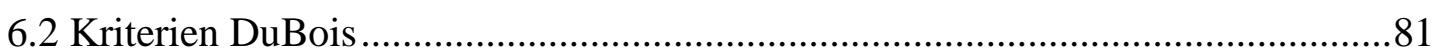

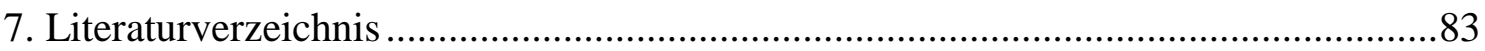


1. Einleitung

\subsection{Definition}

Demenzen sind Erkrankungen, die sich durch einen fortschreitenden Verlust verschiedener geistiger Fähigkeiten auszeichnen und zu einer erheblichen Beeinträchtigung in der Bewältigung des Alltags führen (Qiu et al. 2007).

Derzeit sind weltweit etwa 35 Millionen Menschen an einer Demenz erkrankt (Ballard und Corbett 2011) und es wird angenommen, dass sich deren Anzahl alle 20 Jahre verdoppeln wird (Qiu et al. 2007, Ferri et al. 2005).

Der Anteil der Alzheimerkrankheit (AD) an der Gesamtheit der Demenzerkrankungen wird mit 50\% bis $60 \%$ angegeben (De Leon et al. 2007).

Es ist zu beachten, dass die Definition des Begriffes Demenz nicht ganz einheitlich ist und die Zahlenangaben aufgrund verschiedener Klassifikationssysteme variieren (Erkinjuntti et al. 1997). Hierzulande findet das Diagnoseklassifikationssystem ICD (International Statistical Classification of Diseases and Related Health Problems) der Weltgesundheitsorganisation (WHO) Anwendung, die das Syndrom "Demenz" als Folge einer meist chronischen Krankheit des Gehirns mit daraus resultierender Störung höherer kortikaler Funktionen definiert (Diener 2008).

Gemäß der ICD-Definition müssen die Symptome wie z.B. Gedächtnis- oder Denkstörungen über einen Zeitraum von mindestens sechs Monaten bestehen.

Dieses ist problematisch, weil viele Verläufe dementieller Erkrankungen, darunter auch der AD, sehr rasch sein können und somit die Anforderungen der ICD-Definition nicht erfüllen (Geschwind et al. 2007, Josephs et al. 2009, Schmidt et al. 2010, Schmidt et al. 2011).

Es ist offensichtlich, dass dieses Thema eine große Herausforderung nicht nur für die Betroffenen selbst, sondern auch für die Gesellschaft und deren Gesundheitssysteme ist (Stefanacci 2011).

\subsubsection{Alzheimer (Historischer Exkurs)}

Am 3. November 1906 beschrieb der Psychiater und Neuropathologe Alois Alzheimer in seinem Vortrag „Über eine eigenartige Erkrankung der Hirnrinde“ im Rahmen der "Versammlung Südwestdeutscher Irrenärzte" in Tübingen den Fall einer Patientin, die ungewöhnlich jung, mit 51 Jahren, an einer dementiellen Symptomatik leidend in der damaligen Irrenanstalt in Frankfurt am Main behandelt wurde.

Die Patientin zeigte ,,als erste auffällige Krankheitserscheinung Eifersuchtsideen gegen ihren Mann“, „eine rasch zunehmende Gedächtnisschwäche“ und war ,zeitlich und örtlich gänzlich desorientiert“ (Alzheimer 1907). Nach einer Krankheitsdauer von 4 1/2 Jahren verstarb die Patientin, woraufhin Alzheimer ihr Gehirn neuropathologisch untersuchte. Er fand „ein gleichmäßig atrophisches Gehirn ohne makroskopische Herde“ vor und beschrieb unter anderem „sehr merkwürdige Veränderungen der Neurofibrillen“ sowie „miliare Herdchen, welche durch Einlagerung eines eigenartigen Stoffes in die Hirnrinde bedingt sind“" (Alzheimer 1907). 


\subsubsection{Pathogenese}

Die neuropathologischen Veränderungen der Alzheimerkrankheit (AD) sind gekennzeichnet durch die fortschreitende Ansammlung faserigen Materials, bestehend aus extrazellulärem Amyloid - sog. Plaques - und intrazellulären neurofibrillären Veränderungen - sog. Tangles - sowie einem Untergang von Nervengewebe.

Hieraus resultiert ein Volumenverlust des Gehirns - zunächst in den Gebieten des entorhinalen Cortex, Hippocampus und posterioren Gyrus cinguli, später auch des temporalen, parietalen und temporalen Cortex (Braak und Braak 1991, Duyckaerts et al. 2009, Frisoni et al. 2010).

\subsubsection{Amyloidplaques}

Die Plaques sind Ablagerungen von $\beta$-Amyloid, einem Polypeptid in der Größe von 3843 Aminosäuren, welches vorwiegend als $A \beta 1-40$ und A $\beta 1-42$ vorliegt, die durch Spaltung des Vorläuferproteins APP (amyloid precursor protein) durch Proteasen entstehen (Thinakaran und Koo 2008, Hardy 2006).

APP ist ein durch das APP-Gen auf Chromosom 21 codiertes Transmembranprotein, das insbesondere an den Synapsen von Neuronen vorkommt und dessen Bedeutung noch nicht vollständig geklärt ist (Zhang et al. 2011). Allerdings ist es an der Bildung von Synapsen, der neuronalen Plastizität und am Eisenstoffwechsel beteiligt (Priller et al. 2006, Turner et al. 2003, Duce et al. 2010).

\subsection{Nicht-amyloidogener Weg}

Im nicht-amyloidogenen Stoffwechselweg wird APP an dessen extrazellulärer Domäne zunächst durch eine $\alpha$-Sekretase gespalten, wobei sAPP $\alpha$, ein 100 - 110 kDa großes, lösliches Fragment freigesetzt wird (Bell et al. 2008).

Verschiedene Zink-Metalloproteinasen der ADAM (a disintegrin and metalloproteinase)-Familie wie ADAM17 (= tumor necrosis factor- $\alpha$ converting enzyme, TACE), ADAM10 und ADAM9 sowie die Aspartylprotease BACE2 ( $\beta$-site APP cleaving enzyme) besitzen $\alpha$-Sekretase-Eigenschaften und können APP in der A $\beta$ Domäne zwischen Lys16 und Leu17 schneiden, so dass sAPP $\alpha$ entsteht (Allinson et al. 2003). sAPP $\alpha$ wird in den Extrazellulärraum freigesetzt und ist bei der Entwicklung des 
Gehirns allgegenwärtig: es stimuliert die neuronale Stammzellproliferation und differenzierung sowie die Neuritenbildung, besitzt neurotrophische sowie neuroprotektive Eigenschaften und verbessert die Langzeitpotenzierung (Gralle und Ferreira 2007, Salbaum und Ruddle 1994, Löffler und Huber 1992, Ohsawa et al. 1999, Caillé et al. 2004, Mattson 1997, Taylor et al. 2008, Freude et al. 2011).

Das verbleibende, membrangebundene 83-Peptid $\alpha \mathrm{CTF}$ (carboxyl terminal fragment, CT83) wird durch den $\gamma$-Sekretase-Komplex gespalten, wobei das 3kDa große Peptid p3 und AICD (APP intracellular domain, 57-59 Aminosäuren) entstehen (Thinakaran und Koo 2008, Chang und Suh 2005).

Die $\gamma$-Sekretase ist eine Aspartylprotease, die neben APP noch weitere Substrate wie APLP2 (amyloid beta (A4) precursor-like protein 2), Notch, Delta und TACE (tumour necrosis factor- $\alpha$ converting enzyme) besitzt (Small et al. 2010).

Der $\gamma$-Sekretase-Komplex besteht aus vier Komponenten: Präsenilin 1 oder 2 (PS1, PS2), Nicastrin, Stabilisierungsfaktor APH-1(anterior pharynx-defective-1) und Präsenilin-Enhancer-2 (PEN-2) (Kimberly et al. 2003) (Takasugi et al. 2003).

Es wird angenommen, dass Präsenilin die katalytische Untereinheit des $\gamma$-SekretaseKomplexes ist, wobei die Rolle der anderen Komponenten (Nicastrin, APH1, PEN2) noch unklar ist (Small et al. 2010).

Mutationen des Präsenilin-Gens auf Chromosom 14 (Presenilin-1, PS1) und Chromosom 1 (Präsenilin-2, PS2) führen zu genetischen Alzheimer-Erkrankungen (Sherrington et al. 1995, Levy-Lahad et al. 1995, Rogaev et al. 1995).

Das durch $\gamma$-Sekretase-Spaltung entstandende AICD kann an der Regulation von Gentranskription - unter anderem als Transkriptionsfaktor für das A $\beta$-abbauende Enzym Neprilysin (Pardossi-Piquard et al. 2005, Belyaev et al. 2009) -, Apoptose und Calciumsignaltransduktion sowie an der Bildung und Prozessierung von APP beteiligt sein (Chang und Suh 2010). AICD wird durch IDE (insulin degrading enzyme) oder durch das Proteasom abgebaut (Cupers et al. 2001, Edbauer et al. 2002, Nunan et al. 2001, Nunan et al. 2003). Dem p3-Peptid werden sowohl aggregationsfördernde als auch neuroprotektive Eigenschaften zugesprochen (Dickson 1997, Higgins et al. 1996, Pike et al. 1995, Han et al. 2011).

\subsection{Amyloidogener Weg}

Im amyloidogenen Stoffwechselweg wird APP zunächst an dessen extrazellulärer Domäne durch eine $\beta$-Sekretase gespalten, wobei sAPP $\beta$ und das 99-Peptid $\beta C F T$ 
(=CT99) entstehen (Chang und Suh 2005).

Die $\beta$-Sekretase BACE1 ( $\beta$-site APP-cleaving enzyme) ist ein Typ 1-Transmembranprotein mit Aspartylprotease-Aktivität (Vassar 2001).

BACE1 ist die einzige Protease mit klar definierten $\beta$-Sekretase-Eigenschaften, wohingegen dessen naher Verwandter BACE2 vorwiegend $\alpha$-Sekretase-Eigenschaften besitzt (Cai et al. 2001, Luo et al. 2001, Yan et al. 2001).

BACE1 wird vorwiegend im Gehirn und Pankreas exprimiert, in geringen Mengen auch in anderen Organen, wohingegen BACE2 in peripheren Geweben vorkommt, mit den höchsten Konzentrationen in den Nieren (Bennett et al. 2000, Marcinkiewicz und Seidah 2000, Vassar et al. 1999). Im Gehirn konnte die mRNA beider Enzyme in Astrozyten nachgewiesen werden, allerdings wurde in Neuronen und Mikroglia ausschließlich BACE1 gefunden (Basi et al. 2003).

Das in den Extrazellulärraum freigesetzte $\operatorname{sAP} \beta$ induziert die neurale Stammzelldifferenzierung - möglicherweise noch potenter als das SAPP $\alpha$ - und ist auch an der Regulierung der Gentranskription beteiligt (Freude et al. 2011, Li et al. 2010). Das verbleibende $\beta C F T$ wird durch den $\gamma$-Sekretase-Komplex zu 4-kDa-großem A $\beta$ und 5759 Aminsäuren umfassendem AICD gespalten (Chang und Suh 2005).

A $\beta$ wird durch Metalloproteasen wie NEP (Neprilysin), ECE (endothelin-converting enzyme) und IDE (insulin degrading enzyme) abgebaut (Carson und Turner 2002).

Eine in den Gehirnen von Alzheimer-Patienten zu beobachtende Verminderung der A $\beta$ abbauenden Enzyme kann zu einem Anstieg der A $\beta$-Konzentration beitragen (Cook et al. 2003, Akiyama et al. 2001).

Des Weiteren kann APP durch Caspasen gespalten werden, wobei die neurotoxischen Fragmente C31 und Jcasp freigesetzt werden, die gemeinsam mit APP den Zelltod initiieren können (Park et al. 2009).

\subsection{A $\beta$}

Wie beschrieben, liegt $A \beta$ vorwiegend als $A \beta 1-40$ und $A \beta 1-42$ vor, wobei der Anteil von A $\beta 1-42$ ca. $10 \%$ der Menge von A $\beta 1-40$ beträgt, allerdings neigt A $\beta 1-42$ aufgrund seiner größeren Hydrophobizität stärker zur Selbstaggregation als sein Pendant und macht mit ca. 60\% einen Großteil des in den Plaques enthaltenen $\beta$-Amyloids aus (Burdick et al. 1992, Prior et al. 1996).

Man ging eine Zeit lang davon aus, dass das in den Plaques enthaltene fibrilläre A $\beta$ hauptursächlich für die Neurodegeneration bei AD war (Hardy und Higgins 1992), da 
die Zytotoxizität von $A \beta$ - insbesondere von $A \beta 1-42$ - nachgewiesen werden konnte (Pike et al. 1991, Pike et al. 1993, Deshpande et al. 2006, Klein et al. 1999). Jedoch korrelieren neuronaler Zellverlust und eingeschränkte Gedächtnisfunktion nur schwach mit der Plaque-Last in Gehirnen von Patienten mit AD (Giannakopoulos et al. 2003). Vielmehr werden nun auch präfibrilläre Aggregationsformen des $A \beta$ als ein Verursacher der Neurodegeneration bei AD vermutet (Catalano et al. 2006, Klein et al. 2004, Klein 2006, Lue et al. 1999, McLean et al. 1999).

Es konnte gezeigt werden, dass $\mathrm{A} \beta$-Oligomere im Gegensatz zu A $\beta$-Monomeren die Gedächtnisfunktion verschlechtern (Selkoe 2008, Balducci et al. 2010), allerdings ist umstritten, ob die oligomere Form von $\mathrm{A} \beta$ tatsächlich einen stärkeren neurotoxischen Effekt hat als dessen monomere oder fibrilläre Pendants (Manzoni et al. 2011, Neniskyte et al. 2011). A $\beta$ unterdrückt die synaptische Aktivität, doch könnte dieses sowohl eine physiologische als auch eine pathologische Eigenschaft sein (Lacor et al. 2004, Kar et al. 2004, Pearson und Peers 2006).

Über verschiedene PRR (=pattern recognition receptor)-vermittelte Signalwege wie TLR (=toll-like receptor), RAGE (receptor for advanced glycation endproducts) und NRL (NOD-like receptor) vemag $A \beta$ eine Immunantwort auszulösen, die eine lokale Inflammation bedingen kann (Glass et al. 2010). Darüberhinaus erfüllt $A \beta$ die Eigenschaften eines antimikrobiellen Peptids (AMP), die als ein Bestandteil der angeborenen Immunantwort der Bekämpfung von Bakterien, umhüllten Viren, Pilzen, Protozoen und veränderten Wirtszellen dienen (Soscia et al. 2010).

Weiterhin kann A $\beta$ über die Aktivierung der Glykogensynthase-Kinase 3 (GSK3) zur Tau-Hyperphosphorylierung beitragen (s.u.) (Jin et al. 2011, Mines et al. 2011).

\subsubsection{Tau}

Tau ist der Hauptbestandteil des zweiten histopathologisch hervorstechenden Merkmals des Morbus Alzheimer, der neurofibrillären Tangles (NFT) (Grundke-Iqbal et al. 1986, Braak und Braak 1991, Braak und Braak 1995), deren Anzahl hier mit der Abnahme der kognitiven Leistung korreliert (Arriagada et al. 1992, Giannakopoulos et al. 2003). Innerhalb dieser neurofibrillären Tangles liegt das üblicherweise aggregationsträge Tau als paarige helicale Filamente (PHF) vor (Grundke-Iqbal et al. 1986, Iqbal et al. 1989, Iqbal et al. 1986, Lee et al. 1991, Goedert et al. 1992).

Das zu den Mikrotubuli-assoziierten Proteinen (MAP) zählende 50 bis 64 kDa große Tau-Protein (Robert und Mathuranath 2007) stabilisiert in Neuronen die Struktur der 
Mikrotubuli durch den Einbau von Tubulin (Weingarten et al. 1975).

Im ZNS liegt Tau in sechs Isoformen vor (Goedert et al. 1989, Himmler et al. 1989, Buée et al. 2000). Allen Isoformen sind die folgenden funktionellen Regionen gemein: eine C-terminale Domäne, über deren Phosphorylierung die Bindung an Mikrotubuli reguliert werden kann, eine Mikrotubuli-Bindungs-Domäne, eine phosphorylierbare, positiv geladene prolinreiche Domäne sowie eine negativ geladene N-terminale Domäne (Metcalfe und Figueiredo-Pereira 2010).

Die biologische Aktivität von Tau wird durch den Grad der Phosphorylierung bestimmt (Lindwall und Cole 1984, Köpke et al. 1993, Alonso et al. 1994, Johnson und Stoothoff 2004, Feijoo et al. 2005, Reynolds et al. 2008).

Tau wird durch Serin/Threoninkinasen phosphoryliert, die in proline-directed protein kinases (PDPK) und non-proline directed protein kinases (NPDPK) eingeteilt werden können, also in Proteinkinasen, die Serin und Threonin phosphorylieren, wenn ihnen ein Prolin folgt (PDPK) oder nicht folgt (NPDPK) (Morishima-Kawashima et al. 1995).

$\mathrm{Zu}$ den PDPKs zählen GSK3 (= tau kinase I), cdk5 (= tau kinase II) und Stresskinasen wie JNK und p38, zu den NPDPKs zählen unter anderem CAMK2 (Ca2+/calmodulindependent kinase II), die Proteinkinasen A, B und C (PKA, PKB, PKC), SGK (serum and glucocorticoid-dependent kinase) und MARK (microtubule affinity regulating kinase) (Gómez-Ramos et al. 2004, Metcalfe und Figueiredo-Pereira 2010).

Das beim Morbus Alzheimer auftretende hyperphosphorylierte Tau (pTau) verhindert die Bindung von Tubulin und stört das mikrotubuläre Gefüge (Alonso et al. 1994, Li et al. 2007, Drewes 2004). Außerdem scheint die Hyperphosphorylierung auch die Aggregation von Tau zu fördern (Alonso et al. 1996, Maeda et al. 2006).

Allerdings liegt Tau auch physiologischerweise teilweise und reversibel hyperphosphoryliert vor, so z.B. fetales Tau, daher könnte insbesondere die irreversible Art der abnormen Hyperphosphorylierung von Tau eine Ursache für die Neurodegeneration bei AD sein (Iqbal et al. 2010).

Tau wird durch verschiedene Phosphatasen dephosphoryliert (Drewes et al. 1993, Gong et al. 2000, Liu et al. 2005). Die verminderte Aktivität der Proteinphosphatase-2A (PP2A) in den Gehirnen von Patienten mit Morbus Alzheimer oder Down Syndrom wird als eine Ursache für die dauerhafte und irreversible Hyperphosphorylierung von Tau verdächtigt (Gong et al. 1995, Gong et al. 1993, Vogelsberg-Ragaglia et al. 2001, Liang et al. 2008, Sontag et al. 2004).

Die Hyperphosphorylierung des Tau-Proteins scheint dessen Konformationsänderung 
und Spaltung vorauszugehen (Delobel et al. 2008), was sich auch bei anderen neurodegenerativen Erkrankungen wie FTDP-17 (fronto-temporal dementia with Parkinsonism linked to chromosome 17), Morbus Pick, Dementia Pugilistica, Kortikobasale Degeneration und Progressive Supranukleäre Blickparese (PSP) beobachten lässt (Iqbal et al. 2010).

Die Mechanismen der Tau-vermittelten Neurodegeneration sind noch nicht vollends entschlüsselt, allerdings scheint die Bildung neurofibrillärer Tangles keine Voraussetzung für eine neuronale Schädigung zu sein.

Infolge eines Zusammenbruchs des intrazellulären Transports könnte nicht nur die ATPabhängige Signaltransmission beeinträchtigt werden, sondern das Neuron insgesamt anfälliger für Stressoren wie Inflammation (s.u.), oxidativen Stress, mitochondriale Dysfunktion, Calciumdysregulation und Excitotoxizität sein (LaPointe et al. 2009, Gendron und Petrucelli 2009).

\subsubsection{Inflammation}

Akute und chronische Inflammation führen zu oxidativem Stress, dessen Folge Zellalterung und schädigung sowie Neurodegeneration sein kann (Calabrese et al. 2004). Ein Zusammenhang zwischen chronischer Inflammation des Gehirns und AD wurde mehrfach beschrieben (Akiyama 1994, Town 2010, Herrup 2010) und es konnte gezeigt werden, dass die Schwere der Inflammation mit dem Erkrankungsalter und dem kognitiven Abbau korreliert (Barber 2011).

Dieses scheint auch dadurch untermauert $\mathrm{zu}$ werden, dass einige anti-inflammatorische Medikamente, wie z.B. das NSAID (= nonsteroidal anti-inflammatory drug) Ibuprofen einen geringen protektiven Effekt bezüglich AD besitzen könnten (Vlad et al. 2008), verursacht z.B. durch eine aufgrund von indirekter oder direkter Modulation der Sekretasen $\beta$ und $\gamma$ bedingten Verringerung der Bildung von A $\beta 1-42$ oder durch darüberhinausgehende, bislang unbekannte Effekte der Wirkstoffe (Sastre et al. 2008).

Proinflammtorische Zytokine wie IFN- $\gamma$ können die Produktion von A $\beta$ stimulieren (Giunta et al. 2008) und ein inflammatorisches Milieu scheint die Aggregation von Tau in NFTs zu begünstigen (Metcalfe und Figueiredo-Pereira 2010).

\subsubsection{CSF-Biomarker}

Biomarker können definiert werden als Merkmale, die objektiv gemessen werden können als ein Indikator für normale biologische Prozesse, pathologische Prozesse oder pharmakologische Antworten auf therapeutische Interventionen (Schmitz 2008).

Sie können helfen, pathologische Veränderungen von physiologischen abzugrenzen und somit eine Diagnosestellung zu ermöglichen.

Im Folgenden werden die in der Alzheimerdiagnostik etablierten Biomarker vorgestellt. 


\subsubsection{A $\beta$}

Wie beschrieben, wird $A \beta$ größtenteils in den Extrazellulärraum des Gehirns freigesetzt, wo es zum Teil in den Liquor cerebrospinalis (=CSF, cerebrospinal fluid) diffundiert und dort in mäßigen Konzentrationen ( 10-15 ng/ml) nachgewiesen werden kann (Holtzman 2011). A $\beta 1-42$ im CSF ist als Biomarker in der AD-Diagnostik etabliert, erniedrigte Werte sprechen für eine AD (Shaw et al. 2009, Humpel 2011), obgleich auch andere neurodegenerative Erkrankungen verminderte Konzentrationen von Aß1-42 im CSF aufweisen können (Holtzman 2011, Gloeckner 2010).

Auch konnte gezeigt werden, dass erniedrigte Werte für A $\beta 1-42$ im CSF eine negative Korrelation mit der Alzheimer-Pathologie aufweisen (Strozyk et al. 2003, Tapiola et al. 2009, Bendlin et al. 2012).

Man nimmt an, dass die Ablagerung in Form von Plaques ein Übertreten von A $\beta 1-42$ in den CSF erschwert und dieses dort somit nur in geringeren Konzentrationen nachweisbar ist (Holtzman 2011, Irwin et al. 2013).

Die Konzentration von A $\beta 1-42$ im CSF von Probanden mit AD scheint im Verlauf der Erkrankung weitestgehend stabil zu sein (Sunderland et al. 1999, Blennow et al. 2007, De Leon et al. 2007), obgleich sie bei ApoE \&4-Allelträgern mit der Zeit etwas abnehmen soll (Huey et al. 2006).

Im Gegensatz zu A $\beta 1-42$ ist $A \beta 1-40$ im CSF von Probanden mit AD gegenüber gesunden Kontrollen unverändert stark ausgeprägt (Holtzman 2011), womit A $\beta 1-40$ allein als Biomarker für die ADDiagnostik ungeeignet ist.

In der Diagnostik anderer neurodegenerativer Erkrankungen, z.B. der cerebralen Amyloidangiopathie (CAA) kann A $\beta 1-40$ von Bedeutung sein (Verbeek et al. 2009).

\subsubsection{Tau / pTau}

Tau und pTau sind - insbesondere in Kombination mit A $\beta 1-42$ - geeignete CSF-Biomarker für die Diagnostik von AD (Bendlin et al. 2012).

Erhöhte Konzentrationen von Tau im CSF werden als allgemeiner Hinweis auf eine neuronale Schädigung angesehen, da es hier sowohl bei neurodegenerativen Erkrankungen als auch nach Traumata des zentralen Nervensystems vermehrt nachgewiesen werden kann (Irwin et al. 2013).

Es konnte gezeigt werden, dass die CSF-Konzentration von pTau positiv mit der Anzahl neurofibrillärer Tangles korreliert (Buerger et al. 2006, Tapiola et al. 2009).

Im Verlauf der Alzheimerkrankheit scheinen die CSF-Konzentrationen von Tau weitgehend stabil zu sein (Sunderland et al. 1999, Blennow et al. 2007, De Leon et al. 2007, Vemuri et al. 2010).

Bei Gesunden wurde ein Ansteigen der Konzentrationen von Tau im CSF mit zunehmendem Lebensalter beschrieben (Sjögren et al. 2001, Vemuri et al. 2010).

Insbesondere dem hyperphophorylierten pTau wird aufgrund seiner engen Assoziation zur Alzheimerkrankheit (s.o.) eine besondere Bedeutung bei der CSF-Diagnostik beigemessen 
(Holtzman 2011, Irwin et al. 2013).

\subsection{Klinik}

\subsubsection{Klassische Verläufe}

Obgleich das klinische Bild der Alzheimerkrankheit insgesamt recht heterogen ist (Wilkosz et al. 2010, Komarova und Thalhauser 2011), soll im Folgenden die derzeitige Vorstellung eines "klassischen" Verlaufs aufgezeigt werden.

Erste Symptome zeigen sich in einer Verschlechterung des episodischen Gedächtnisses, insbesondere des anterograden (Butters et al. 1983, Butters et al. 1987, Kopelman 1985, Moss et al. 1986, Heindel et al. 1989, Christensen et al. 1998, Fox et al. 1998), da die ersten neurofibrillären Veränderungen den transentorhinalen Cortex des medialen Temporallappens betreffen und die Verbindung des Hippocampus zu anderen kortikalen Regionen stören. Im weiteren Verlauf der Krankheit wird die hippocampale Formation selbst befallen (Hyman et al. 1984, Braak und Braak 1995).

In den meisten Fällen geht der Demenz ein jahrelanges Prodromalstadium einer leichten kognitiven Störung (= mild cognitve impairment, MCI) voraus (Petersen et al. 1994, Petersen 2004, Hodges 1998, Fabrigoule et al. 1998, Bäckman et al. 2001). Die Deutsche Gesellschaft für Neurologie (DGN) definiert MCI ,als subjektive und objektivierbare kognitive Leistungsverschlechterung bei erhaltener Alltagskompetenz“, wobei allerdings bislang keine allgemeingültige Definition gefunden wurde (Petersen 2004, Diener 2008). Ausgehend von einer Unterteilung des MCI in die Subtypen aMCI (amnestic), md-MCI (multiple domains slightly impaired) und na-MCI (single nonmemory domain) (Busse et al. 2003), sind insbesondere Patienten mit einer Beeinträchtigung des episodischen Gedächtnisses (Typ a-MCI) gefährdet, eine Demenz vom Alzheimer-Typ zu entwickeln (Sarazin et al. 2007, Landau et al. 2010, Blacker et al. 2007), wobei sich möglicherweise viele Fälle unter den a-MCI bereits in einem prä-dementiellen Stadium von AD befinden, da angenommen wird, dass die Krankheit bereits 25 bis 30 Jahre vor ihrer klinischen Manifestation beginnt (Markesbery et al. 2006, Davies et al. 1988).

Die Konversionsrate vom MCI zur ausgeprägten Demenz wird je nach MCI-Subtyp und Studie im Schnitt mit 10\% bis 25\% pro Jahr angegeben (Petersen et al. 2001, Bruscoli und Lovestone 2004, Geslani et al. 2005, Mitchell und Shiri-Feshki 2009, Fischer et al. 2007, Petersen und Negash 2008, Schmidtke und Hermeneit 2008).

Der verzögerte Abruf neuer Informationen, z.B. von Wortlisten, ist bereits im frühen Krankheitsstadium eingeschränkt und dient somit als sensitives Testwerkzeug (Butters et al. 1987, Greene et al. 1996, Clague et al. 2005, Fox et al. 1998, Locascio et al. 1995, Perry und Hodges 2000). 
Ebenfalls früh betroffen ist das semantische Gedächtnis: so ist bei AD-Patienten die verbale Flüssigkeit (z.B. Aufzählung von Tieren) deutlich stärker beeinträchtigt als die phonematische Flüssigkeit (Aufzählen von Wörtern mit demselben Anfangsbuchstaben) (Rosser und Hodges 1994, Henry et al. 2004).

Auch lässt die Fähigkeit zur Benennung von Objekten und Personen im frühen Krankheitsverlauf nach (Bayles und Tomoeda 1983, Martin und Fedio 1983, Greene und Hodges 1996, Thompson et al. 2002).

Selektive und geteilte Aufmerksamkeit sind bereits in einem frühen Krankheitsstadium vermindert (Perry und Hodges 1999, Amieva et al. 2004, Pignatti et al. 2005), wohingegen Daueraufmerksamkeit bzw. Vigilanz (Perry und Hodges 1999, Sahakian et al. 1988) sowie Exekutive Funktionen erst im weiteren Verlauf beeinträchtigt sind (Perry und Hodges 1999, Kopelman 1991).

Räumlich-visuelle sowie Wahrnehmungsstörungen folgen zumeist den Gedächtnis- und Aufmerksamkeitsdefiziten (Perry et al. 2000, Caine und Hodges 2001).

Mit der Schwere der Erkrankung nehmen auch die neuropsychiatrischen Symptome zu:

so finden sich bei einem Viertel bis der Hälfte der Patienten Antriebslosigkeit, häufig im Rahmen einer Depression (Hodges 2006).

Darüberhinaus scheint Antriebslosigkeit einen Hinweis auf einen möglicherweise aggressiveren Verlauf der Krankheit zu geben (Starkstein et al. 2006), obgleich die Datenlage über die Rolle einer Depression in der Ätiologie der AD widersprüchlich ist (Wint 2011, Beekman 2011).

Wahnvorstellungen, insbesondere paranoide Ideen, treten häufiger auf als Halluzinationen, die eher in späteren Krankheitsstadien zu beobachten sind (Hodges 2006).

Im Verlauf der Krankheit nehmen motorische Symptome wie Gangstörungen und Rigidität zu (Scarmeas et al. 2004) und das Auftreten von Krampfanfällen ist im Spätstadium möglich (Bird 1993).

Die Überlebenszeit beträgt durchschnittlich acht bis zwölf Jahre; der Tod tritt dann zumeist als Folge von Sekundärkomplikationen ein (Bird 1993).

Die Progressionsrate - definiert durch die Punktdifferenz zwischen den Ergebnissen der MMSE im Verlauf - beträgt bei einem "klassischen" Verlauf ungefähr drei Punkte Verlust im MMSE pro Jahr (Goldberg 2007), obgleich auch deutlich schnellere Verläufe beschrieben wurden (s.u.) (Schmidt et al. 2010).

\subsubsection{Rapid-progressive Verläufe}

Aufgrund der nur sehr kurzen Überlebenszeit von durchschnittlich zwei bis drei Jahren und einer Vielzahl früh auftretender motorischer und fokalneurologischer Symptome ist die Diagnose einer sehr schnell verlaufenden Alzheimerkrankheit (=rapidly progressive Alzheimer's Disease, rpAD) mitunter recht schwierig und lässt differentialdiagnostisch eher an eine schnell verlaufende Demenz anderer Ursache denken (Schmidt et al. 2010). Hierzu zählen andere neurodegenerative Erkrankungen wie die Creutzfeldt-Jakob-Krankheit (CJD), Infektionen wie die Herpes-simplex- 
Enzephalitis oder Autoimmunerkrankungen wie die Hashimoto-Enzephalopathie (Geschwind u. a. 2007). Der Anteil rapid-progressiver Verläufe an der Gesamtheit von AD liegt je nach Definition des Begriffs "rapid" - vorgeschlagen wurde eine Progression von mindestens sechs Punkten Verlust im MMSE pro Jahr - bei 10\% bis 30\%, wobei die Datenlage zu deren Prädiktoren oft widersprüchlich ist (Schmidt et al. 2011).

\subsection{Diagnose / Kriterien}

Die Deutsche Gesellschaft für Neurologie empfiehlt in ihren aktuellen Leitlinien (November 2009) die Anwendung der NINCDS-ADRDA (National Institute of Neurological and Communicative Disorders and Stroke / Alzheimer's Disease and Related Disorders Association)-Kriterien nach McKhann (siehe auch 6.3) (McKhann et al. 1984, Diener 2008). Die Genauigkeit der klinischen Diagnose kann durch Bestimmung von Biomarkern im CSF - erhöhte Konzentrationen von GesamtTau und Phospho-Tau sowie erniedrigte Konzentrationen von A $\beta 1-42$ - und durch Volumenmessung mittels bildgebender Verfahren wie Magnetresonanz- (=MRI) und Positronenemissions-Tomographie (=PET) erhöht werden (Shaw et al. 2009, Weiner et al. 2010). Daher werden in der Studie, auf deren Daten die Ergebnisse dieser Arbeit beruhen, die "revidierten McKhann-Kriterien zur Diagnose des M. Alzheimer modifiziert nach Dubois" angewandt (siehe auch 6.4), die insbesondere das im Krankheitsverlauf zunächst betroffene episodische Gedächtnis (s.o.) berücksichtigen und laborchemische- sowie Bildgebungsverfahren zur Unterstützung der klinischen Hypothese miteinbeziehen (Dubois et al. 2007).

\subsection{Risiko}

Es wird zwischen einer früh beginnenden $\mathrm{AD}$ (early-onset Alzheimer disease, EOAD) und einer spät beginnenden $\mathrm{AD}$ (late-onset Alzheimer disease, LOAD) unterschieden. Die Altersgrenze wird üblicherweise bei 65 Jahren festgelegt. Der Anteil von EOAD beträgt 1\% bis 6\% aller AlzheimerErkrankungen (Szigeti und Doody 2011).

Mutationen in den im Abschnitt "Pathogenese" genannten Genen APP, PSEN1 und PSEN2 sind lediglich bei der autosomal-dominant vererbten, familiären Form, die mit ca. $0,1 \%$ nur einen Bruchteil aller AD ausmacht, ursächlich (Campion et al. 1999).

Die sporadische Form, die den Großteil aller AD ausmacht, scheint eine multifaktoriell bedingte Krankheit zu sein, zu deren Risikofaktoren neben steigendem Alter, einem ungesunden und bildungsarmen Lebensstil sowie Traumata möglicherweise auch zahlreiche genetische Faktoren gehören, zu denen das ع4-Allel des Apolipotrotein E-Gens (ApoE) zählt (Blennow et al. 2006, Coon et al. 2007).

\subsubsection{ApoE}

Apolipoprotein E (ApoE) wird vorwiegend in der Leber gebildet und dient als Ligand für die 
rezeptorvermittelte Endozytose von Lipoprotein-Partikeln (Kim et al. 2009). ApoE ist das am häufigsten auftretende Apolipoprotein im ZNS und ist dort entscheidend am Fettstoffwechsel beteiligt. Es wird hier hauptsächlich von Astrozyten sezerniert, doch wird es in Folge einer Schädigung wahrscheinlich auch von Neuronen und Mikroglia gebildet (Hayashi 2011).

Insgesamt ist die Produktion von ApoE infolge von neuronaler Schädigung erhöht (Ignatius et al. 1986, Snipes et al. 1986, Boyles et al. 1990).

ApoE kommt in den Isoformen ApoE2, ApoE3 und ApoE4 vor, die durch die Allele $\varepsilon 2$, $\varepsilon 3$ sowie $\varepsilon 4$ verschlüsselt werden (Hayashi 2011) und es scheint sowohl anti-inflammatorische als auch neuroprotektive Eigenschaften zu besitzen (LaDu et al. 2001, Hayashi et al. 2009, Leoni et al. 2010). Das $\varepsilon 4$-Allel bringt dabei das höchste Risiko mit sich, an AD zu erkranken, wobei das ع2-Allel mit dem geringsten Erkrankungsrisiko assoziiert ist (Corder et al. 1994, Coon et al. 2007), allerdings ist umstritten, welchen Einfluß $\varepsilon 4$ auf den weiteren Krankheitsverlauf hat (Wilkosz et al. 2010).

Eine höhere Gendosis von $\varepsilon 4$ bedingt auch eine höhere Amyloid-Last in den Gehirnen von an AD Erkrankten (Schmechel et al. 1993) sowie von Gesunden (Reiman et al. 2009). Hierzu kann auch beitragen, dass die Passage von ApoE4-A $\beta$-Komplexen durch die Blut-Hirn-Schranke deutlich

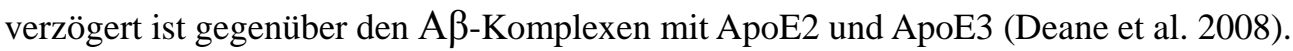

Im Versuch konnte gezeigt werden, dass die anti-inflammatorischen Eigenschaften von ApoE4 geringer sind als die von ApoE3 (Kim et al. 2009) und dass die neuronale bzw. synaptische Reparationsleistung unter Beteiligung von ApoE4 infolge einer Schädigung ebenfalls schwächer ist (Bu 2009).

\subsubsection{PRNP}

Das humane Prion-Proteingen (PRNP) ist auf dem kurzen Arm von Chromosom 20 lokalisiert und verschlüsselt das Prion-Protein (s.u.) (Puckett et al. 1991).

Mutationen des Prion-Proteingens können zu verschiedenen Krankheiten führen wie der familiären Creutzfeldt-Jakob-Erkrankung (CJK), dem Gerstmann-Sträussler-Scheinker-Syndrom (GSS) sowie der tödlichen familiären Schlaflosigkeit (fatal familial insomnia = FFI) (Takada und Geschwind 2013).

Insbesondere am Codon 129 des Prion-Proteingens besteht ein Methionin/Valin-Polymorphismus, der für Ausbruch und Verlauf sporadischer Prionerkrankungen mitentscheidend ist (Gambetti et al. 2011).

Inwiefern dieser Polymorphismus Entstehung und Verlauf der Alzheimerkrankheit beeinflusst, wird derzeit diskutiert (Riemenschneider et al. 2004, Smid et al. 2013).

\subsection{Therapie}

Den Leitlininien der Deutschen Gesellschaft für Neurologie (DGN) entsprechend, stehen für die pharmakologische Therapie der "Kernsymptomatik der Demenz" zwei Wirkstoffgruppen Acetylcholinesterase-Hemmer und der nicht-kompetitive NMDA-Antagonist Memantin - zur 
Verfügung.

Acetylcholinesterase-Hemmer (Donepezil, Galantamin, Rivastigmin) sind zur Behandlung einer leichten bis mittelschweren Alzheimer-Demenz zugelassen, Memantin findet bei mittelschwerer und schwerer Demenz Anwendung.

Ein kausale Therapie existiert derzeit nicht (Diener 2008).

\subsection{Prion-Protein}

Zelluläres Prion-Protein (PrPc) ist ein 208 bis 209 Aminsosäuren großes, GPI(=Glycosylphosphatidylinositol)-verankertes Protein, das auf der Zelloberfläche zahlreicher Gewebe vorkommt: insbesondere an Zellen des Nerven- und des Immunsystems hoch exprimiert, konnte es auch in anderen Geweben nachgewiesen werden (Linden et al. 2008). Das durch das PRNP-Gen auf Chromosom 20 verschlüsselte Prion-Protein besteht aus einer ungefähr 100 Aminosäuren großen, unstrukturierten N-terminalen Domäne und einer ebenso großen C-terminalen strukturierten Domäne (Mead 2006).

Die physiologischen Eigenschaften des Prion-Proteins sind noch weitgehend unbekannt.

Der wissenschaftliche Blick war bislang überwiegend auf die pathologisch veränderte Form des Prion-Proteins, PrPsc, die in den transmissiblen spongiformen Enzephalopathien anzufinden ist, gerichtet.

Es wird angenommen, dass PrPc eine wichtige Rolle in der Signaltransduktion, insbesondere von Stresssignalen auf zellulärer oder systemischer Ebene, einnimmt (Linden et al. 2008, Gadotti und Zamponi 2011).

PrPc scheint eine Bedeutung für die synaptische Funktion zu haben: es verändert die neuronale Erregbarkeit und Langzeitpotenzierung, besitzt neuroprotektive Eigenschaften und schützt vor Excitotoxizität. Im Tierversuch beeinflusst PrPc Lernen und Verhalten (Collinge et al. 1994, McLennan et al. 2004, Maglio et al. 2004, Criado et al. 2005, Weise et al. 2006, Maglio et al. 2006, Gadotti et al. 2012).

PrPc wird infolge ischämischer Läsionen des Gehirns vermehrt gebildet, was als eine protektive Funktion gedeutet wird (Weise et al. 2006, McLennan et al. 2004, Mitsios et al. 2007).

Gestützt wird die Annahme, dass PrPc eine Rolle in der Abwehr von oxidativem Stress einnimmt (Voigtländer et al. 2001), auch durch die Feststellung, dass PrPc als Modulator von Phagozytose und inflammatorischer Antwort wirkt (De Almeida et al. 2005).

Es konnte nachgewiesen werden, dass Prion-Protein die Produktion von sAPP $\beta$ - und damit von AICD und A $\beta$ - durch Hemmung von BACE1 vermindert (Hooper und Turner 2008, Kellett und Hooper 2009, Parkin et al. 2007, Griffiths et al. 2011). Welchen Einfluss AICD wiederum als Transkriptionsfaktor für die Regulation der Synthese von PrPc hat, wird derzeit diskutiert (Vincent et al. 2009, Lewis et al. 2012).

Darüberhinaus wurde beobachtet, dass PrPc auf bislang nicht vollends entschlüsseltem Wege die Bildung von pTau vermindert (Larson et al. 2012, Schmitz et al. 2013).

Die Expression von PrPc im Hirngewebe von AD-Patienten ist gegenüber Gesunden unverändert 
(Saijo et al. 2011), obgleich frühere Veröffentlichungen hirnregionale Unterschiede in der Expression von PrPc aufzeigten (Rezaie et al. 2005, Velayos et al. 2009, Whitehouse et al. 2010).

Allerdings konnte gezeigt werden, dass die Konzentration von PrPc im CSF von Patienten mit neurodegenerativen Erkrankungen wie AD geringer ist als gegenüber gesunden Kontrollen (Meyne et al. 2009).

Die Konzentration von PrPc im CSF ist auch um so geringer, je größer das Ausmaß der neuronalen Schädigung ist, ob nun bedingt durch Neurodegeneration (Boesenberg-Grosse et al. 2006) oder Trauma (Carnini et al. 2010).

Auf welchem Weg PrPc in den CSF freigesetzt wird, ist bislang nicht geklärt.

Es wird angenommen, dass zellmembranständiges PrPc überwiegend internalisiert und rezykliert sowie zum Teil mittels Exosomen ausgeschleust wird (Fevrier et al. 2004, Robertson et al. 2006, Linden et al. 2008).

\subsection{Zielsetzung der Arbeit}

Ziel der vorliegenden Arbeit war die Untersuchung von PrPc sowie von A $\beta 1-40$,

A $\beta 1-42$, Tau und pTau aus dem CSF von Probanden mit Alzheimerdemenz zum Zeitpunkt der Diagnosestellung auf die mögliche Eignung hin als Verlaufsprädiktoren.

Darüberhinaus wurden mögliche Zusammenhänge von PrPc mit den etablierten CSF-Biomarkern A $\beta 1-40, A \beta 1-42$, Tau und pTau untersucht. 
2. Material und Methoden

\subsection{Studiendesign}

Bei dem Forschungsprojekt handelte es sich um eine unizentrische longitudinale Studie.

Das Studienkollektiv rekrutierte sich aus Probanden, die im Rahmen der Demenzdiagnostik durch das Klinische Demenzzentrum und durch das Nationale

Referenzzentrum für humane TSE vorgestellt wurden.

Die Datenerhebung erfolgte sowohl vor Ort, im Zuge der jährlichen Verlaufsuntersuchung, als auch telefonisch - im ersten Jahr quartalsweise, in den Folgejahren halbjährlich. Für die Anamnese wurden nach Möglichkeit sowohl der Proband selbst als auch ihm nahestehende oder ihn betreuende Personen wie Angehörige und Pflegekräfte befragt. Auch der Zeitpunkt des Auftretens der ersten Krankheitszeichen wurde herausgearbeitet, um die Präprogression, also den Verlauf vor Einschluss in die Studie, abschätzen zu können.

Als Einschlusskriterien für die Studie dienten die revidierten McKhann-Kriterien zur Diagnose des M. Alzheimer, modifiziert nach DuBois (McKhann et al. 1984, Dubois et al. 2007) (siehe auch 6.4).

Klinische Untersuchungen hielten den körperlichen Status des Probanden fest und dienten weiterhin der Erkennung von Begleiterkrankungen und Differentialdiagnosen.

Die Ergebnisse der neuropsychologischen und klinischen Untersuchungen wurden mit folgenden standardisierten Skalen festgehalten:

1. Die CERAD PLUS-Testbatterie, eine um die Tests "Trail Making Test A + B" und "Phonematische Flüssigkeit (S-Wörter)" erweiterte neuropsychologische Testbatterie

(Aebi 2002)

2. Ein für telefonische Interviews adaptierter MMSE (Newkirk et al. 2004)

3. Activities of Dailiy Living B-ADL und i-ADL (Lawton und Brody 1969)

4. Global Deterioration Scale (GDS) (Reisberg et al. 1988)

5. The Unified Parkinsons Disease Rating Scale, Section III (UDPRS III) (Fahn et al. 1987)

Die Progressionsrate wurde definiert als Quotient aus MMSE-Differenz (Punkte) und Zeit (Jahre).

2.2 Labor

Alle CSF-Proben wurden durch das Laborpersonal des NRZ (Nationales Referenzzentrum für die Surveillance Transmissibler Spongiformer Enzephalopathien) untersucht und ausgewertet. Folgende Test-Kits wurden verwandt:

Für die Bestimmung von PrPc wurde der "BetaPrion® BSE EIA Test Kit" von "aj roboscreen", Leipzig angewandt. Der Test wurde durch das NRZ-Labor für die Messung der PrPc-Konzentration im CSF modifiziert. Die CSF-Konzentration von A $\beta 1-42$ wurde mit dem "Innotest ${ }^{\circledR} \beta$ Amyloid(1-42)" von "INNOGENETICS", Gent (Belgien) mit einem Standardmessbereich zwischen 125 und 2000 pg/ml bestimmt. 
Die CSF-Konzentration von A $\beta 1-40$ wurde mit dem "hAmyloid $\beta 40-E L I S A "$ von "The Genetics Company", Schlieren (Schweiz) mit einem Standardmessbereich zwischen 100 und 2000 pg/ml bestimmt. Die CSF-Konzentration von Tau wurde mit dem "Innotest ${ }^{\circledR}$ hTau Ag" von "INNOGENETICS", Gent (Belgien) mit einem Standardmessbereich zwischen 75 und 1200 pg/ml bestimmt. Die CSF-Konzentration von Phospho-Tau wurde mit dem "Innotest ${ }^{\circledR}$ Phospho-Tau(181P)" von "INNOGENETICS", Gent (Belgien) mit einem Standardmessbereich zwischen 15,6 und 500 pg/ml bestimmt.

\subsection{Statistisches Vorgehen}

Die in der Studie erhobenen Daten wurde mit dem Programm SPSS Statistics in den Versionen 19 und 21 (IBM, Armonk, USA) ausgewertet.

Bei der Untersuchung auf Mittelwertunterschiede von einer unabhängigen, intervallskalierten Variablen über mehr als zwei Gruppen wurde bei gegebener Normalverteilung und Varianzhomogenität die einfaktorielle Varianzanalyse ANOVA (analysis of variance) angewandt, bei Varianzheterogenität wurde mit dem Games-Howell-Test auf Einzelunterschiede geprüft.

Die Normalverteilung wurde mit dem Shapiro-Wilk-Test geprüft und die Gleichheit der Varianzen mittels Levene-Test. Bei Verletzung der Normalverteilung wurde der Kruskal-Wallis H-Test als Alternative zur ANOVA angewandt.

Bei der Untersuchung auf Mittelwertunterschiede von einer unabhängigen, intervallskalierten Variablen über nur zwei Gruppen wurde bei gegebener Normalverteilung der für varianzhomogene bzw. varianzheterogene Stichproben entsprechende t-Test ausgewertet.

Die obere Grenze für die Signifikanz (= Signifikanzniveau) betrug stets maximal 5\% ( $\mathrm{p}=0,05)$.

Lineare Zusammenhänge zwischen intervallskalierten, normalverteilten Variablen wurden mit der Korrelation nach Pearson beschrieben.

Bei ordinalskalierten oder nicht-normalverteilten Variablen wurde Kendalls Tau als Grundlage für die Berechnung angewandt.

Die deskriptive Darstellung der Daten erfolgte durch Mittelwert und Standardabweichung (SD), sofern eine Normalverteilung vorlag. In sämtlichen anderen Fällen wurden Mediane und Interquartilenabstände (IQR) angegeben.

In den Abbildungen wurden signifikante Ergebnisse $(\mathrm{p} \leq 0,05)$ mit einem Stern $(*)$ gekennzeichnet, sehr signifikante Ergebnisse $(\mathrm{p} \leq 0,01)$ mit zwei Sternen $(* *)$ sowie hoch signifikante Ergebnisse $(\mathrm{p}$ $\leq 0,001)$ mit drei Sternen $(* * *)$.

Ergebnisse, die das Signifikanzniveau von $5 \%$ überschritten, wurden als nicht signifikant (n.s.) gekennzeichnet.

Das Demenzstadium wurde definiert durch die erreichten Punkte im Mini-Mental-Status-Test zur Erstuntersuchung: keine oder leichte Demenz $=21-30$ Punkte, mittelschwere Demenz $=11-20$ Punkte, schwere Demenz = 0-10 Punkte.

Die Progression wurde definiert durch den Verlust an Punkten im Mini-Mental-Status- Test pro Jahr: 
langsam $\leq 5$ Punkte/Jahr, rapid $\geq 6$ Punkte/Jahr.

Zur Kontrolle von potentiellen Confoundern wurde stratifiziert nach Geschlecht, Alter, ApoE- bzw. PRNP-Genotyp, Krankheitsstadium und Progressionstyp.

\section{Ergebnisse}

\section{1 Übersicht Kollektiv}

Das Kollektiv umfasste 38 Probanden (weiblich $n=21$, männlich n=17).

Das durchschnittliche Alter betrug 69,3 \pm 9,8 Jahre (w) bzw. 62,8 \pm 7,8 Jahre (m) (p=0,031) (Abb. 1). Die mittlere Punktzahl beim MMSE zur Erstuntersuchung ergab 17,6 $\pm 6,4$ (w) bzw. 23,2 $\pm 4,0$ (m) von 30 Punkten ( $\mathrm{p}=0,004)$ (Abb. 2).

Der Anteil rapid-progressiver Verläufe ( $\geq 6$ Punkte Verlust im MMSE pro Jahr) betrug bei beiden Geschlechtern ungefähr ein Viertel (w: 23,8\%, m: 23,5\%) (Abb. 12 und 13).

Alle Probanden wurden mindestens bis zur Verlaufsuntersuchung nach ungefähr einem Jahr (385 \pm

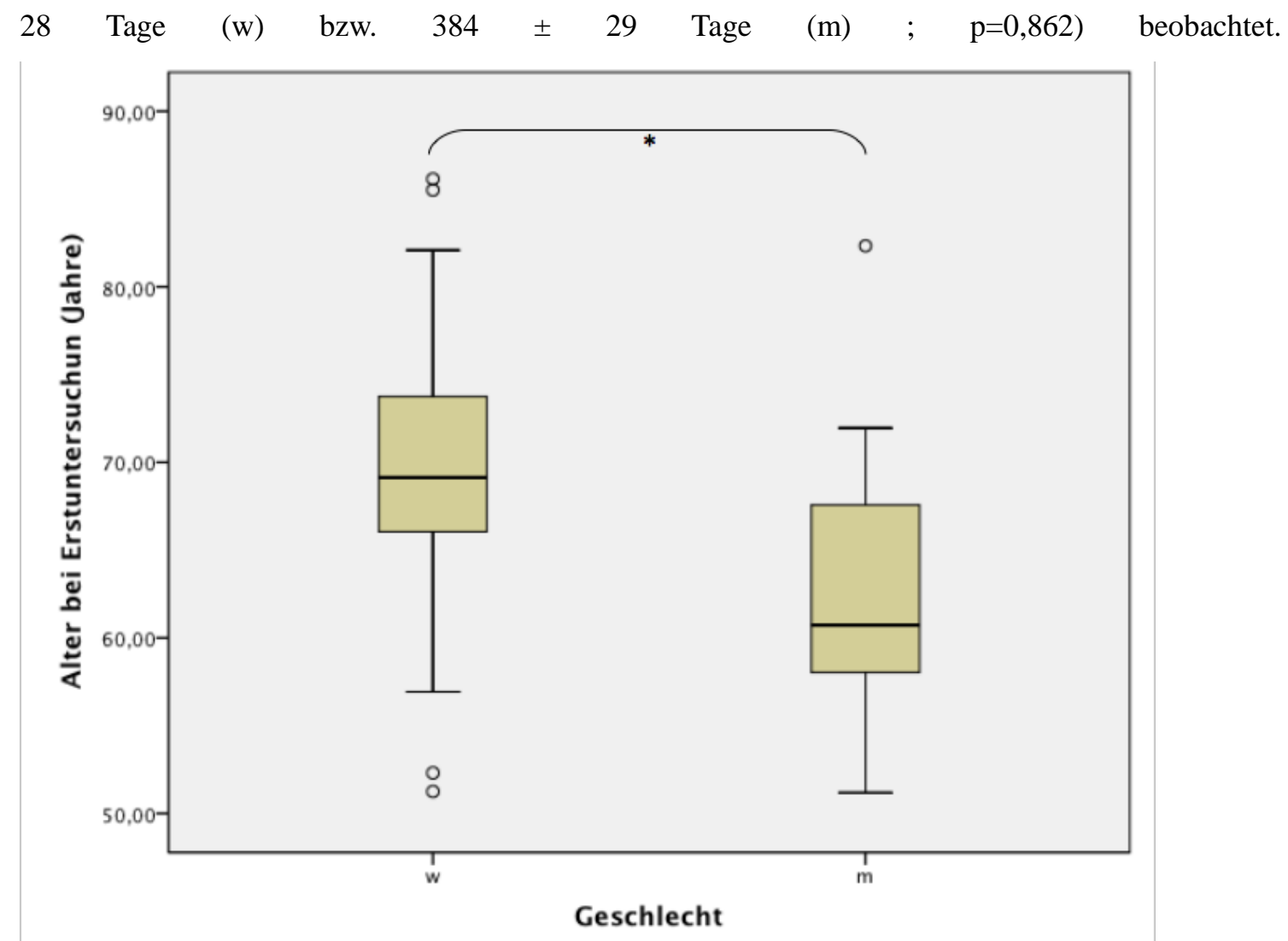

Abb. 1: Alter bei Erstuntersuchung 
$-23-$

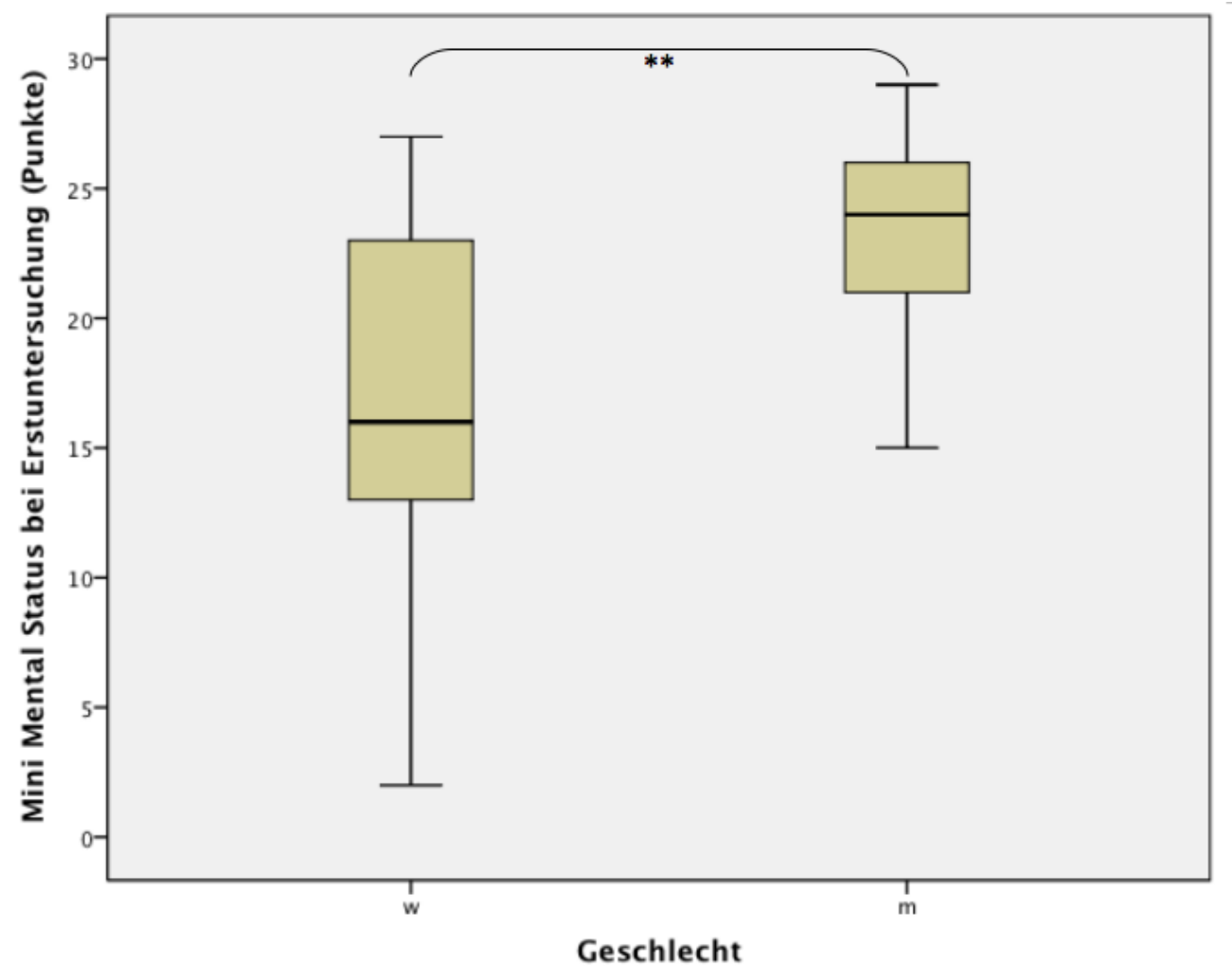

Abb. 2: Mini-Mental-Status bei Erstuntersuchung

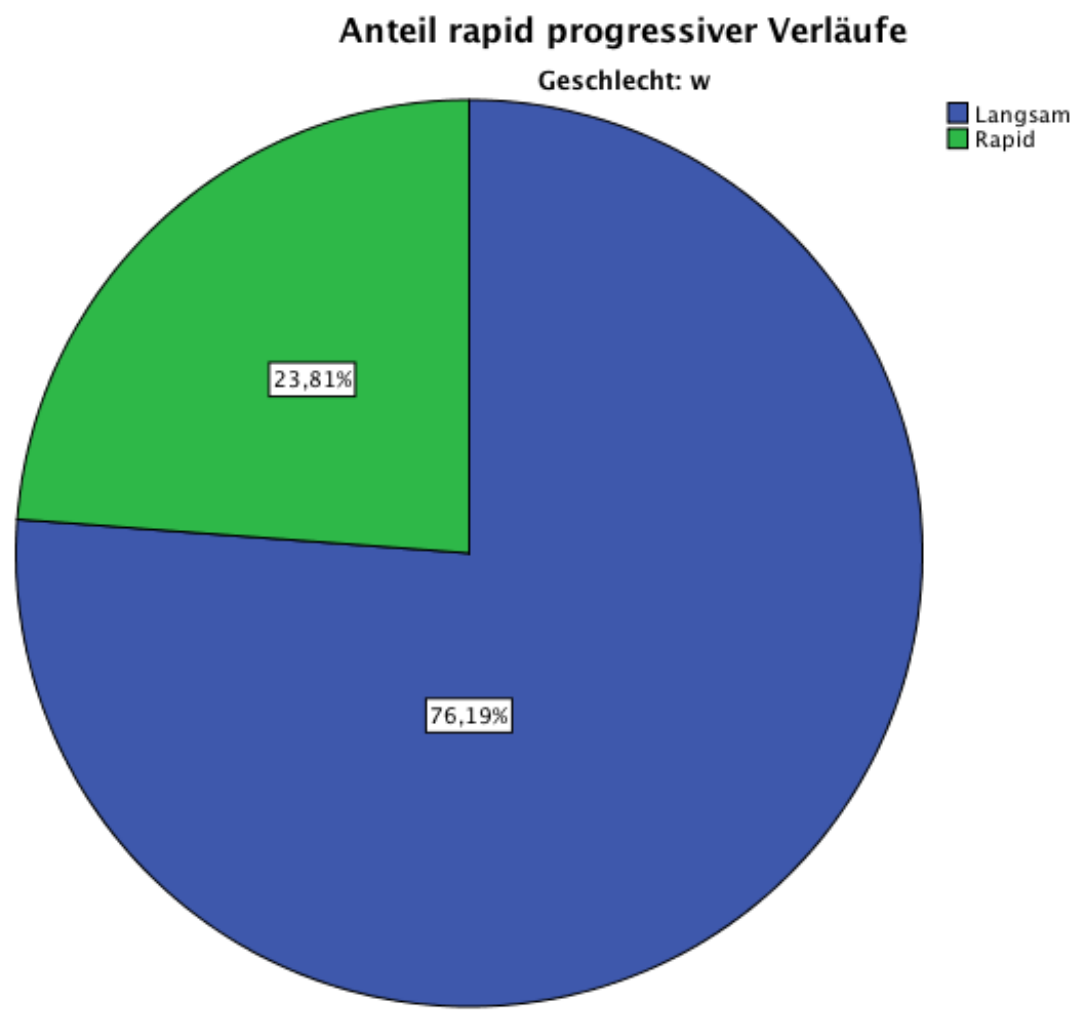

Abb. 3: Anteil rapid-progressiver Verläufe bei Frauen 


\section{Anteil rapid progressiver Verläufe}

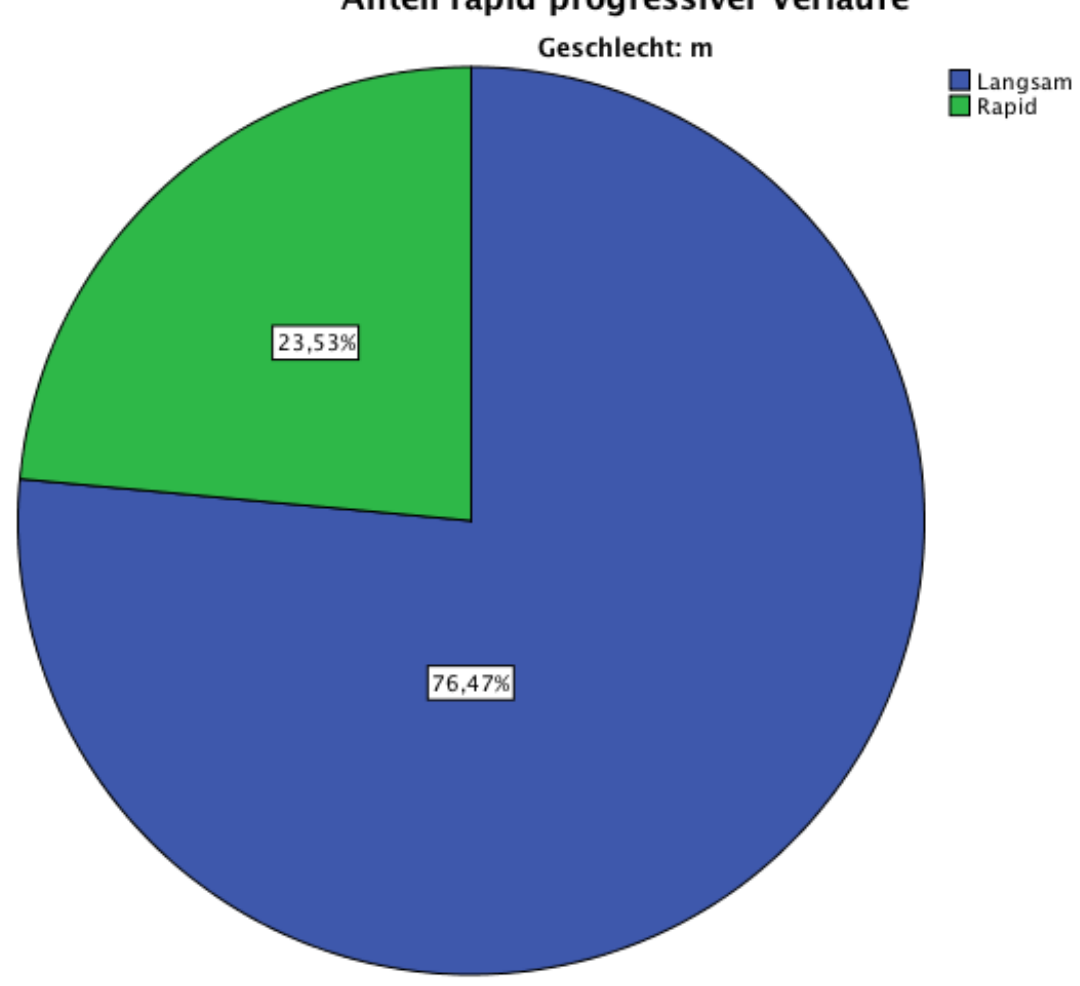

Abb. 4: Anteil rapid-progressiver Verläufe bei Männern

3.2 Verteilung der CSF-Parameter

Die Verteilung der Parameter PrPc, Tau, pTau, A $\beta 1-40$ und A $\beta 1-42$ im CSF war ausgeglichen (Tab. 1 sowie Abb. 5 bis 9).

\begin{tabular}{|c|c|c|c|c|c|c|}
\hline & Geschlecht & $\mathrm{n}$ & NV & MW / MD & SD / IQR & $\begin{array}{l}\text { Signifikanz- } \\
\text { wert }\end{array}$ \\
\hline \multirow{2}{*}{$\begin{array}{l}\mathrm{PrPc} \\
(\mathrm{pg} / \mathrm{ml})\end{array}$} & W & 21 & + & 45,7 & 18,4 & \multirow{2}{*}{$\mathrm{p}=0,349$} \\
\hline & $\mathrm{m}$ & 17 & + & 40,1 & 17,4 & \\
\hline \multirow{2}{*}{$\begin{array}{l}\text { Tau } \\
(\mathrm{pg} / \mathrm{ml})\end{array}$} & w & 21 & - & 670,0 & 606,0 & \multirow{2}{*}{$p=0,059$} \\
\hline & $\mathrm{m}$ & 16 & - & 337,0 & 432,0 & \\
\hline \multirow{2}{*}{$\begin{array}{l}\text { pTau } \\
(\mathrm{pg} / \mathrm{ml})\end{array}$} & w & 21 & - & 103,0 & 79,0 & \multirow{2}{*}{$p=0,308$} \\
\hline & $\mathrm{m}$ & 17 & + & 85,5 & 29,2 & \\
\hline \multirow{2}{*}{$\begin{array}{l}\text { A } \beta 1-40 \\
(\mathrm{pg} / \mathrm{ml})\end{array}$} & W & 20 & + & 6233,5 & 2081,5 & \multirow{2}{*}{$\mathrm{p}=0,903$} \\
\hline & $\mathrm{m}$ & 15 & + & 6140,3 & 2396,4 & \\
\hline \multirow{2}{*}{$\begin{array}{l}\mathrm{A} \beta 1-42 \\
(\mathrm{pg} / \mathrm{ml})\end{array}$} & W & 21 & + & 362,9 & 101,7 & \multirow[b]{2}{*}{$\mathrm{p}=0,314$} \\
\hline & $\mathrm{m}$ & 17 & + & 401,3 & 130,0 & \\
\hline
\end{tabular}

Tab. 1: Verteilung der CSF-Parameter PrPc, Tau, pTau, A $\beta 1-40, A \beta 1-42$ $\mathrm{n}=$ Anzahl, NV +/- = Normalverteilung der Werte positiv/negativ, MW/MD = Mittelwert/Median, SD/IQR = Standardabweichung/Interquartilenabstand. 
$-25-$

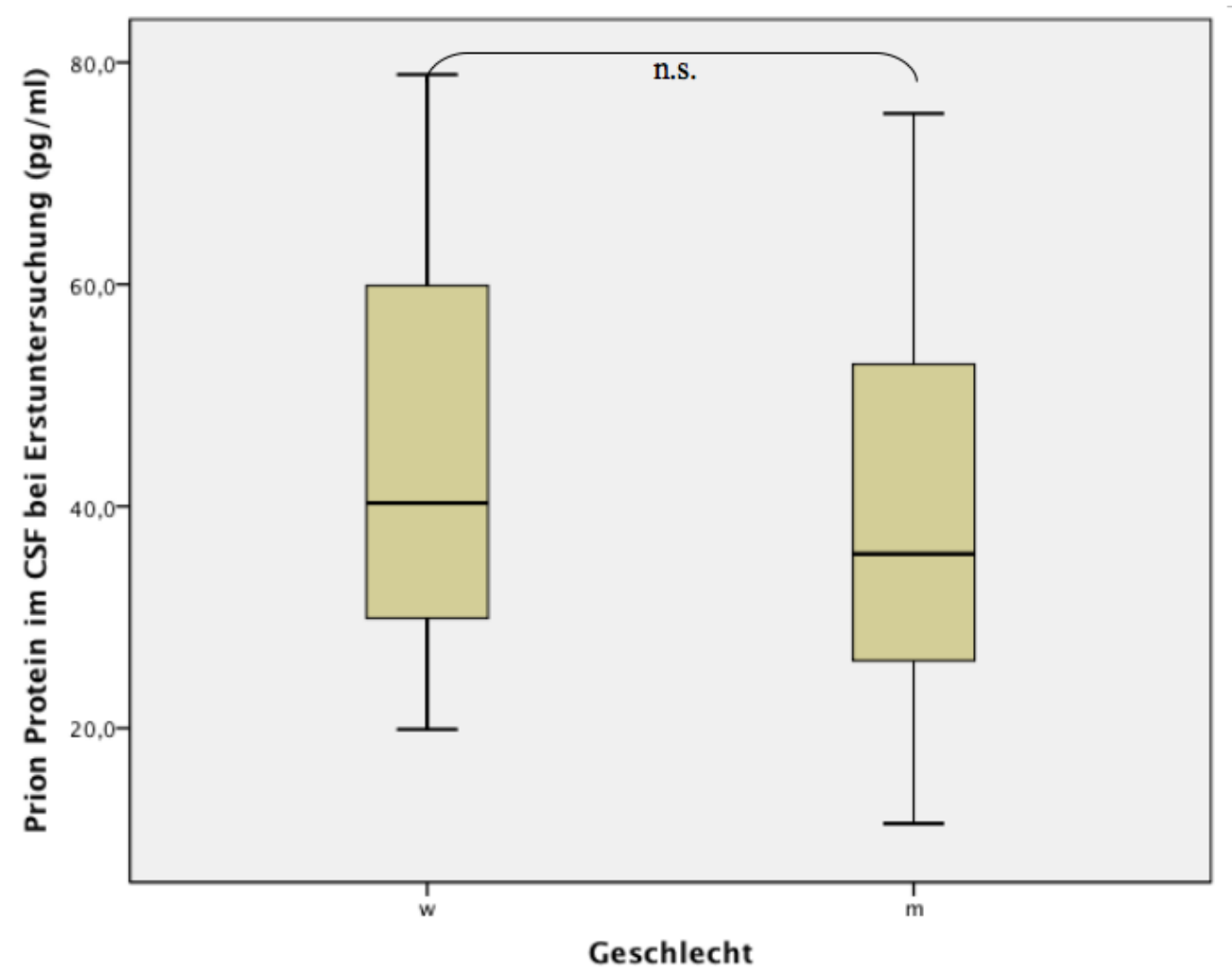

Abb. 5: Prion-Protein im CSF (pg/ml) bei Erstuntersuchung

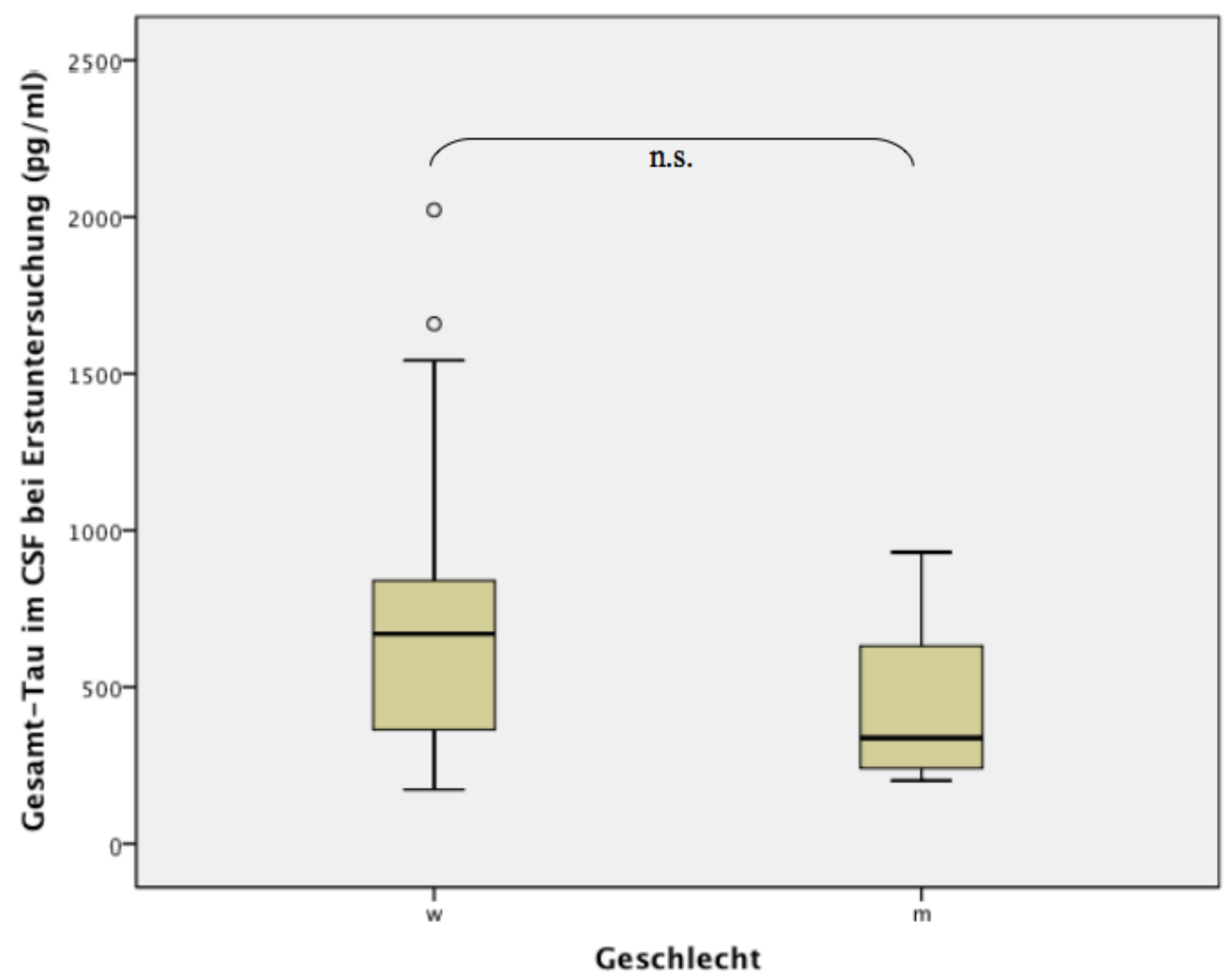

Abb. 6: Gesamt-Tau im CSF (pg/ml) bei Erstuntersuchung 


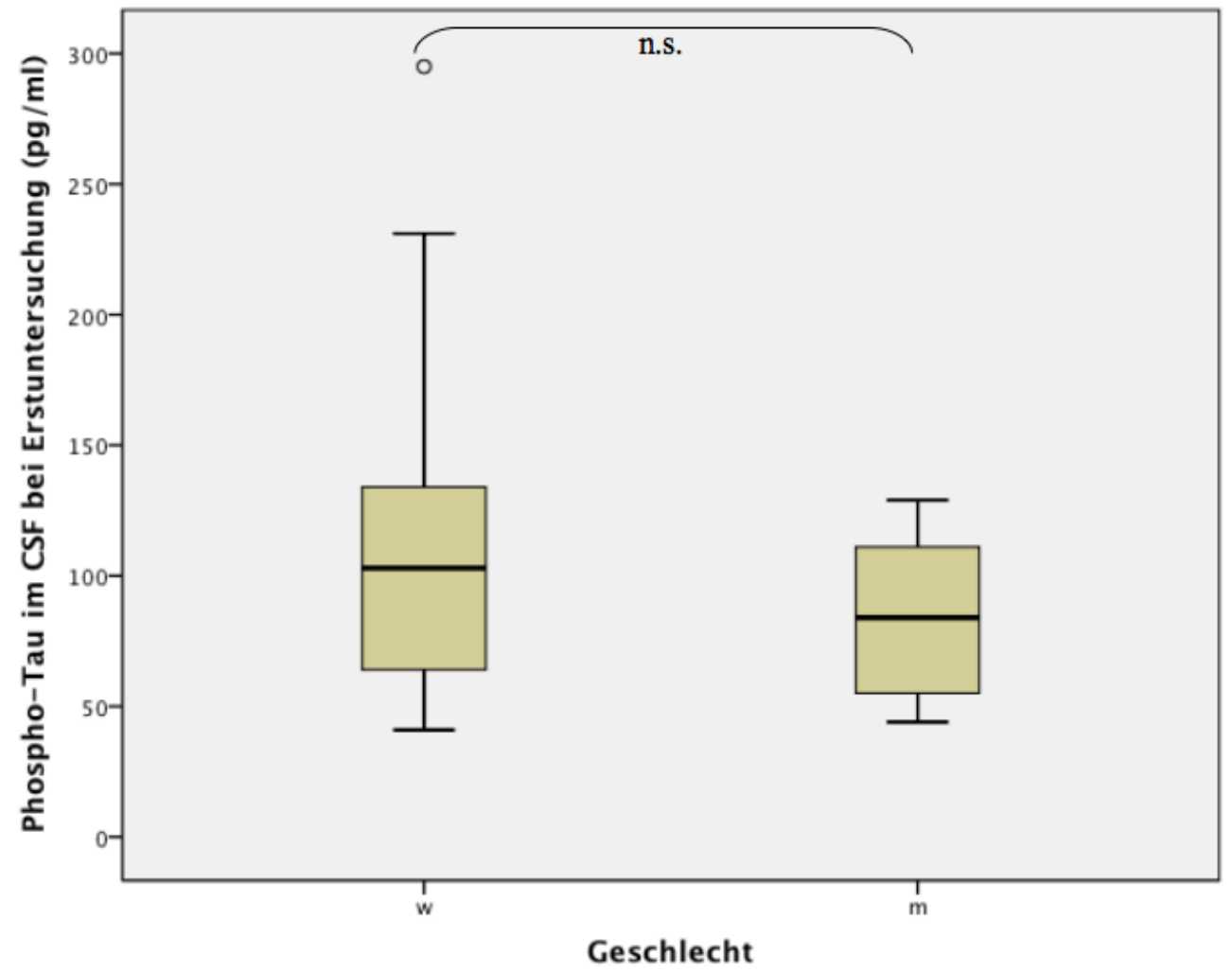

Abb. 7: Phospho-Tau im CSF (pg/ml) bei Erstuntersuchung

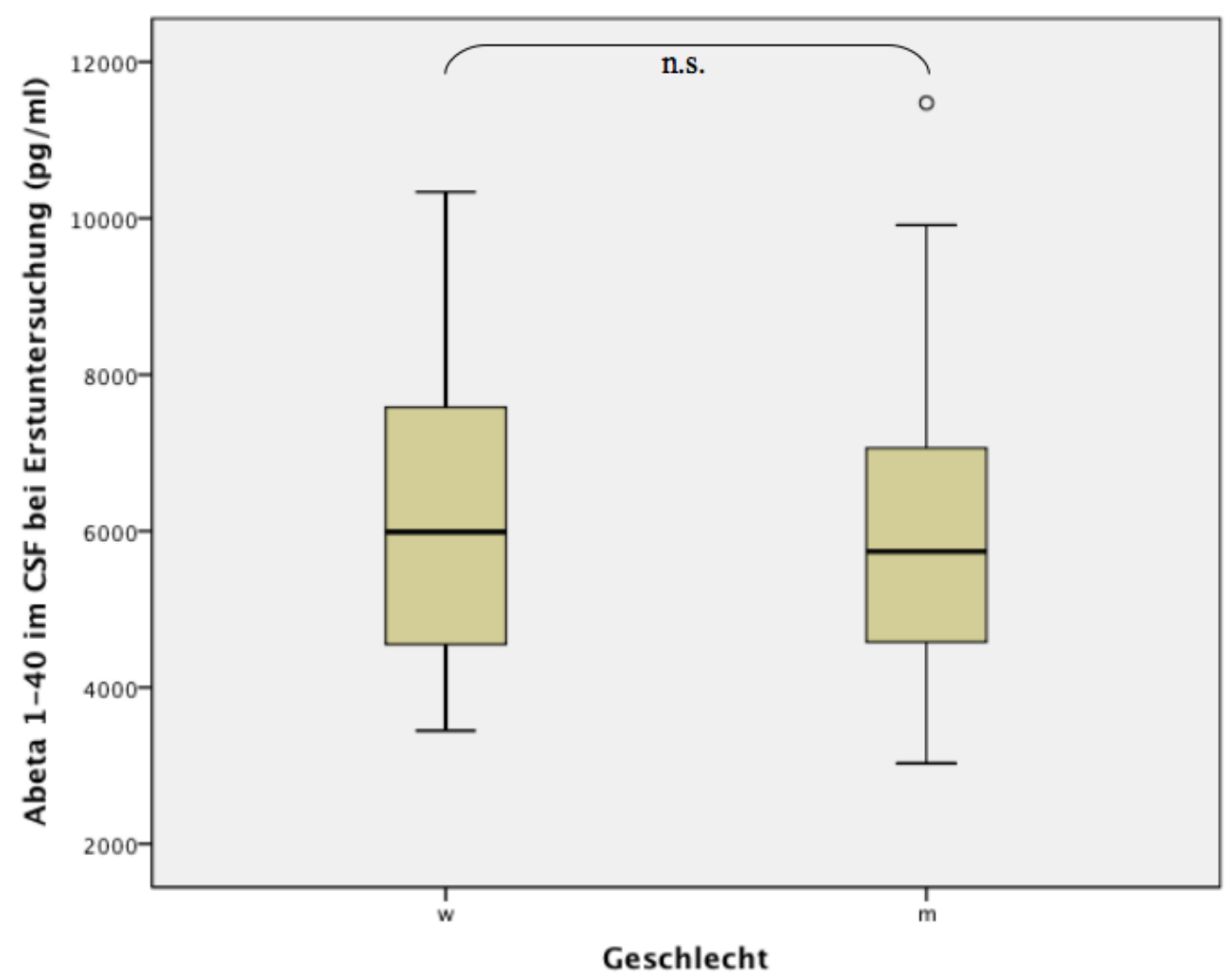

Abb. 8: A $\beta 1-40 \mathrm{im} \mathrm{CSF} \mathrm{(pg/ml)} \mathrm{bei} \mathrm{Erstuntersuchung}$ 


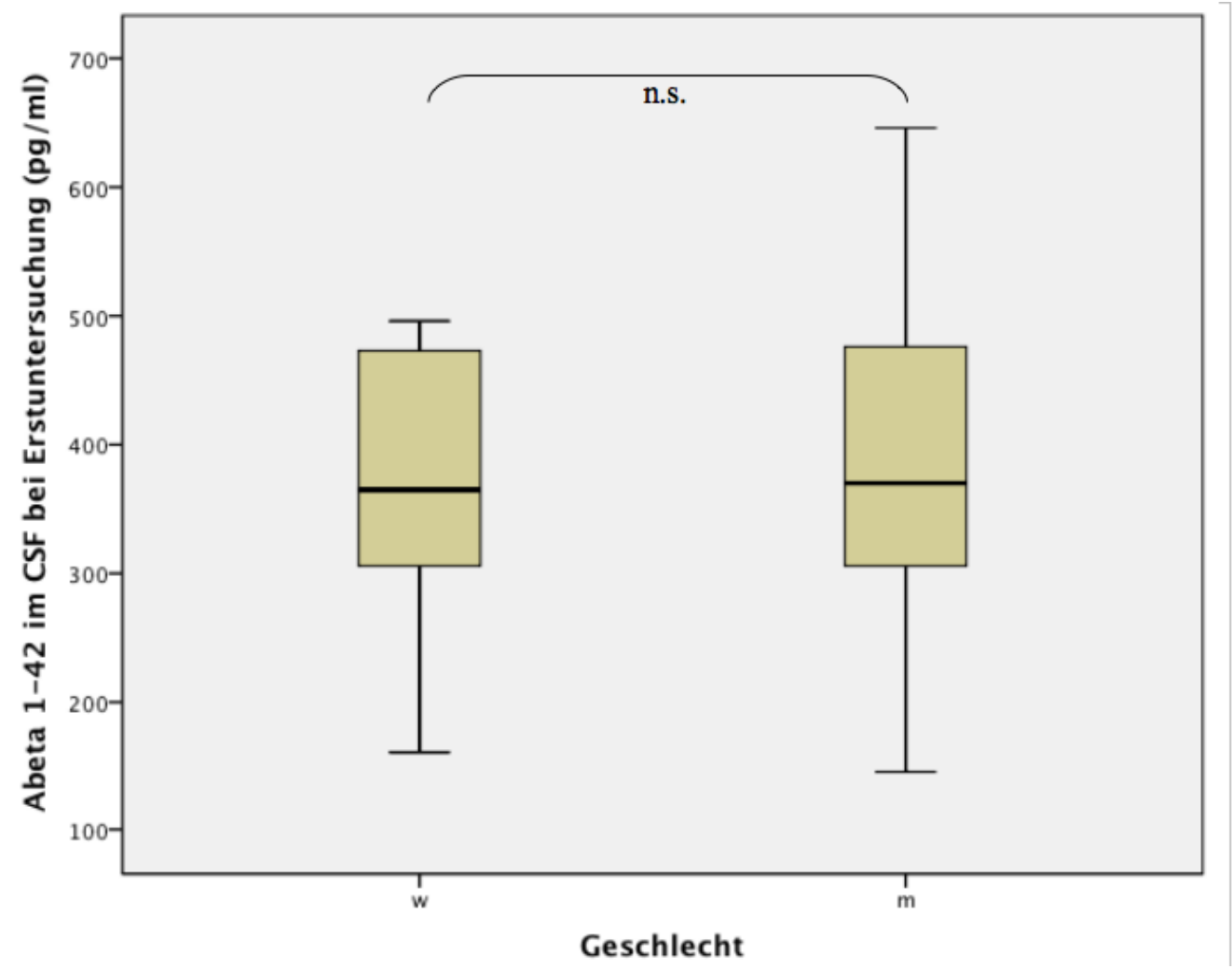

Abb. 9: A $\beta 1-42$ im CSF (pg/ml) bei Erstuntersuchung

\subsection{Genetik}

\subsubsection{ApoE-Genetik}

Die Verteilung der Allele des Apolipoproteins E (ApoE) war bei den Frauen 2/4 n=1 (5\%), 3/3n=7 (35\%), 3/4 n=9 (45\%) und 4/4 n=3 (15\%), bei den Männern 2/2 n=1 (6,25\%), 3/3 n=8 (50\%), 3/4 $\mathrm{n}=5(31,25 \%)$ und $4 / 4 \mathrm{n}=2(12,5 \%)$ (Abb. 10 und 11$)$.

\subsubsection{PRNP-Genetik}

52,4\% der Frauen waren Methionin-homozygot ( $\mathrm{m} / \mathrm{m} ; \mathrm{n}=11), 4,8 \%$ Valin-homozygot (v/v; $\mathrm{n}=1)$ und 42,9\% waren Methionin-Valin-heterozygot $(\mathrm{m} / \mathrm{v} ; \mathrm{n}=9)$ am Codon 129 des PRNP-Gens, wohingegen bei den Männern 33,3\% Methionin-homozygot $(\mathrm{m} / \mathrm{m}$; $\mathrm{n}=5)$, 26,7 Valin-homozygot (v/v; $\mathrm{n}=4)$ und 40\% Methionin-Valin-heterozygot $(\mathrm{m} / \mathrm{v} ; \mathrm{n}=6)$ waren (Abb. 12 und 13). 


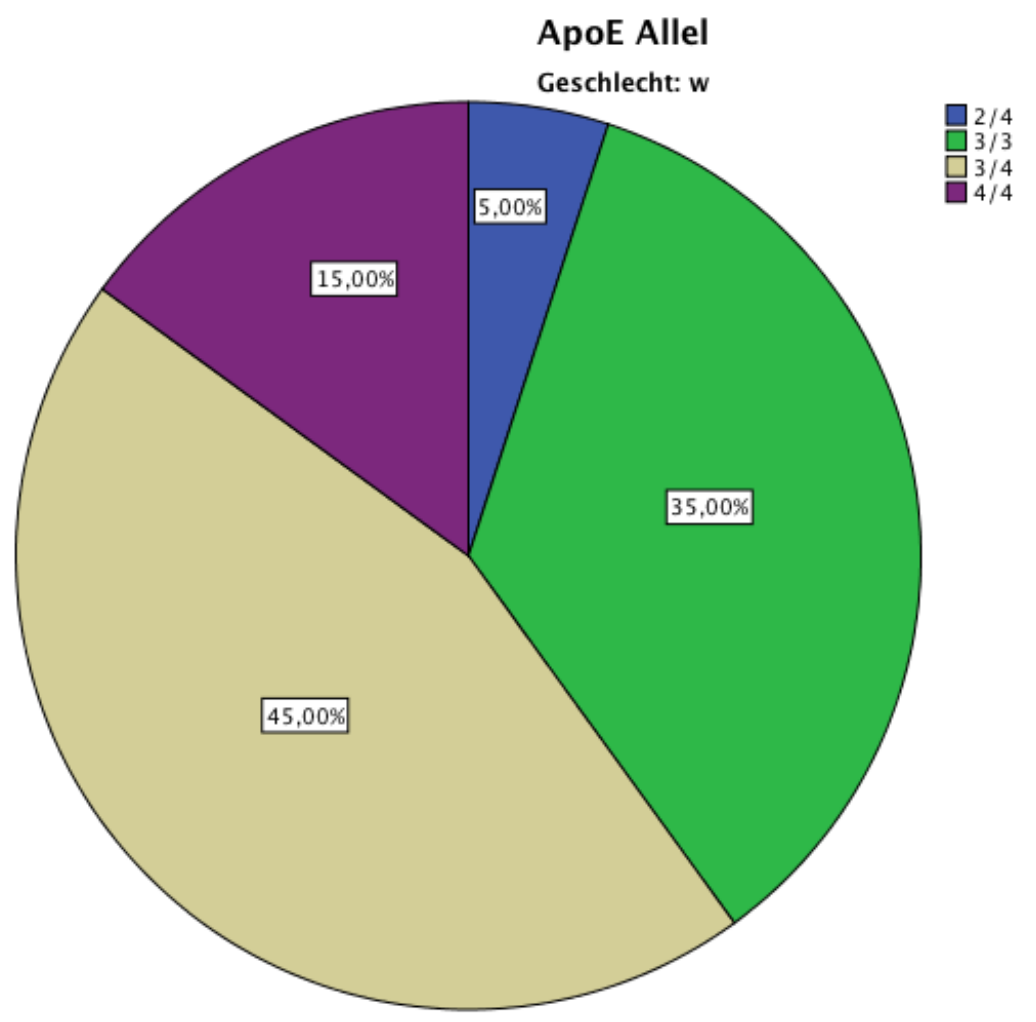

Abb. 10: Verteilung ApoE-Allel bei Frauen

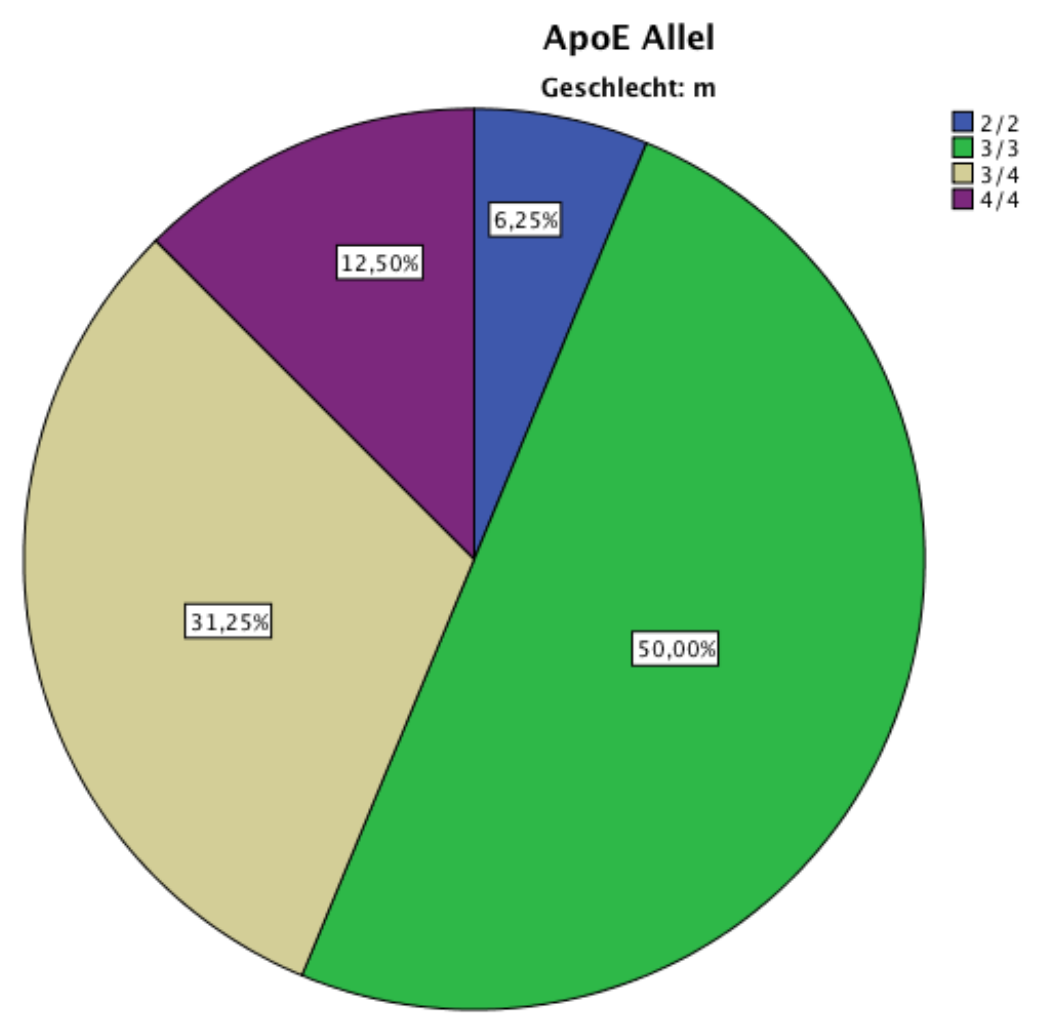

Abb. 11: Verteilung ApoE-Allel bei Männern 


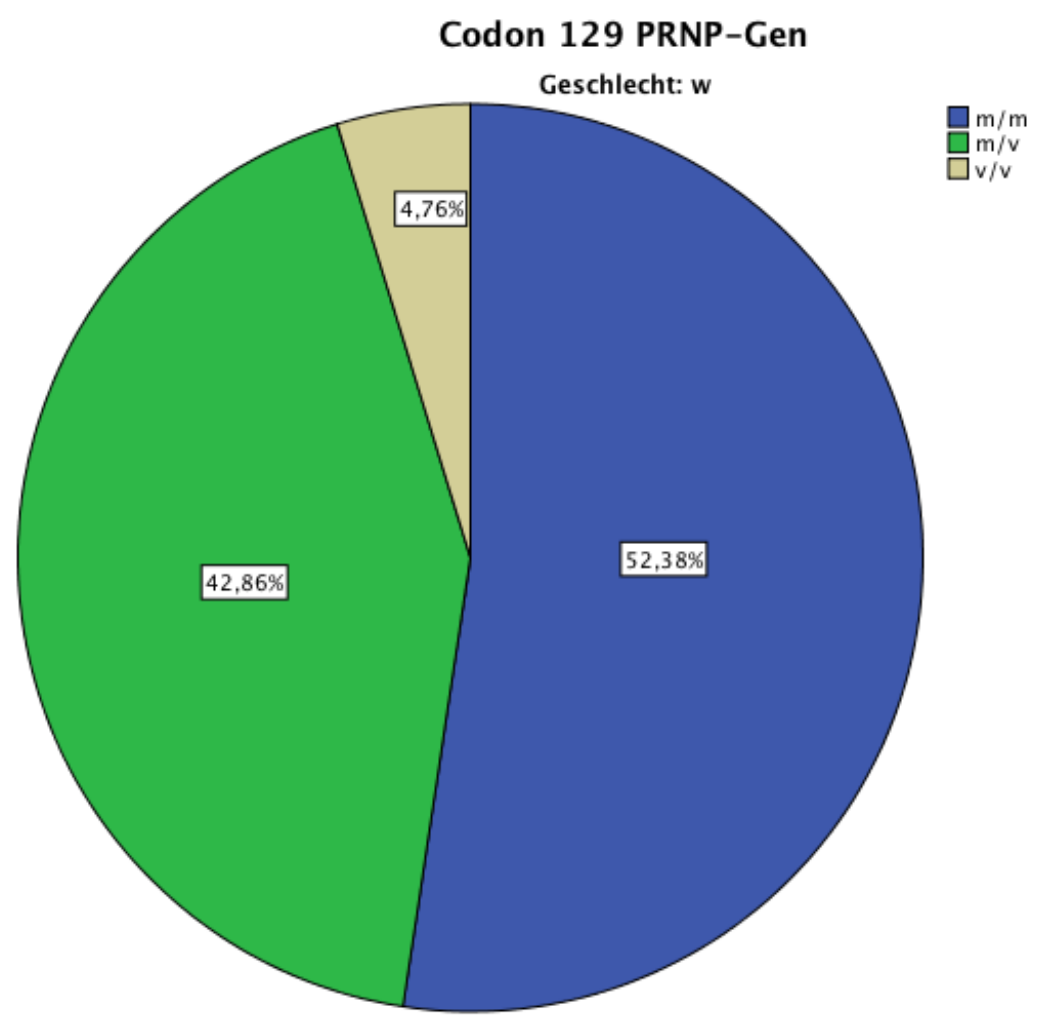

Abb. 12: Codon 129-Polymorphismus des Prion-Proteingens (PRNP) bei Frauen

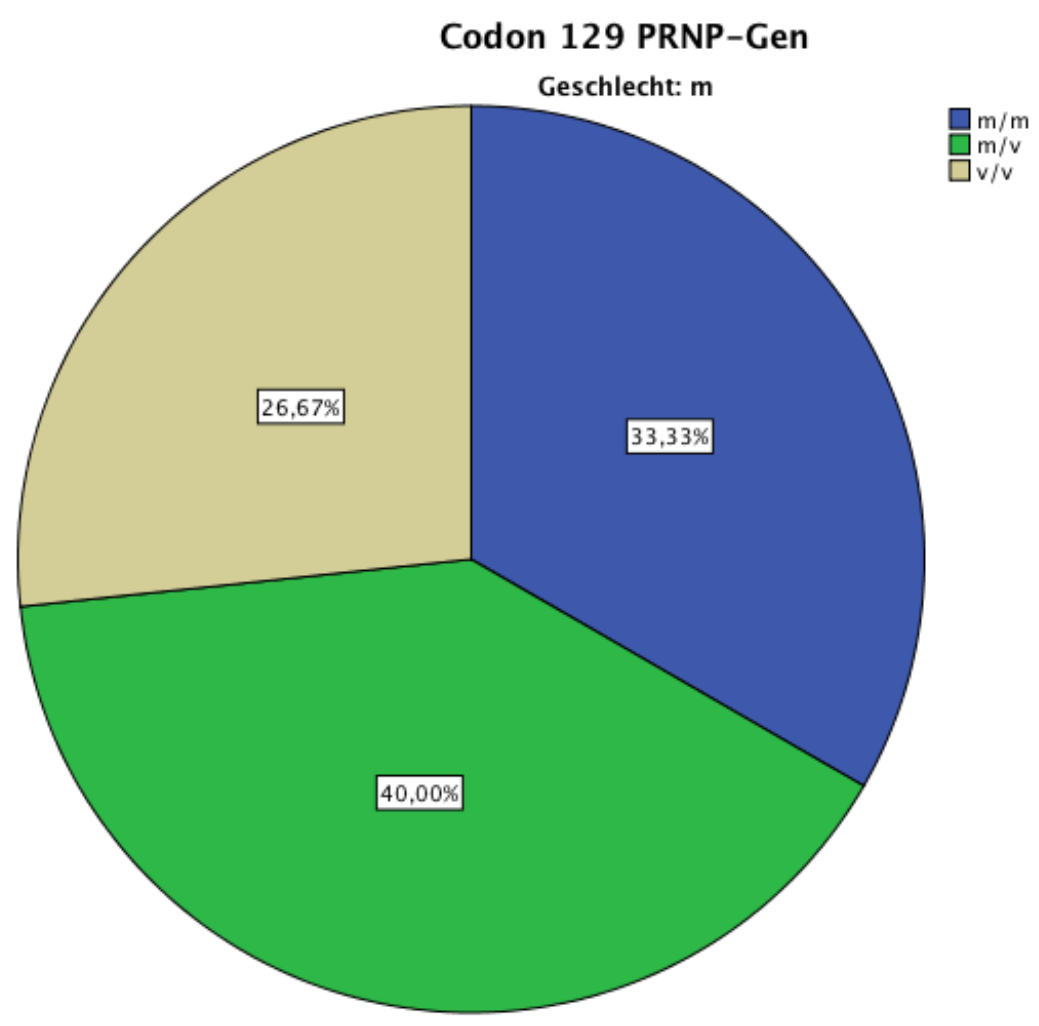

Abb. 13: Codon 129-Polymorphismus des Prion-Proteingens (PRNP) bei Männern

3.4 Mittelwertanalyse CSF-Marker 
In den Altersgruppen "bis einschließlich 65 Jahre", "66 bis 80 Jahre" und "über einschließlich 81 Jahre" konnten sowohl bei Männern als auch bei Frauen keine signifikanten Unterschiede in der mittleren Konzentration von PrPc im CSF gefunden werden (w: $p=0,759$; m: $p=0,601$ ) (Tab. 2, Abb. 14 und 15).

Auch bezogen auf das Demenzstadium wurden zwischen den Kategorien "leichte oder keine Demenz" (MMSE 21-30 Pkt.), "mittelschwere Demenz" (MMSE 11-20 Pkt.) und "schwere Demenz" (MMSE 0 - 10 Pkt.) keine signifikanten Unterschiede gesehen (w: $p=0,904$; m: $p=0,858$ ) (Tab. 2, Abb. 16 und 17).

Die mittlere PrPc-Konzentration zwischen den Gruppen mit langsamen Verläufen $(\leq 5$ Punkte Verlust im MMSE/Jahr) und rapiden Verläufen ( $\geq 6$ Punkte Verlust im MMSE/Jahr) zeigte sowohl bei den Frauen (Mittelwert "Langsam" ( $\mathrm{n}=16)$ : 43,54 \pm 18,23 pg/ml , "Rapid" (n=5): 52,4 \pm 19,5 $\mathrm{pg} / \mathrm{ml} ; \mathrm{p}=0,362$ ) als auch bei den Männern (Mittelwert "Langsam" ( $\mathrm{n}=13): 41,8 \pm 18,0 \mathrm{pg} / \mathrm{ml}$, "Rapid" (n=4): 34,4 \pm 16,4 pg/ml ; p=0,470) keinen signifikanten Unterschied (Tab. 2, Abb. 18 und 19).

Die Konzentration von PrPc im CSF zwischen den Trägern der unterschiedlichen ApoE-Allele war ausgewogen (w: $\mathrm{p}=0,708$; $\mathrm{m}: \mathrm{p}=0,319$ ) (Tab. 2, Abb. 20 und 21).

Ebensowenig zeigte der Codon 129-Polymorphismus des Prion-Proteingens einen signifikanten Einfluss auf die Konzentration von PrPc im CSF bei Frauen $(p=0,388)$ und Männern $(p=0,964)$ (Tab. 2, Abb. 22 und 23).

Innerhalb der Gruppe mit der Allelkombination ApoE 3/3 konnte zwischen den Geschlechtern ein signifikanter Unterschied zwischen den Mittelwerten der Konzentration von Prion-Protein im CSF dargestellt werden (w: 51,3 $\pm 17,5 \mathrm{pg} / \mathrm{ml}, \mathrm{n}=7 ; \mathrm{m}: 31,6 \pm 14,7 \mathrm{pg} / \mathrm{ml}, \mathrm{n}=8 ; \mathrm{p}=0,033$ ) (Abb. 24).

\begin{tabular}{|c|c|c|c|c|c|c|c|}
\hline & & Geschlecht & $\mathrm{n}$ & $\mathrm{NV}$ & $\begin{array}{l}\mathrm{MW} / \mathrm{MD} \\
\mathrm{PrPc}(\mathrm{pg} / \mathrm{ml})\end{array}$ & SD/IQR & Signifikanzwert \\
\hline \multirow{5}{*}{ 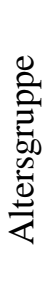 } & $\leq 65$ Jahre & \multirow{3}{*}{ w } & 5 & + & 43,6 & 10,8 & \multirow{3}{*}{$\mathrm{p}=0,759$} \\
\hline & 66 - 80 Jahre & & 12 & - & 36,7 & 32,3 & \\
\hline & $\geq 81$ Jahre & & 3 & + & 52,9 & 30,1 & \\
\hline & $\leq 65$ Jahre & \multirow{2}{*}{$\mathrm{m}$} & 12 & + & 39,3 & 16,8 & \multirow{2}{*}{$\mathrm{p}=0,531$} \\
\hline & 66 - 80 Jahre & & 4 & + & 46,0 & 21,7 & \\
\hline \multirow{4}{*}{ 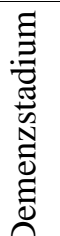 } & leicht & \multirow{3}{*}{ w } & 9 & + & 45,7 & 22,8 & \multirow{3}{*}{$\mathrm{p}=0,738$} \\
\hline & mittel & & 10 & + & 44,5 & 16,8 & \\
\hline & schwer & & 2 & - & 51,2 & n.a. & \\
\hline & leicht & $\mathrm{m}$ & 13 & + & 40,5 & 19,1 & $\mathrm{p}=0,858$ \\
\hline
\end{tabular}




\begin{tabular}{|c|c|c|c|c|c|c|c|}
\hline & mittel & & 4 & + & 38,7 & 12,8 & \\
\hline \multirow{4}{*}{ 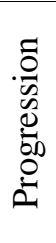 } & langsam & \multirow{2}{*}{ w } & 16 & + & 43,5 & 18,2 & \multirow{2}{*}{$\mathrm{p}=0,362$} \\
\hline & rapid & & 5 & + & 52,4 & 19,5 & \\
\hline & langsam & \multirow{2}{*}{$\mathrm{m}$} & 13 & + & 41,8 & 18,0 & \multirow{2}{*}{$\mathrm{p}=0,470$} \\
\hline & rapid & & 4 & + & 34,4 & 16,4 & \\
\hline \multirow{6}{*}{ 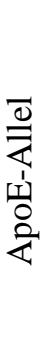 } & $3 / 3$ & \multirow{3}{*}{ w } & 7 & + & 51,3 & 17,5 & \multirow{3}{*}{$\mathrm{p}=0,708$} \\
\hline & $3 / 4$ & & 9 & + & 42,3 & 18,2 & \\
\hline & $4 / 4$ & & 3 & + & 44,9 & 29,1 & \\
\hline & $3 / 3$ & \multirow{3}{*}{$\mathrm{m}$} & 8 & + & 31,6 & 14,7 & \multirow{3}{*}{$\mathrm{p}=0,293$} \\
\hline & $3 / 4$ & & 5 & + & 40,8 & 17,0 & \\
\hline & $4 / 4$ & & 2 & - & 46,1 & n.a. & \\
\hline \multirow{4}{*}{ 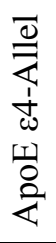 } & $\varepsilon 4$ neg & \multirow{2}{*}{ w } & 7 & + & 51,3 & 17,5 & \multirow{2}{*}{$\mathrm{p}=0,304$} \\
\hline & $\varepsilon 4$ pos & & 13 & + & 42,0 & 19,4 & \\
\hline & $\varepsilon 4$ neg & \multirow{2}{*}{$\mathrm{m}$} & 9 & + & 34,4 & 16,2 & \multirow{2}{*}{$\mathrm{p}=0,325$} \\
\hline & $\varepsilon 4$ pos & & 7 & + & 42,3 & 14,1 & \\
\hline \multirow{5}{*}{$\begin{array}{l}\text { ปे } \\
\text { ठే } \\
\text { ठ }\end{array}$} & $\mathrm{m} / \mathrm{m}$ & \multirow{2}{*}{ w } & 11 & + & 50,8 & 19,8 & \multirow{2}{*}{$\mathrm{p}=0,177$} \\
\hline & $\mathrm{m} / \mathrm{v}$ & & 9 & + & 39,1 & 16,6 & \\
\hline & $\mathrm{m} / \mathrm{m}$ & \multirow{3}{*}{$\mathrm{m}$} & 5 & + & 36,7 & 13,2 & \multirow{3}{*}{$\mathrm{p}=0,964$} \\
\hline & $\mathrm{m} / \mathrm{v}$ & & 6 & + & 35,8 & 16,1 & \\
\hline & $\mathrm{v} / \mathrm{v}$ & & 4 & + & 38,7 & 20,7 & \\
\hline
\end{tabular}

Tab. 2: Konzentration von Prion-Protein im CSF der verschiedenen Untergruppen $\mathrm{n}=$ Anzahl, $\mathrm{NV}+/-$ = Normalverteilung der Werte positiv/negativ, MW/MD = Mittelwert/Median, SD/IQR = Standardabweichung/Interquartilenabstand, $\varepsilon 4$ neg $=$ ApoE $\varepsilon 4$-Allel nicht vorhanden, $\varepsilon 4$ pos $=A p o E \varepsilon 4$-Allel vorhanden 


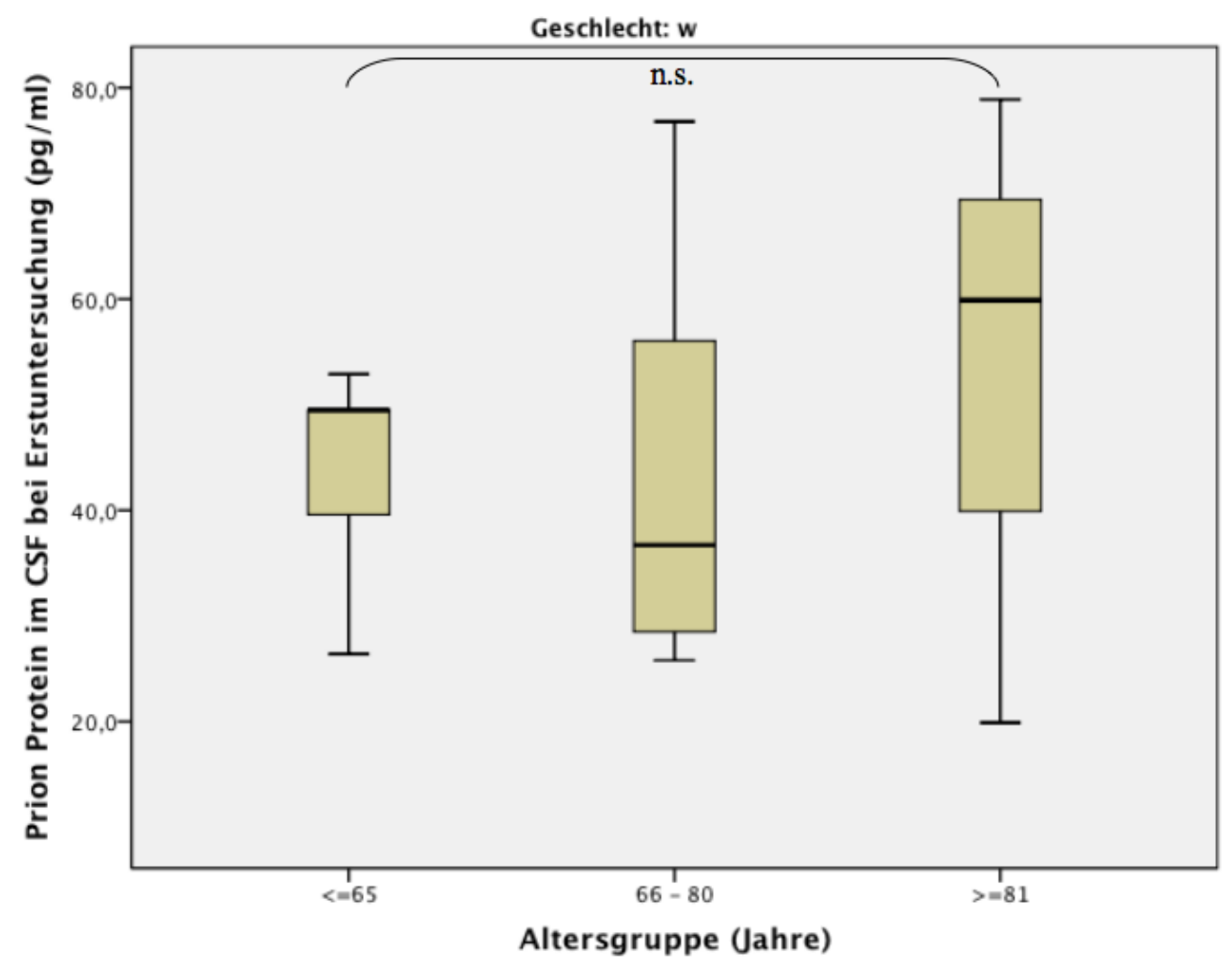

Abb. 14: Prion-Protein im CSF (pg/ml) in verschiedenen Altersgruppen bei Frauen

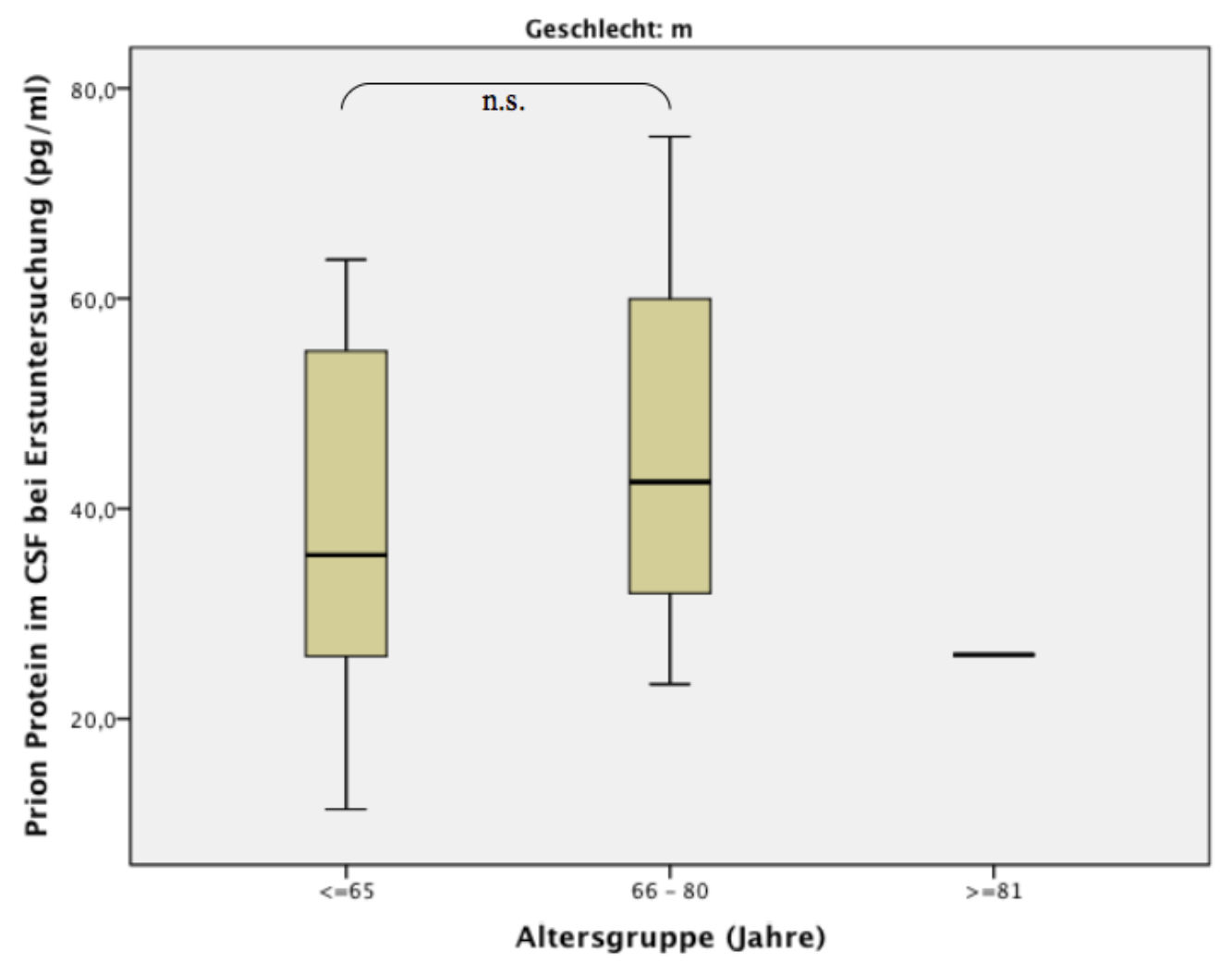

Abb. 15: Prion-Protein im CSF (pg/ml) in verschiedenen Altersgruppen bei Männern 


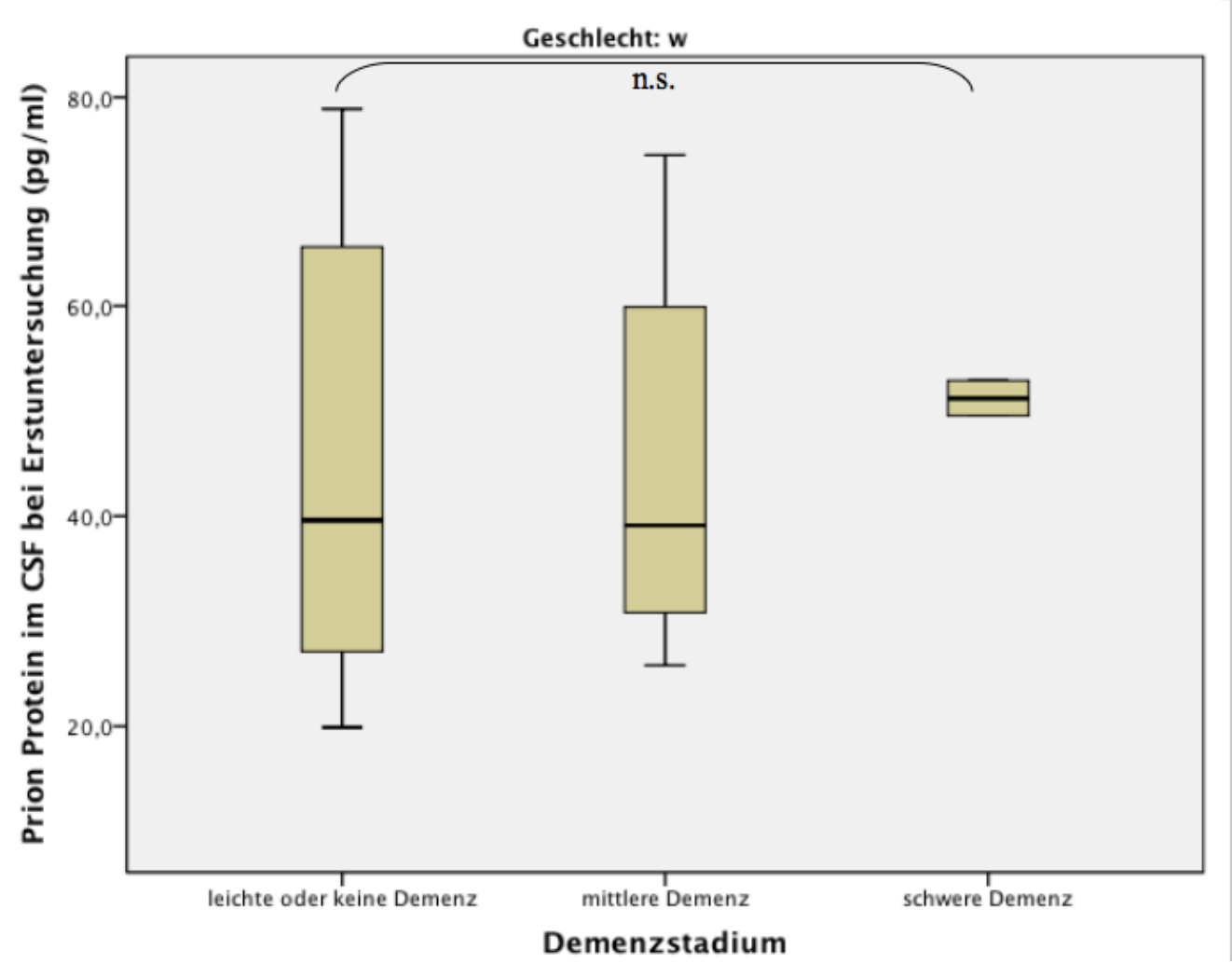

Abb. 16: Prion-Protein im CSF (pg/ml) in verschiedenen Demenzstadien bei Frauen

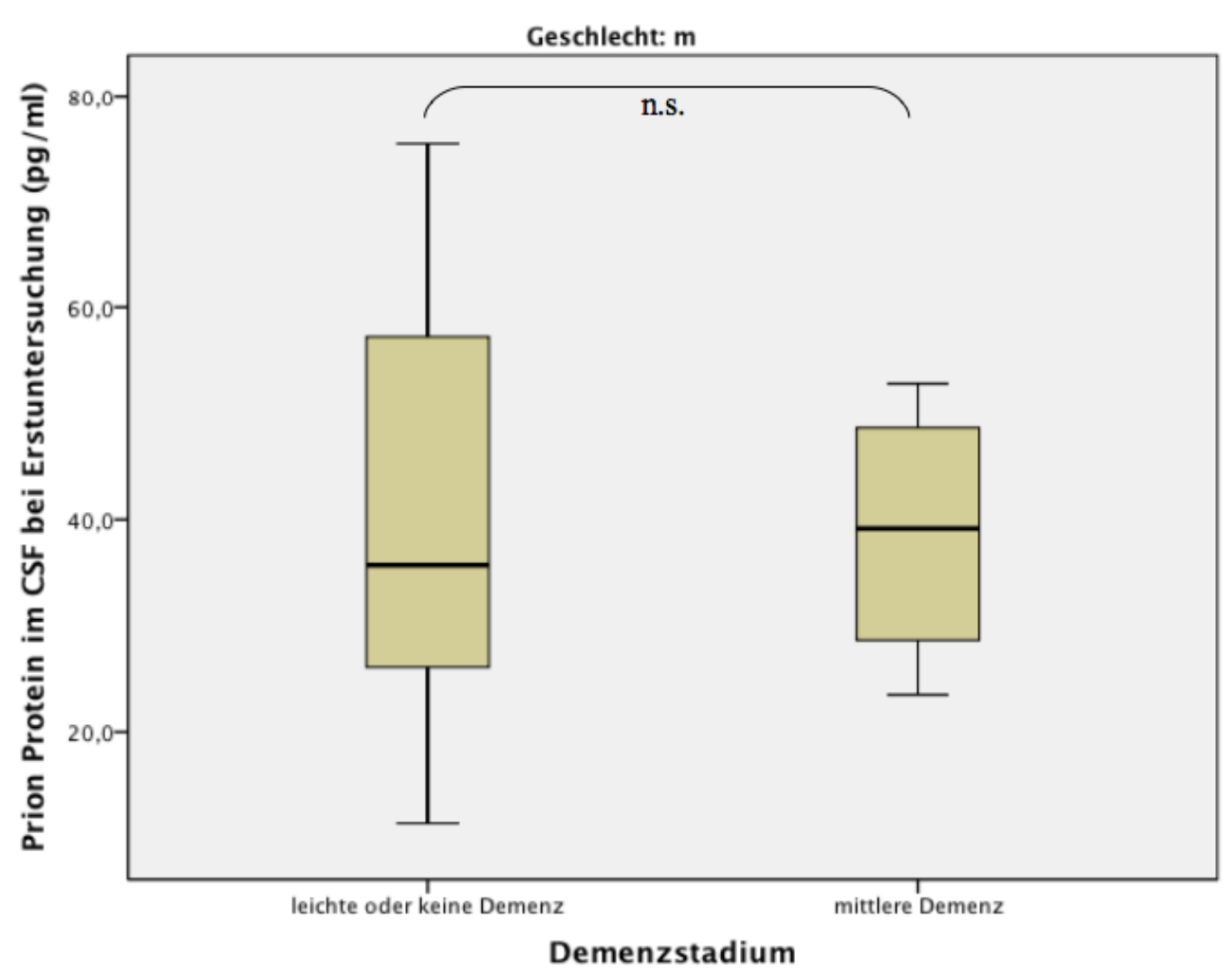

Abb. 17: Prion-Protein im CSF (pg/ml) in verschiedenen Demenzstadien bei Männern 


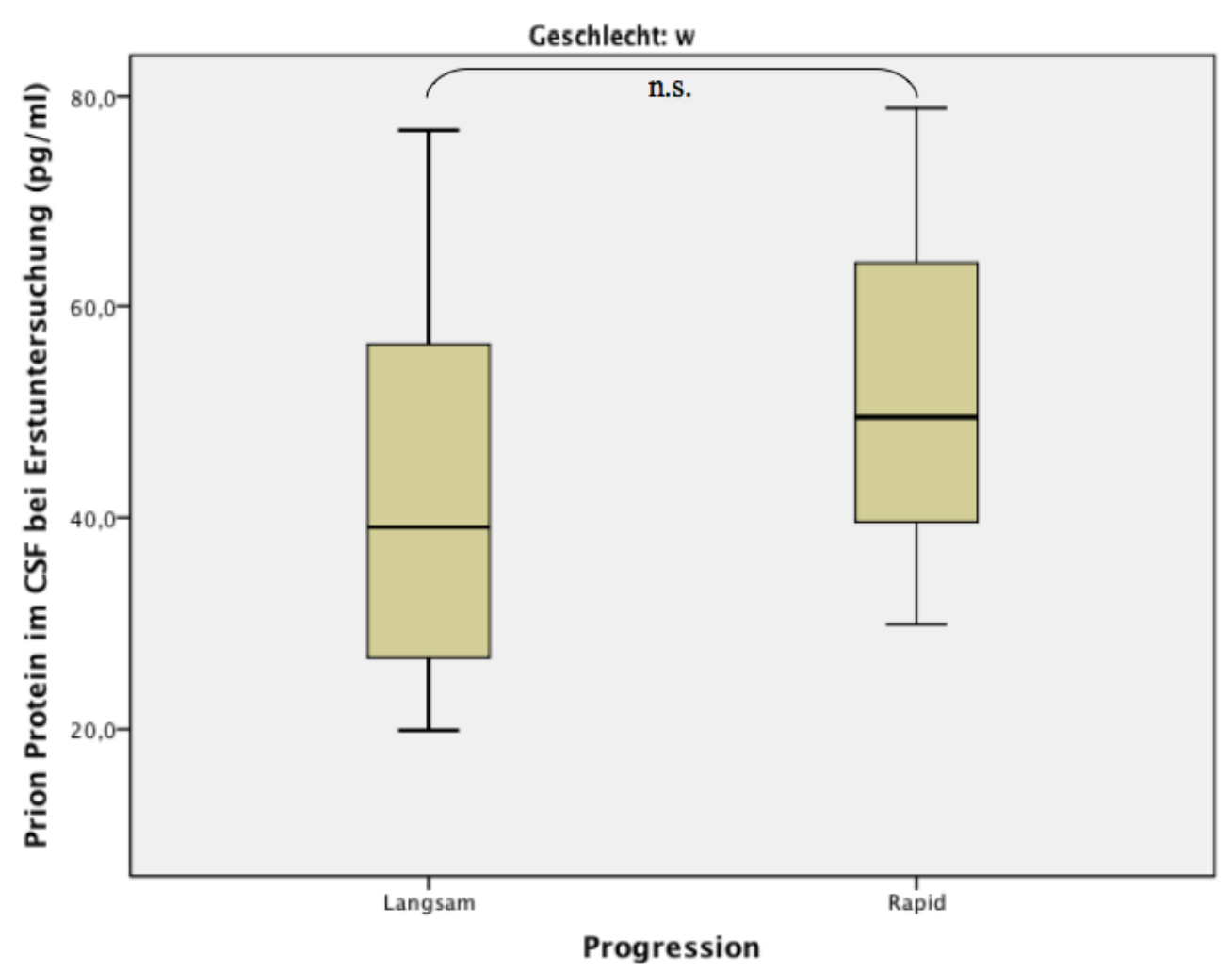

Abb. 18: Prion-Protein im CSF (pg/ml) in langsamen / schnellen Verläufen bei Frauen

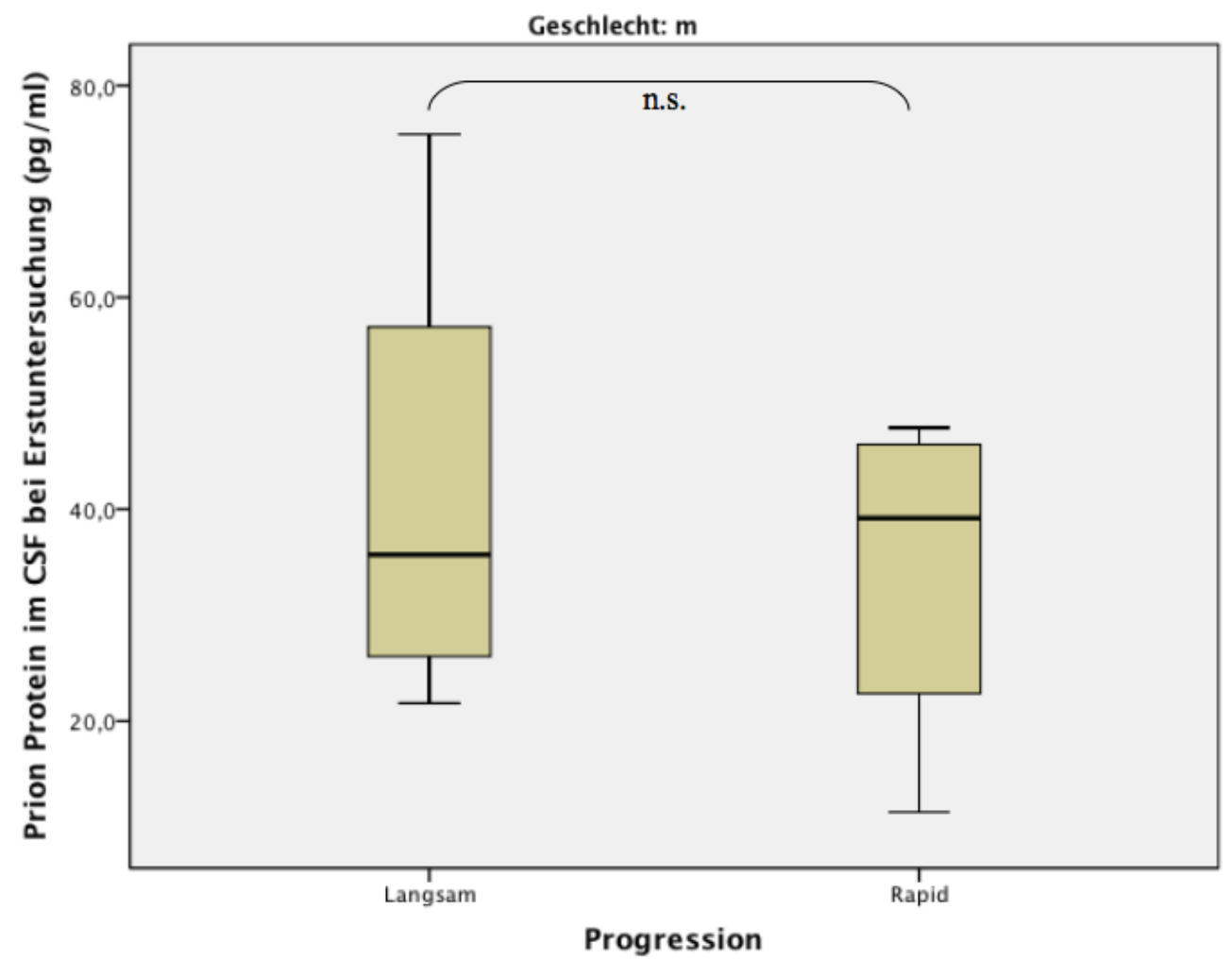

Abb. 19: Prion-Protein im CSF (pg/ml) in langsamen / schnellen Verläufen bei Männern 


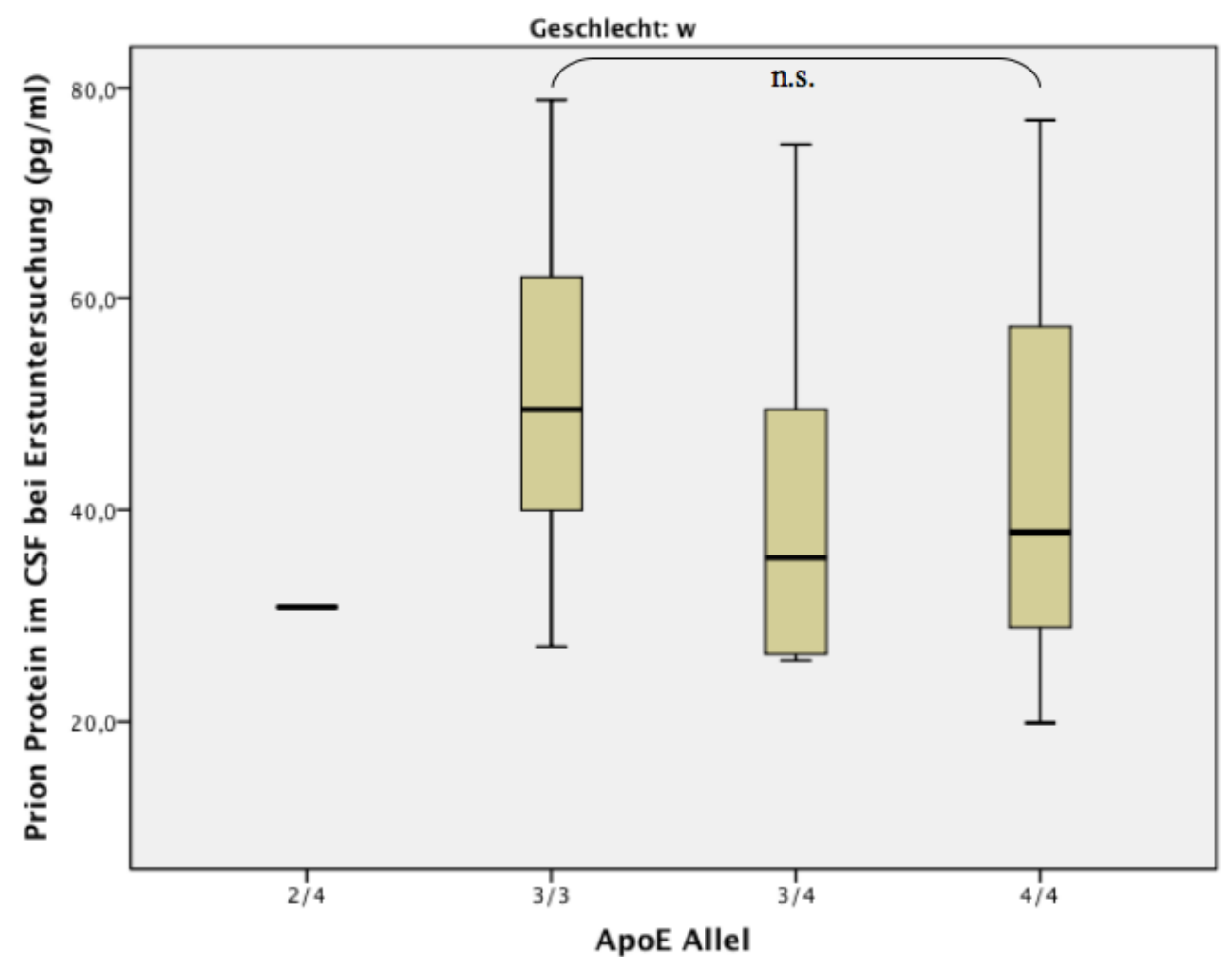

Abb. 20: Prion-Protein im CSF (pg/ml) und ApoE-Allel bei Frauen

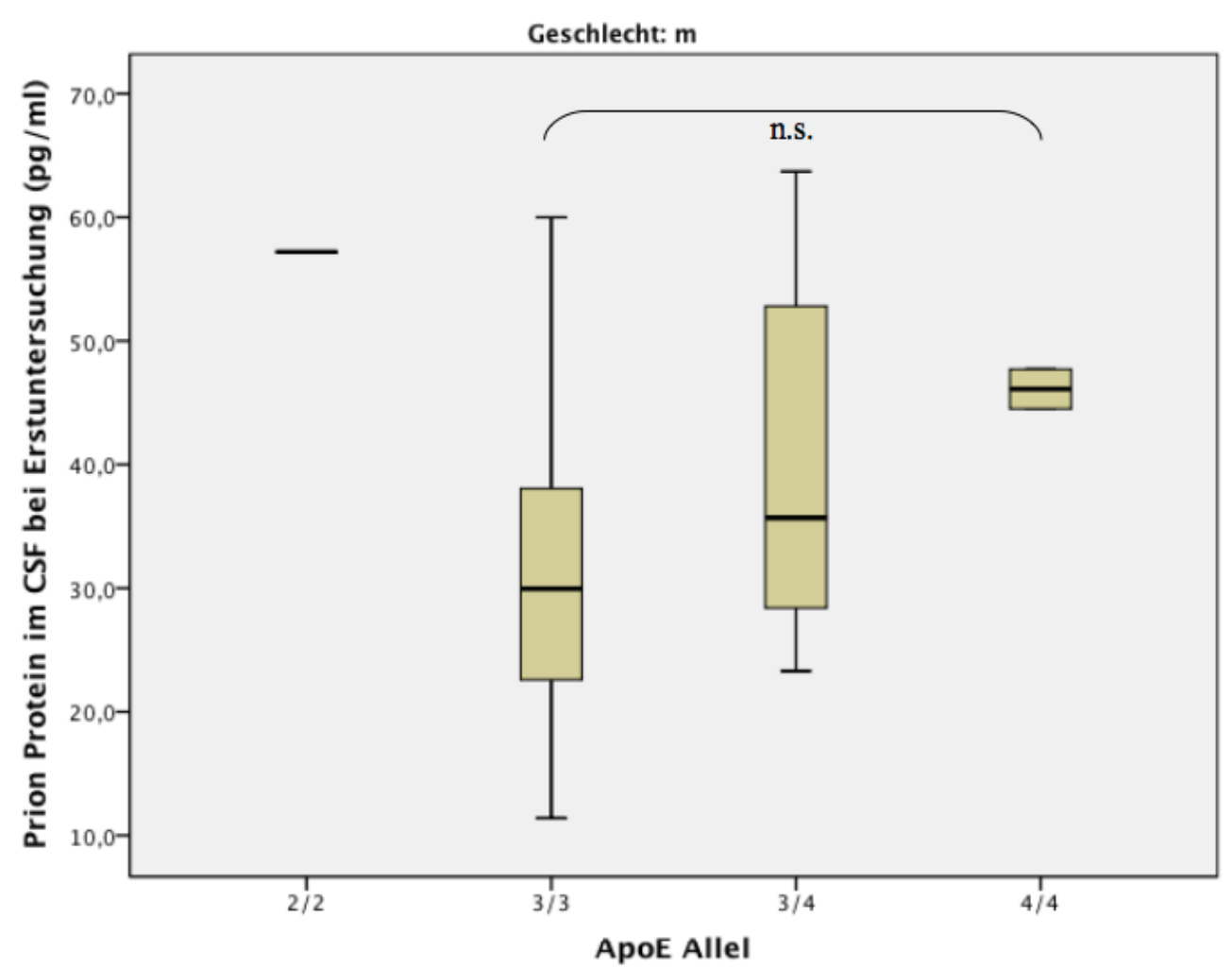

Abb. 21: Prion-Protein im CSF (pg/ml) und ApoE-Allel bei Männern 


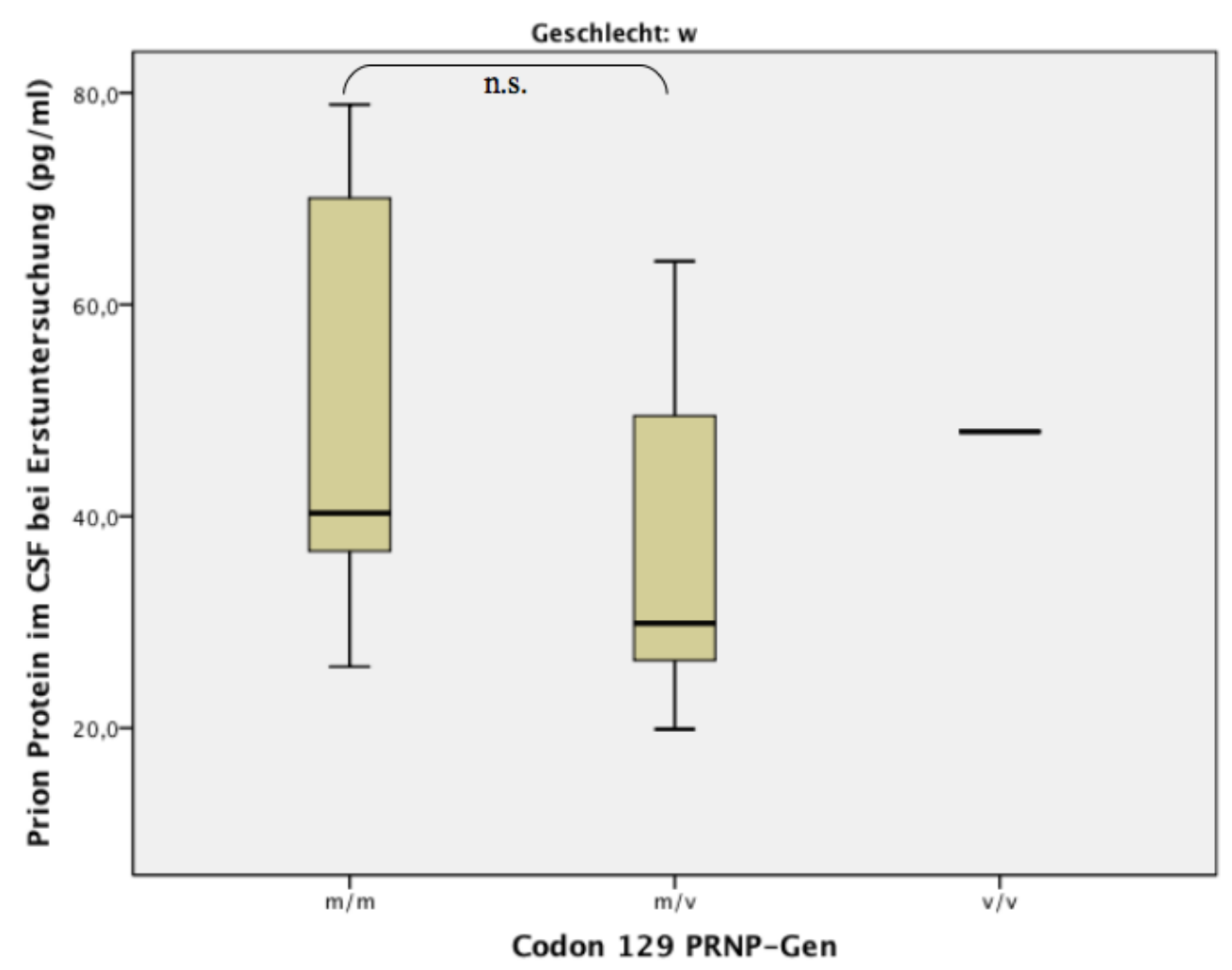

Abb. 22: Prion-Protein im CSF (pg/ml) und Codon 129-Polymorphismus bei Frauen

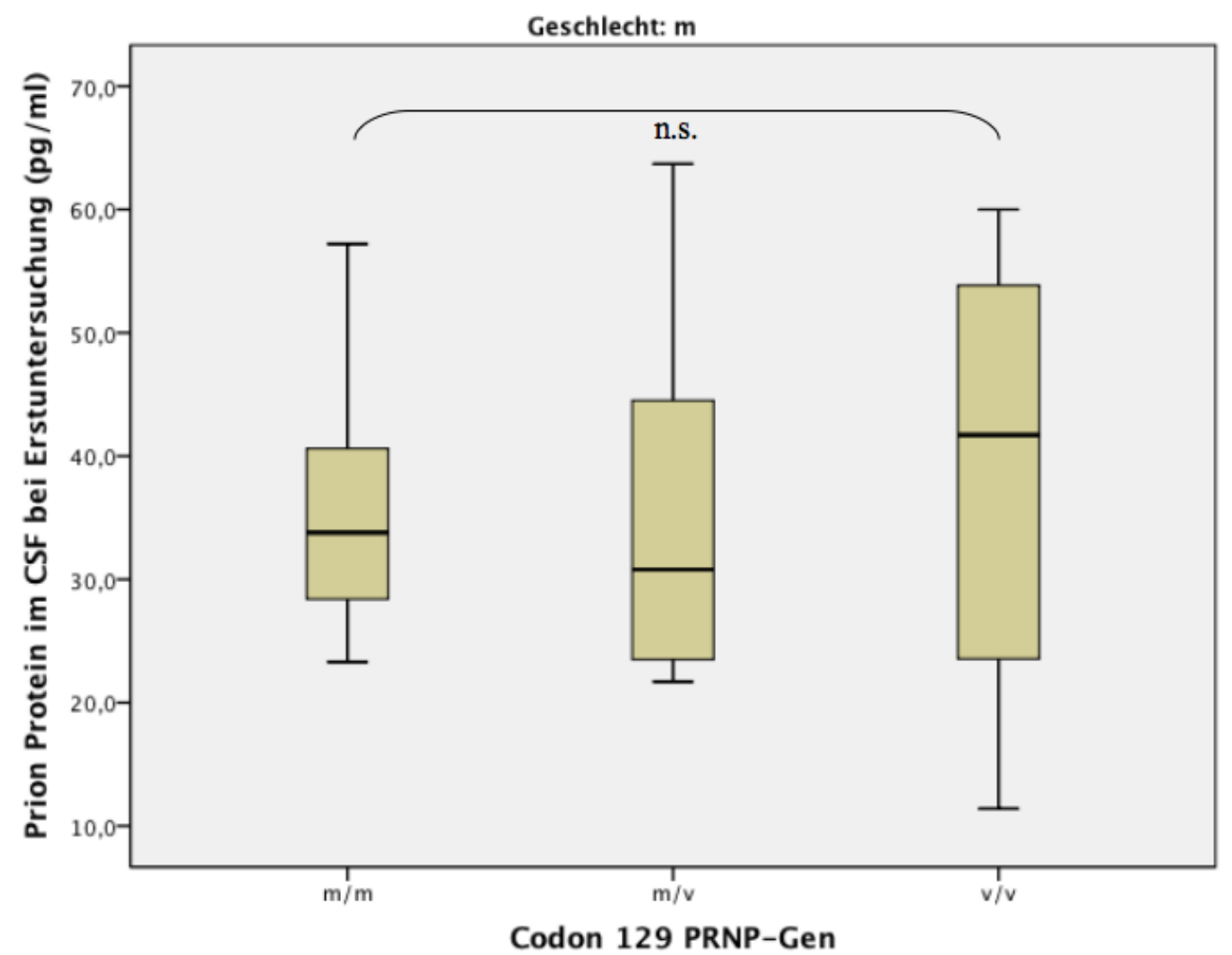

Abb. 23: Prion-Protein im CSF (pg/ml) und Codon 129-Polymorphismus bei Männern 


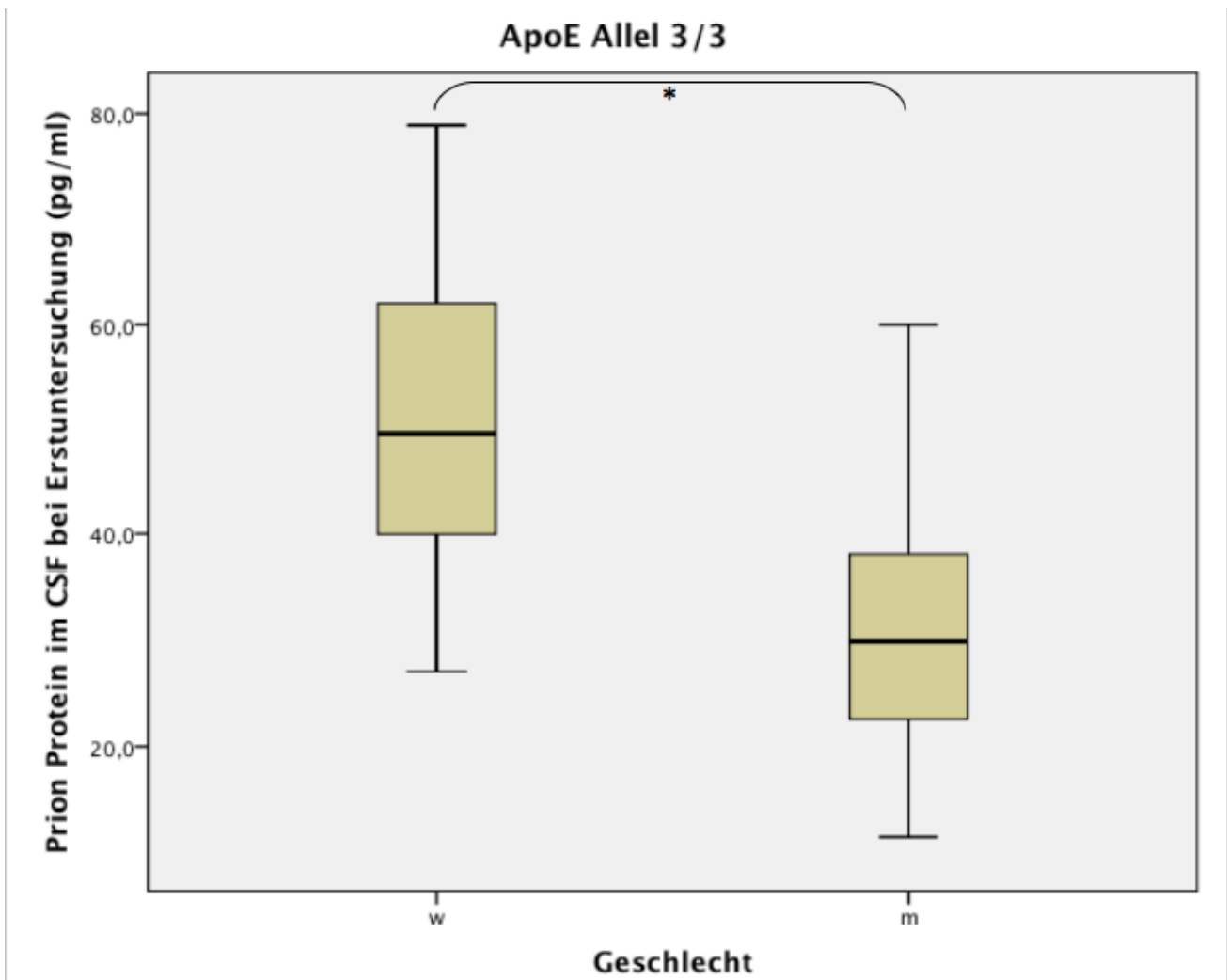

Abb. 24: Prion-Protein im CSF (pg/ml) bei ApoE-Allel 3/3

Innerhalb der anderen Untergruppen konnten zwischen den Geschlechtern keine weiteren Mittelwertunterschiede herausgearbeitet werden, entweder aufgrund von Mittelwertgleichheit (Altersgruppe " $<=65$, p=0,543; Altersgruppe "66 bis 80 Jahre", p=0,770; Demenzstadium "leicht", $\mathrm{p}=0,567$; Demenzstadium "mittel", $\mathrm{p}=0,548$; Progression "langsam", $\mathrm{p}=0,803$; Progression "rapid", $\mathrm{p}=0,183 ;$ ApoE 3/4, p=0,878; ApoE \&4-Allel neg., $\mathrm{p}=0,065 ;$ ApoE $\varepsilon 4$-Allel pos., $\mathrm{p}=0,975$; Codon129 $\mathrm{m} / \mathrm{m}, \quad \mathrm{p}=0,119$; sowie Codon $129 \mathrm{~m} / \mathrm{v}, \mathrm{p}=0,710$ ) oder aufgrund einer zu geringen Gruppengröße (ApoE 2/2, ApoE 2/3, ApoE 2/4, ApoE 4/4, Codon129 v/v, Demenzstadium "schwer" sowie Altersgruppe " $\geq 81$ Jahre").

\subsubsection{A $\beta 1-40$}

Bei den Männern konnte zwischen den Gruppen mit langsamen Verläufen und rapiden Verläufen ein signifikanter Unterschied in der mittleren Konzentration an A $\beta 1-40$ ermittelt werden (Mittelwert "Langsam" ( $\mathrm{n}=11): 6794,8 \pm 2427,6$ pg/ml, "Rapid" ( $\mathrm{n}=4): 4340,3 \pm 1124,4 \mathrm{pg} / \mathrm{ml} ; \mathrm{p}=0,021)$. Ansonsten konnten keine weiteren Mittelwertunterschiede herausgearbeitet werden (Tab. 3 und Abb. 25).

\begin{tabular}{|c|c|c|c|c|c|c|c|}
\hline & & Geschlecht & $n$ & NV & $\begin{array}{l}\text { MW/MD } \\
\text { A } \beta 1-40(\mathrm{pg} / \mathrm{ml})\end{array}$ & SD/IQR & Signifikanzwert \\
\hline \multirow{3}{*}{ 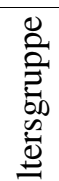 } & $\leq 65$ Jahre & \multirow{3}{*}{ w } & 5 & + & 5466,6 & 1649,2 & \multirow{3}{*}{$\mathrm{p}=0,458$} \\
\hline & 66 - 80 Jahre & & 11 & + & 6315,8 & 2139,8 & \\
\hline & $\geq 81$ Jahre & & 3 & + & 7473,7 & 2949,5 & \\
\hline
\end{tabular}




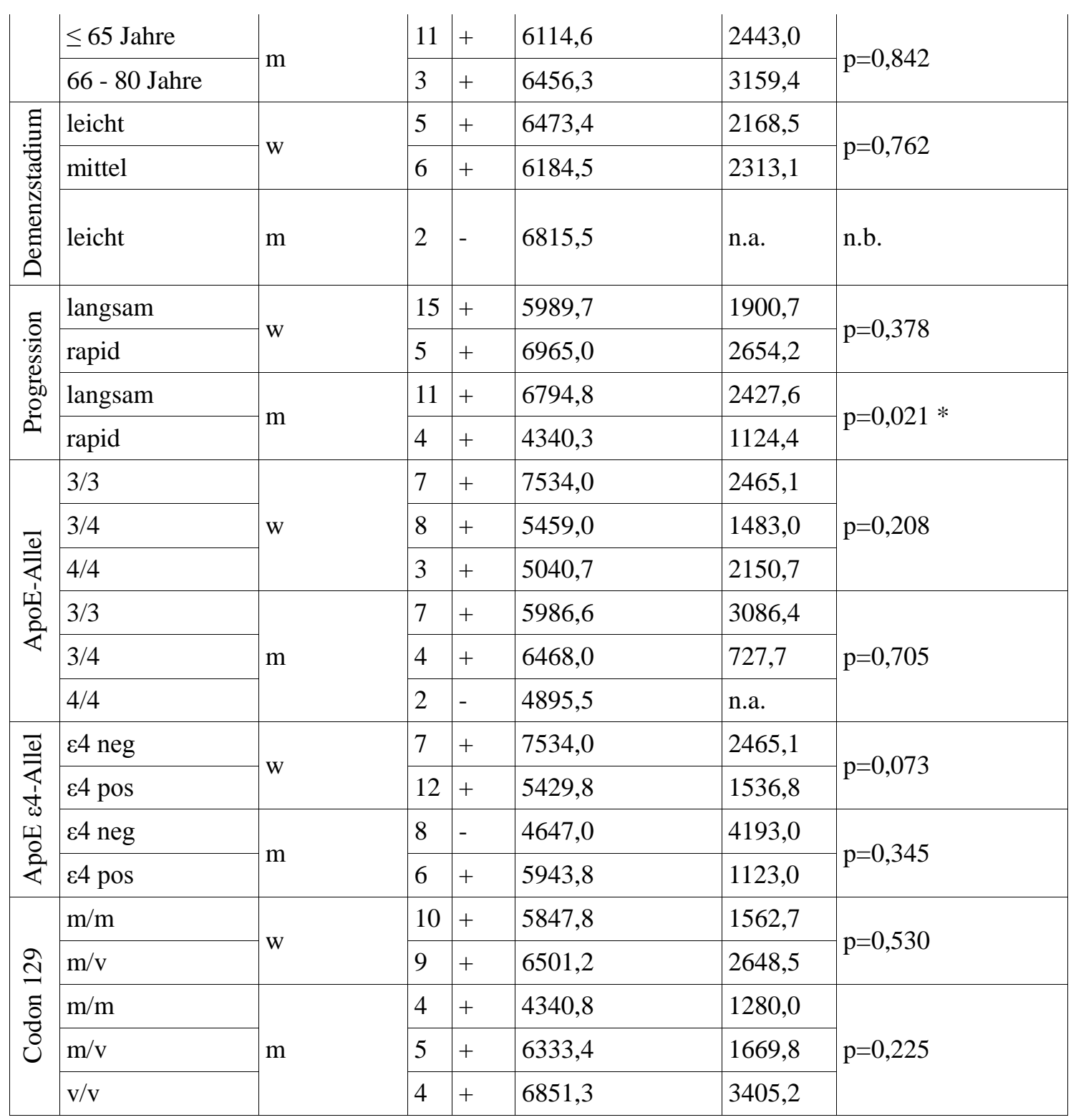

Tab. 3: Konzentration von A $\beta 1-40$ im CSF der verschiedenen Untergruppen $\mathrm{n}=$ Anzahl, $\mathrm{NV}+/$ - = Normalverteilung der Werte positiv/negativ,

MW/MD = Mittelwert/Median, SD/IQR = Standardabweichung/Interquartilenabstand, $\varepsilon 4$ neg $=A p o E \varepsilon 4$-Allel nicht vorhanden, $\varepsilon 4$ pos $=A p o E \varepsilon 4$-Allel vorhanden 


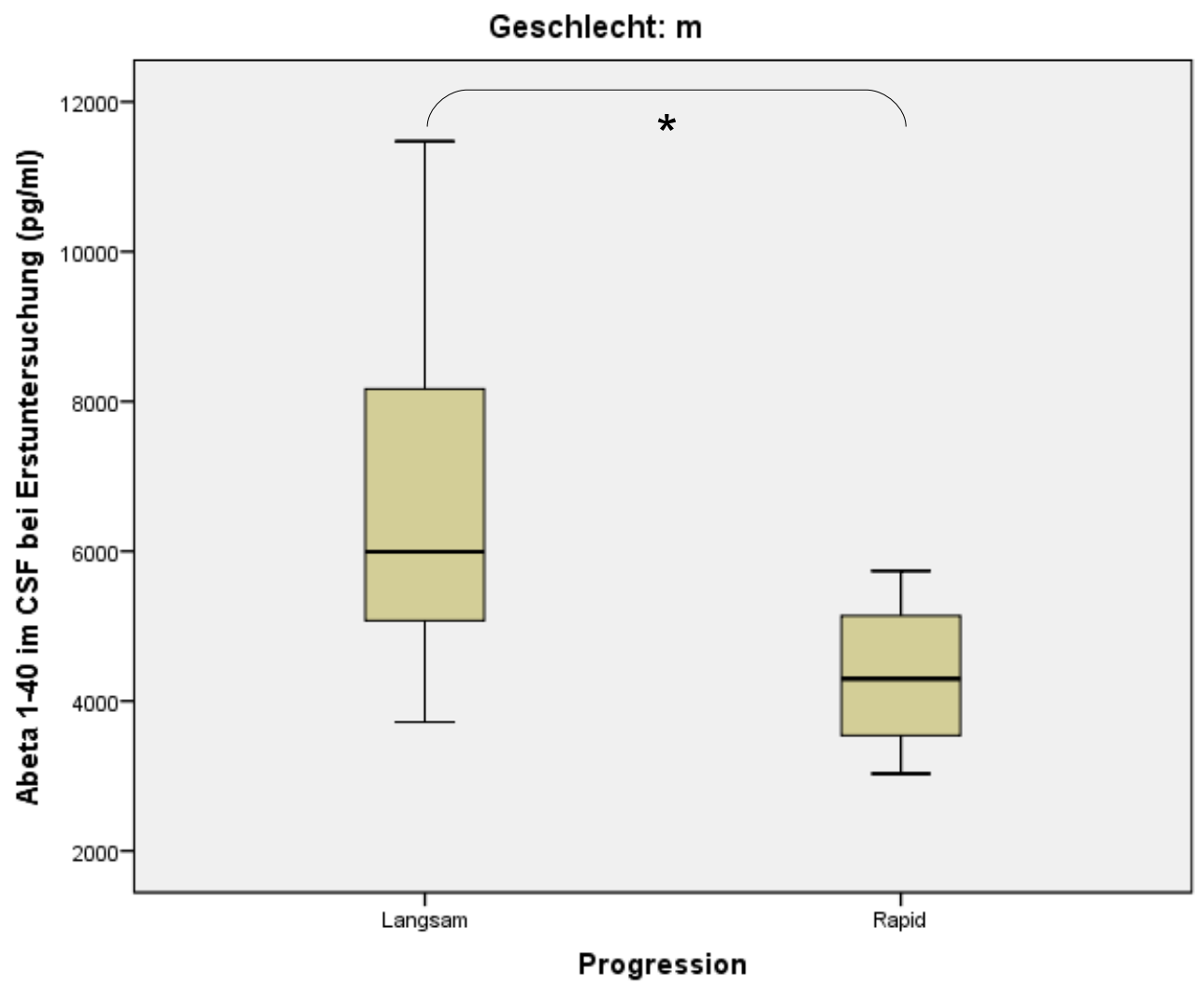

Abb. 25: A $1-40 \mathrm{im} \mathrm{CSF} \mathrm{(pg/ml)} \mathrm{in} \mathrm{langsamen} \mathrm{/} \mathrm{schnellen} \mathrm{Verläufen} \mathrm{bei} \mathrm{Männern}$

\subsubsection{A $\beta 1-42$}

Bei den Männern zeigten sich signifikante Unterschiede der mittleren Konzentration an A $\beta 1-42$ im CSF zwischen den Altersgruppen " $\leq 65$ Jahre" und "66 bis 80 Jahre"

(Mittelwert " $\leq 65$ Jahre" ( $\mathrm{n}=12): 427,0 \pm 140,9$ pg/ml ; "66 bis 80 Jahre": ( $=4): 310,3 \pm 51,9$ pg/ml ; $\mathrm{p}=0,030$ ) sowie zwischen den Gruppen mit langsamen und rapiden Verläufen (Mittelwert "Langsam" ( $\mathrm{n}=13): 443,3 \pm 112,3 \mathrm{pg} / \mathrm{ml}$; "Rapid" ( $\mathrm{n}=4): 264,8 \pm 85,7 \mathrm{pg} / \mathrm{ml}$; $\mathrm{p}=0,011$ ) (Tab. 4, Abb. 26 und Abb. 27).

Zwischen den Geschlechtern konnten signifikante Mittelwertunterschiede bezüglich der CSFKonzentration von A $\beta 1-42$ sowohl in der Gruppe mit langsamen Verläufen (w: 349,7 $\pm 97,6, n=16$; m: 443,3 $\pm 112,2 \mathrm{n}=13 ; \mathrm{p}=0,023$ ) als auch in der Gruppe der ApoE 3/4-Allelträger (w: 371,8 \pm 90,0 pg/ml, n=9 ; m: 495,0 \pm 75,7 pg/ml, n=5 ; p=0,029) beobachtet werden (Abb. 28 und Abb. 29). Innerhalb der anderen Untergruppen konnten bei Frauen, Männern oder zwischen den Geschlechtern keine weitere Mittelwertunterschiede herausgearbeitet werden.

\begin{tabular}{|c|c|c|c|c|c|c|c|}
\hline & & Geschlecht & $\mathrm{n}$ & NV & $\begin{array}{l}\text { MW/MD } \\
\text { A } \beta 1-42(\mathrm{pg} / \mathrm{ml})\end{array}$ & $\mathrm{SD} / \mathrm{IQR}$ & Signifikanzwert \\
\hline \multirow{2}{*}{ 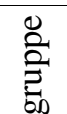 } & $\leq 65$ Jahre & \multirow{2}{*}{ w } & 5 & + & 376,4 & 113,0 & \multirow{2}{*}{$\mathrm{p}=0,937$} \\
\hline & 66 - 80 Jahre & & 12 & + & 363,8 & 103,6 & \\
\hline
\end{tabular}




\begin{tabular}{|c|c|c|c|c|c|c|c|}
\hline & $\geq 81$ Jahre & & 3 & + & 347,7 & 132,5 & \\
\hline & $\leq 65$ Jahre & \multirow{2}{*}{$\mathrm{m}$} & 12 & + & 427,0 & 140,9 & \multirow{2}{*}{$\mathrm{p}=0,030 *$} \\
\hline & 66 - 80 Jahre & & 4 & + & 310,3 & 51,9 & \\
\hline \multirow{5}{*}{ 館 } & leicht & \multirow{3}{*}{ w } & 9 & + & 263,8 & 111,1 & \multirow{3}{*}{$\mathrm{p}=0,951$} \\
\hline & mittel & & 10 & + & 364,4 & 108,5 & \\
\hline & schwer & & 2 & - & 351,5 & n.a. & \\
\hline & leicht & \multirow{2}{*}{$\mathrm{m}$} & 13 & + & 414,9 & 116,4 & \multirow{2}{*}{$\mathrm{p}=0,580$} \\
\hline & mittel & & 4 & + & 357,0 & 180,4 & \\
\hline \multirow{4}{*}{ 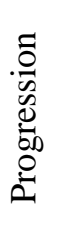 } & langsam & \multirow{2}{*}{ w } & 16 & + & 349,7 & 97,6 & \multirow{2}{*}{$\mathrm{p}=0,218$} \\
\hline & rapid & & 5 & + & 405,2 & 114,2 & \\
\hline & langsam & \multirow{2}{*}{$\mathrm{m}$} & 13 & + & 443,3 & 112,2 & \multirow{2}{*}{$\mathrm{p}=0,011 *$} \\
\hline & rapid & & 4 & + & 264,8 & 85,7 & \\
\hline \multirow{6}{*}{ 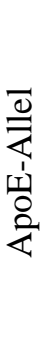 } & $3 / 3$ & \multirow{3}{*}{ w } & 7 & + & 386,7 & 100,4 & \multirow{3}{*}{$\mathrm{p}=0,179$} \\
\hline & $3 / 4$ & & 9 & + & 371,8 & 90,0 & \\
\hline & $4 / 4$ & & 3 & + & 255,7 & 102,8 & \\
\hline & $3 / 3$ & \multirow{3}{*}{$\mathrm{m}$} & 8 & + & 392,4 & 152,0 & \multirow{3}{*}{$\mathrm{p}=0,098$} \\
\hline & $3 / 4$ & & 5 & - & 495,0 & 75,7 & \\
\hline & $4 / 4$ & & 2 & - & 283,0 & n.a. & \\
\hline \multirow{4}{*}{ 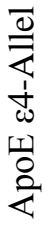 } & $\varepsilon 4$ neg & \multirow{2}{*}{$\mathrm{w}$} & 7 & + & 386,7 & 100,4 & \multirow{2}{*}{$\mathrm{p}=0,508$} \\
\hline & $\varepsilon 4$ pos & & 13 & + & 353,3 & 107,9 & \\
\hline & $\varepsilon 4$ neg & $m$ & 9 & + & 382,8 & 145,1 & $n=0.464$ \\
\hline & $\varepsilon 4$ pos & 111 & 7 & + & 434,4 & 120,6 & $\mathrm{p}=-0,701$ \\
\hline \multirow{5}{*}{ 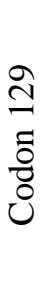 } & $\mathrm{m} / \mathrm{m}$ & \multirow{2}{*}{ w } & 11 & + & 348,2 & 111,6 & \multirow{2}{*}{$\mathrm{p}=0,353$} \\
\hline & $\mathrm{m} / \mathrm{v}$ & & 9 & + & 391,8 & 88,6 & \\
\hline & $\mathrm{m} / \mathrm{m}$ & \multirow{3}{*}{$\mathrm{m}$} & 5 & + & 324,4 & 147,3 & \multirow{3}{*}{$\mathrm{p}=0,453$} \\
\hline & $\mathrm{m} / \mathrm{v}$ & & 6 & - & 458,5 & 136,0 & \\
\hline & $\mathrm{v} / \mathrm{v}$ & & 4 & + & 455,8 & 166,0 & \\
\hline
\end{tabular}

Tab. 4: Konzentration von A $\beta 1-42$ im CSF der verschiedenen Untergruppen $\mathrm{n}=$ Anzahl, NV +/- = Normalverteilung der Werte positiv/negativ, MW/MD = Mittelwert/Median, SD/IQR = Standardabweichung/Interquartilenabstand, $\varepsilon 4$ neg $=$ ApoE $\varepsilon 4$-Allel nicht vorhanden, $\varepsilon 4$ pos $=$ ApoE $\varepsilon 4$-Allel vorhanden 


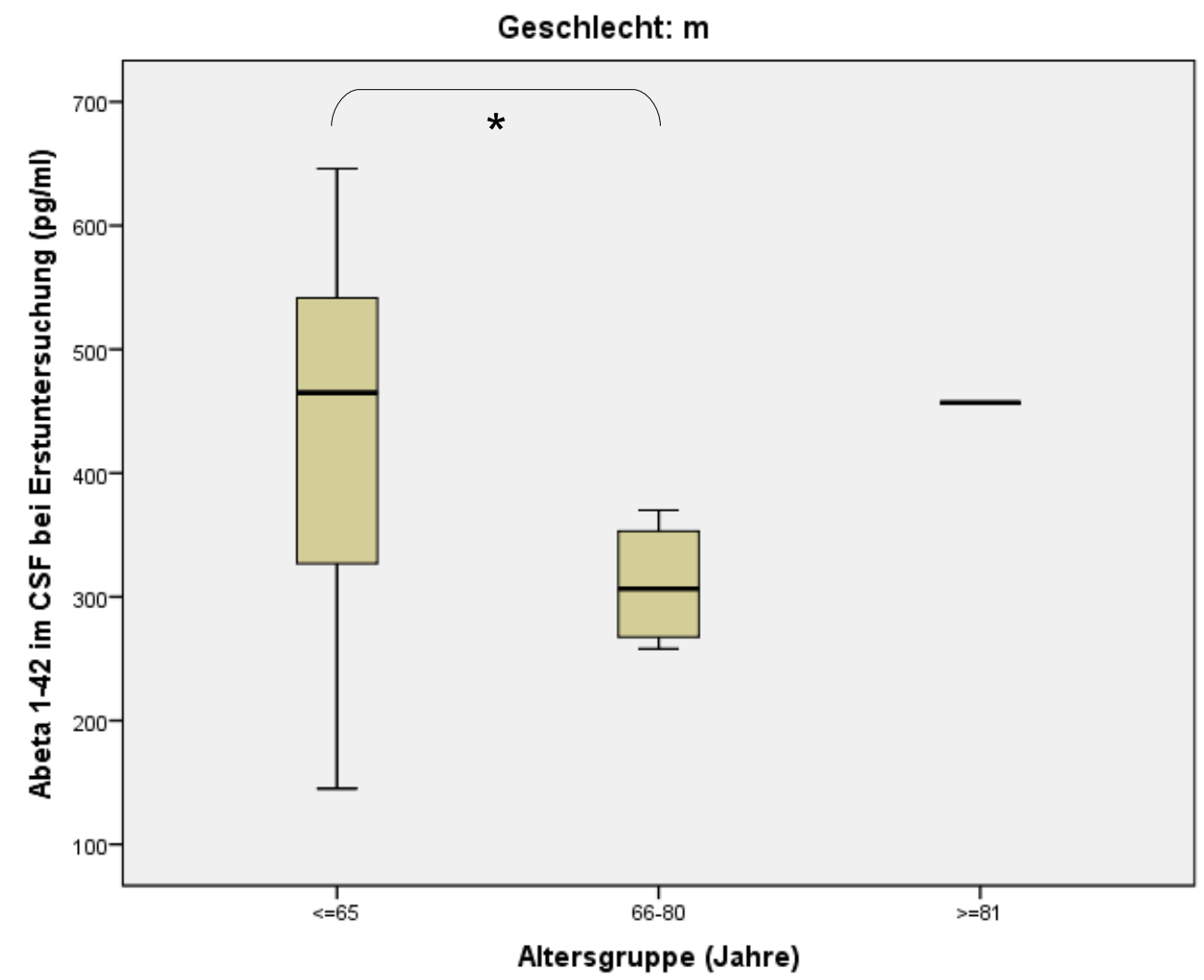

Abb. 26: A $\beta 1-42 \mathrm{im} \mathrm{CSF}(\mathrm{pg} / \mathrm{ml})$ in verschiedenen Altersgruppen bei Männern

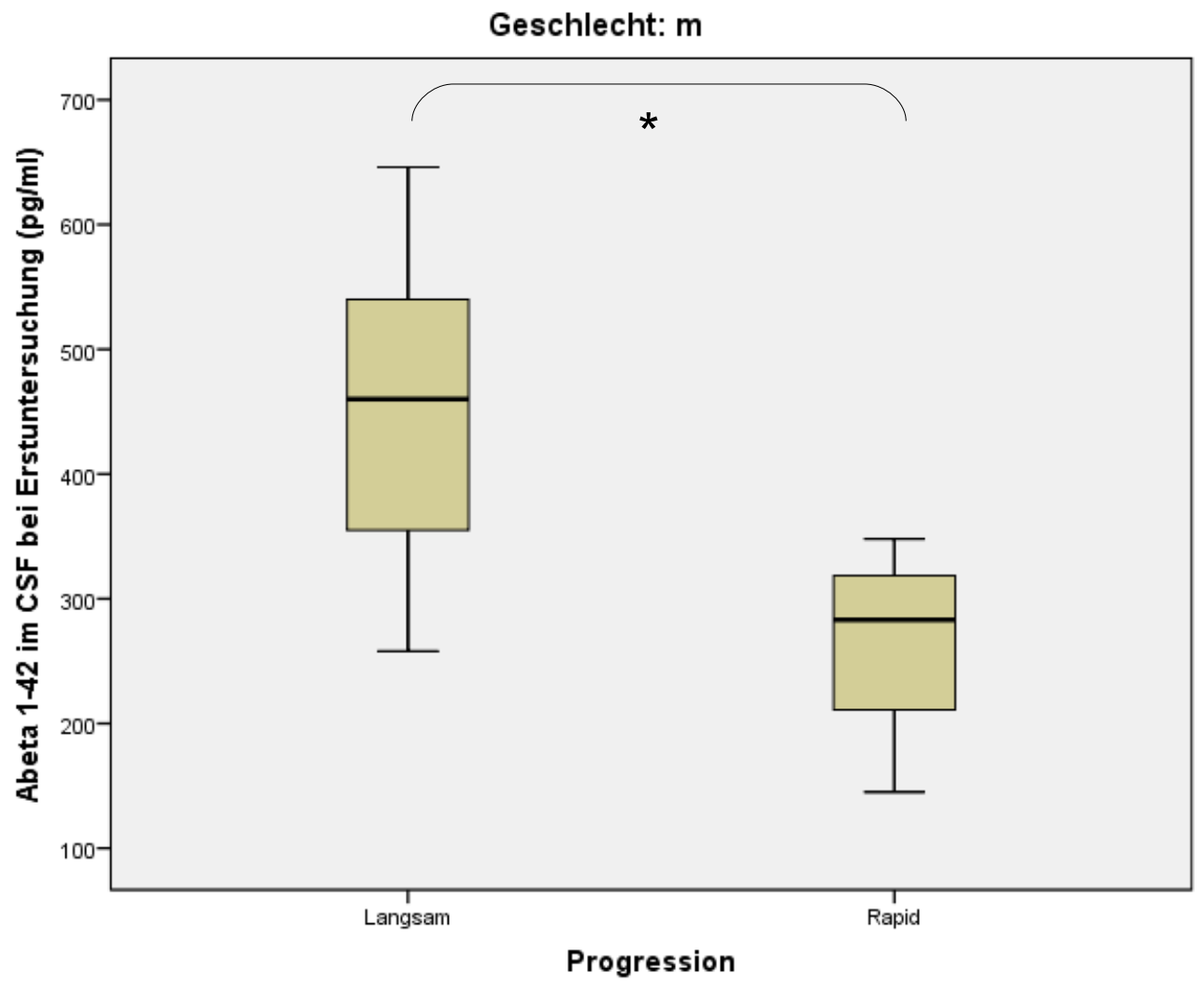

Abb. 27: Aß1-42 im CSF (pg/ml) in langsamen / schnellen Verläufen bei Männern 


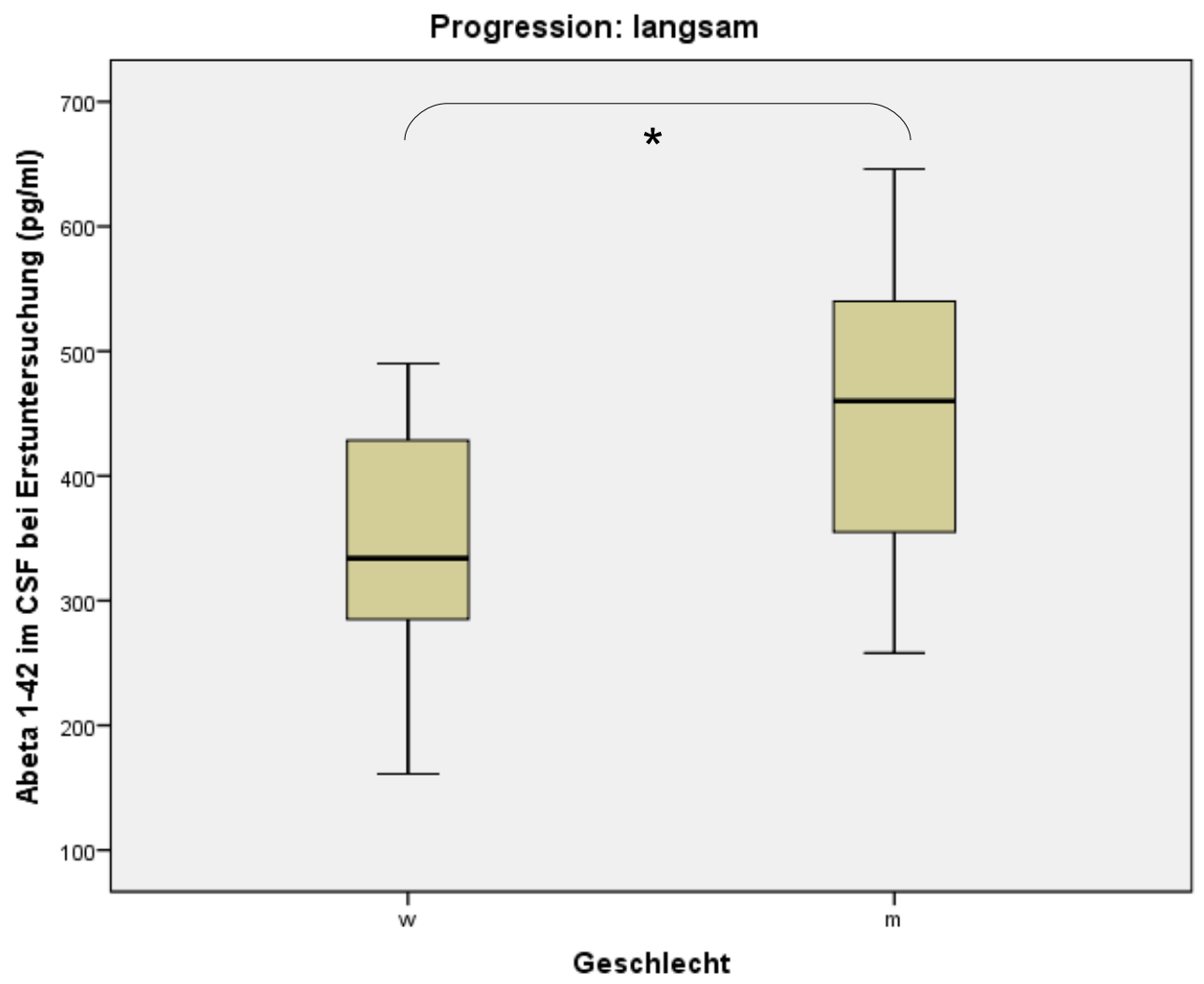

Abb. 28: $A \beta 1-42 \mathrm{im} \mathrm{CSF}(\mathrm{pg} / \mathrm{ml})$ in langsamen Verläufen

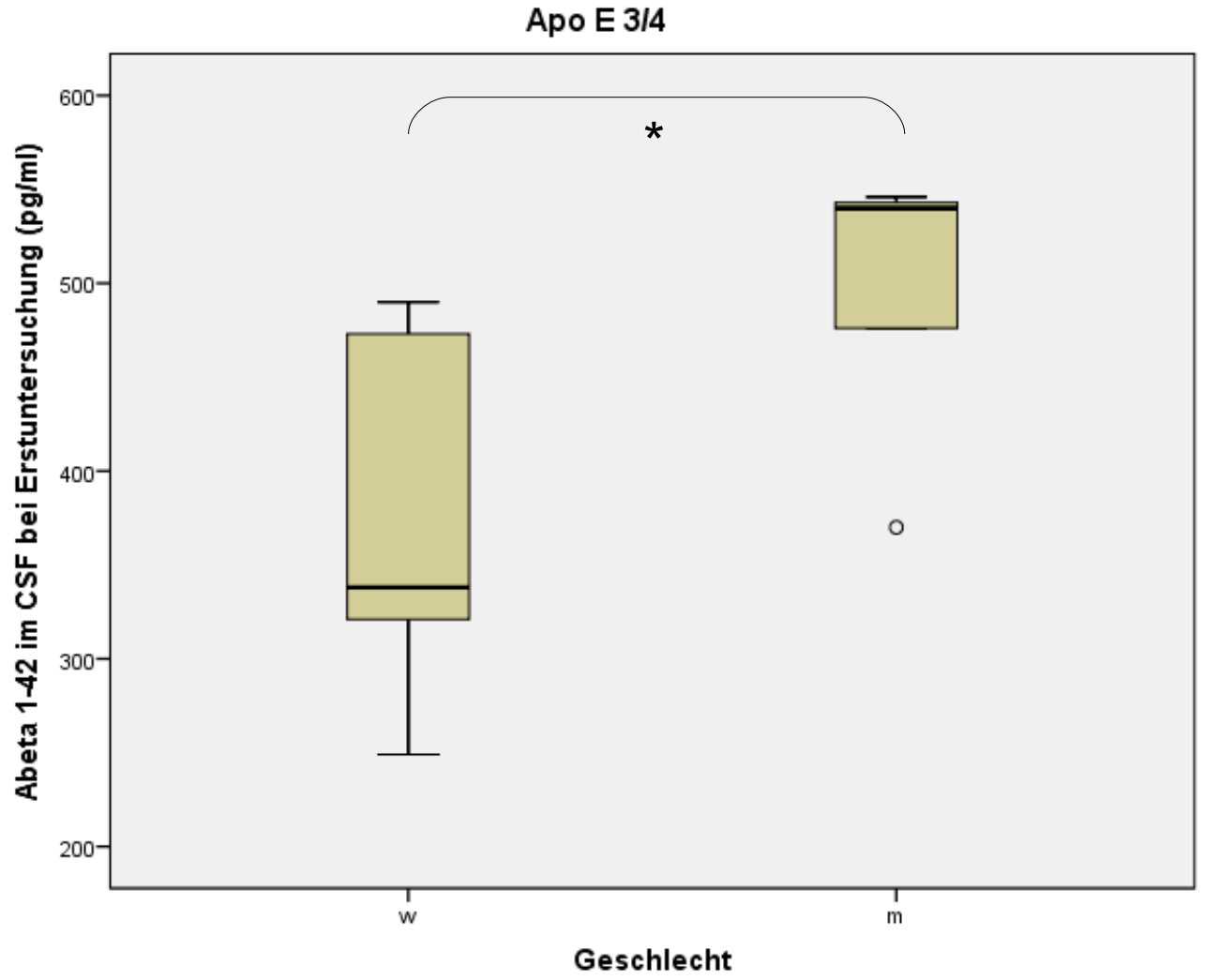


Abb. 29: A $\beta 1-42$ im CSF (pg/ml) bei ApoE-Allel 3/4

3.4.4 Tau

In der Altersgruppe " $\leq 65$ Jahre" konnte zwischen den Geschlechtern ein signifikanter Mittelwertunterschied bezüglich der CSF-Konzentration von Tau festgestellt werden (w: 838,4 $\pm 482,5 \mathrm{pg} / \mathrm{ml}, \mathrm{n}=5 ; \mathrm{m}: 449,0 \pm 236,0 \mathrm{pg} / \mathrm{ml}, \mathrm{n}=12 ; \mathrm{p}=0,038$ ) (Abb. 30).

Innerhalb der anderen Untergruppen konnten weder bei Frauen, Männern oder zwischen den Geschlechtern weitere Mittelwertunterschiede herausgearbeitet werden (Tab 5).

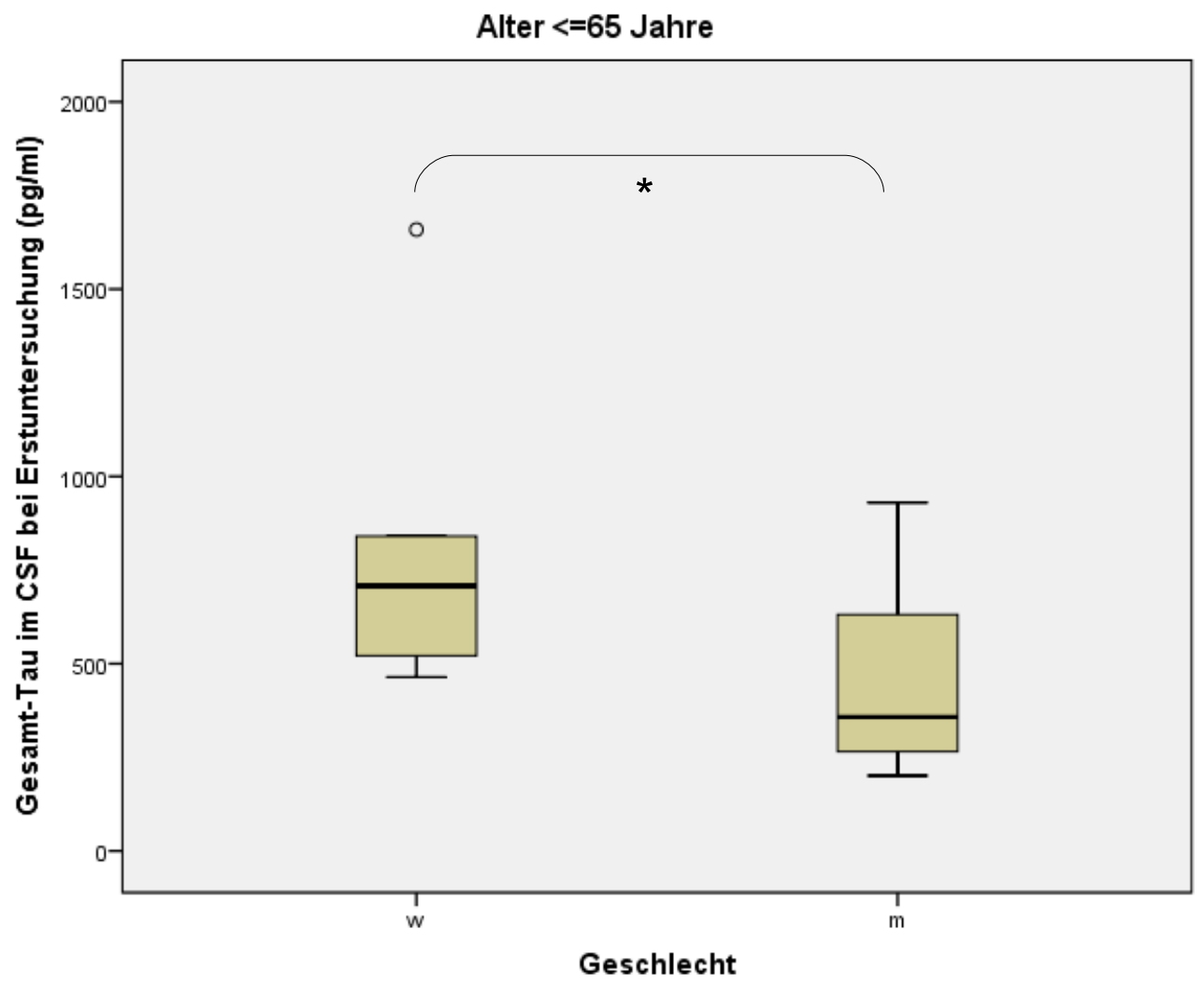

Abb. 30: Tau im CSF (pg/ml) in der Altersgruppe "bis einschließlich 65 Jahre"

\subsection{5 pTau}

In keiner Untergruppe konnte - auch zwischen den Geschlechtern - ein Unterschied bezüglich der mittleren Konzentration an pTau im CSF der Probanden festgestellt werden (Tab. 6).

\begin{tabular}{|c|c|c|c|c|c|c|c|}
\hline & & Geschlecht & $\mathrm{n}$ & NV & $\begin{array}{l}\text { MW/MD } \\
\text { Tau (pg/ml) }\end{array}$ & $\mathrm{SD} / \mathrm{IQR}$ & Signifikanzwert \\
\hline \multirow{3}{*}{ 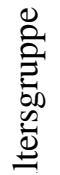 } & $\leq 65$ Jahre & \multirow{3}{*}{ W } & 5 & + & 838,4 & 482,5 & \multirow{3}{*}{$\mathrm{p}=0,731$} \\
\hline & 66 - 80 Jahre & & 12 & + & 711,9 & 468,9 & \\
\hline & $\geq 81$ Jahre & & 3 & + & 978,6 & 928,3 & \\
\hline
\end{tabular}




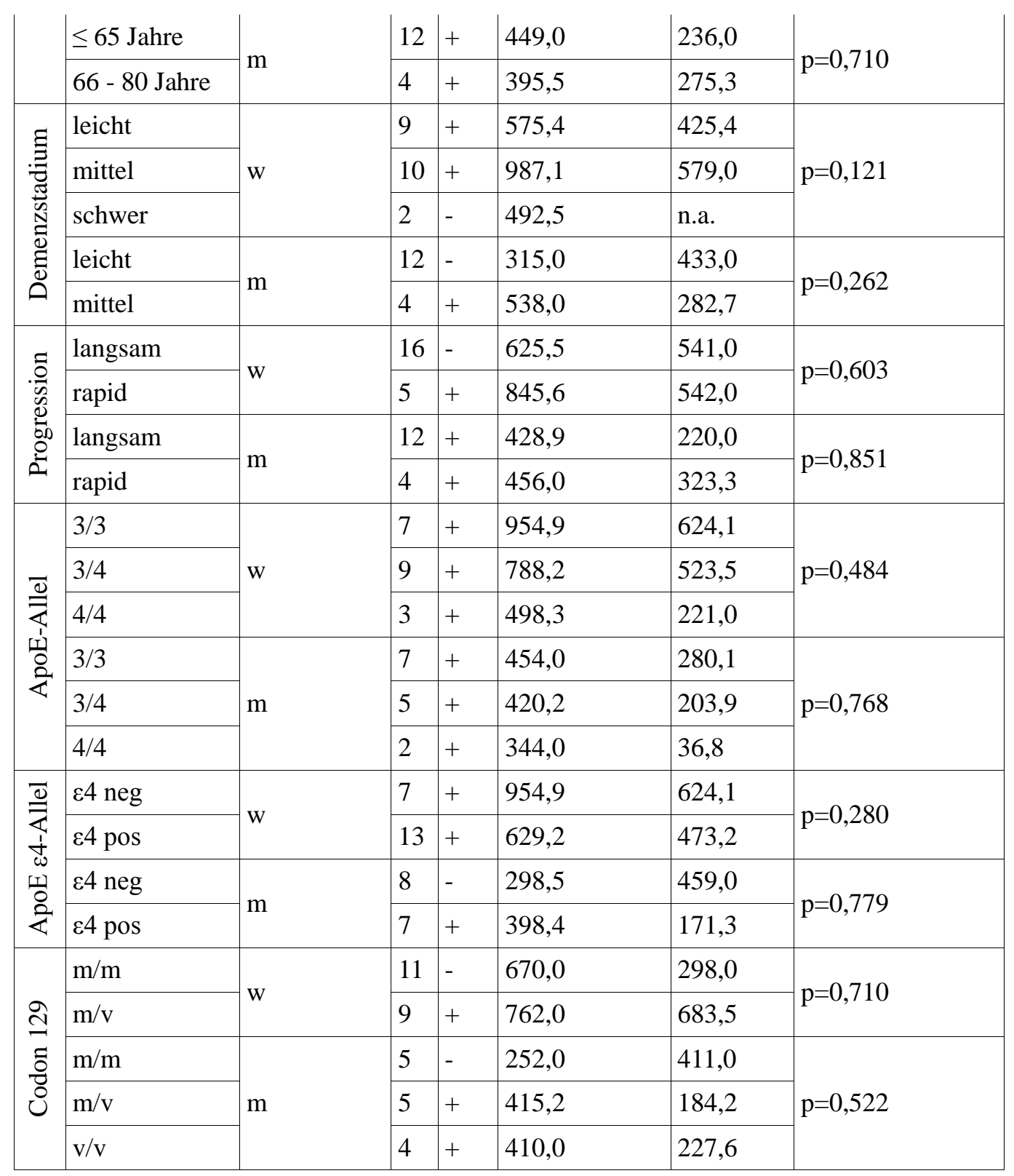

Tab. 5: Konzentration von Tau im CSF der verschiedenen Untergruppen $\mathrm{n}=$ Anzahl, NV +/- = Normalverteilung der Werte positiv/negativ, MW/MD = Mittelwert/Median, SD/IQR = Standardabweichung/Interquartilenabstand, $\varepsilon 4$ neg $=A p o E \varepsilon 4$-Allel nicht vorhanden, $\varepsilon 4$ pos $=A p o E \varepsilon 4$-Allel vorhanden

\begin{tabular}{|c|c|c|c|c|c|c|c|}
\hline & & Geschlecht & $\mathrm{n}$ & NV & $\begin{array}{l}\text { MW/MD } \\
\text { pTau (pg/ml) }\end{array}$ & $\mathrm{SD} / \mathrm{IQR}$ & Signifikanzwert \\
\hline \multirow{5}{*}{ 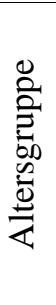 } & $\leq 65$ Jahre & \multirow{3}{*}{ w } & 5 & - & 66,0 & 140,0 & \multirow{3}{*}{$\mathrm{p}=0,667$} \\
\hline & 66 - 80 Jahre & & 12 & + & 117,2 & 53,3 & \\
\hline & $\geq 81$ Jahre & & 3 & + & 104,7 & 88,0 & \\
\hline & $\leq 65$ Jahre & \multirow{2}{*}{$\mathrm{m}$} & 12 & + & 92,9 & 26,5 & \multirow{2}{*}{$\mathrm{p}=0,103$} \\
\hline & 66 - 80 Jahre & & 4 & - & 51,0 & 57,0 & \\
\hline \multirow{3}{*}{ 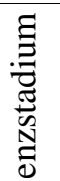 } & leicht & \multirow{3}{*}{ w } & 9 & + & 91,4 & 46,4 & \multirow{3}{*}{$\mathrm{p}=0,091$} \\
\hline & mittel & & 10 & + & 144,0 & 76,9 & \\
\hline & schwer & & 2 & + & 64,0 & 2,8 & \\
\hline
\end{tabular}




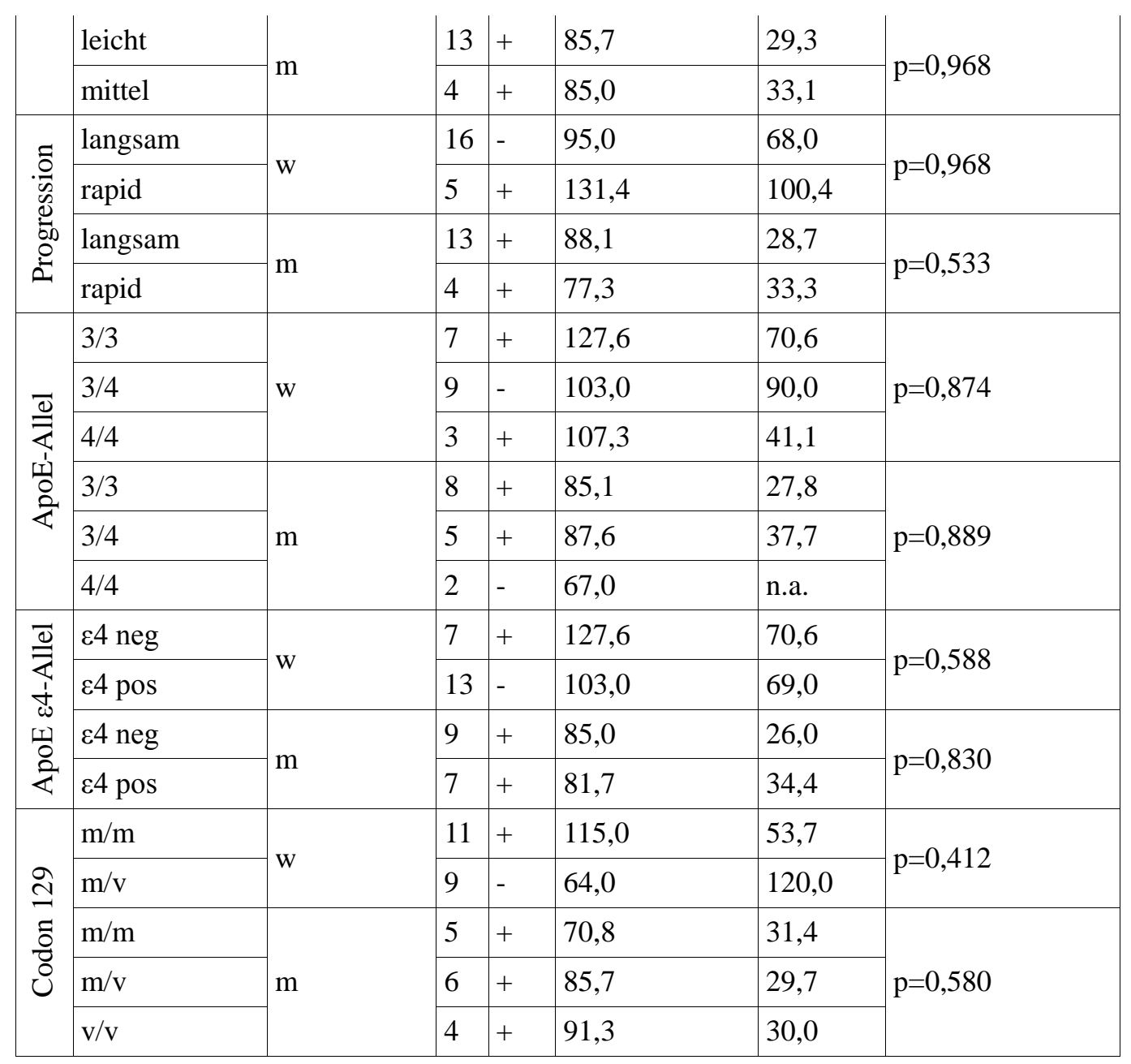

Tab. 6: Konzentration von pTau im CSF der verschiedenen Untergruppen $\mathrm{n}=$ Anzahl, $\mathrm{NV}+/$ - = Normalverteilung der Werte positiv/negativ, MW/MD = Mittelwert/Median, SD/IQR = Standardabweichung/Interquartilenabstand, $\varepsilon 4$ neg $=$ ApoE $\varepsilon 4$-Allel nicht vorhanden, $\varepsilon 4$ pos $=$ ApoE $\varepsilon 4$-Allel vorhanden 3.5 Korrelationsanalyse

Die aufgeführten Parameter wurden innerhalb eines Geschlechtes sowie zwischen den Geschlechtern auf lineare Zusammenhänge bezüglich der verschiedenen Altersgruppen, Demenzstadien, Verlaufstypen sowie der Genetik hin untersucht.

Im Folgenden werden nur die signifikanten Ergebnisse dargestellt.

\subsubsection{Prion-Protein}

\subsubsection{PrPc und $A \beta 1-40$}

Zwischen den Parametern PrPc und A $\beta 1-40$ zeigten sich über das Gesamtkollektiv ( $n=35$, Korrelation nach Pearson 0,489, $\mathrm{p}=0,003$ ) (Abb. 31) sowie in den Untergruppen "Altersgruppe 66 bis 80 Jahre" ( $\mathrm{n}=14$, Kendall-tau-b 0,420, $\mathrm{p}=0,037$ ), "Stadium der leichten Demenz (MMSE 21-30 
Punkte)" ( $\mathrm{n}=20$, Korrelation nach Pearson 0,460, p=0,041), "langsame Progression" ( $\mathrm{n}=26$, Pearson 0,403, p=0,041), "ApoE \&4-Allel-positiv" ( $\mathrm{n}=18$, Pearson 0,494, p=0,037) und "ApoE \&4-Allelpositive Frauen" ( $\mathrm{n}=12$, Kendall-tau-b 0,473, $\mathrm{p}=0,032)$ mindestens signifikante, im mittleren Bereich liegende Zusammenhänge. Hohe bzw. sehr hohe Korrelationen konnten in den Untergruppen "Frauen" ( $\mathrm{n}=20$, Pearson 0,568, p=0,009), "Frauen mit ApoE 3/4-Allel" ( $\mathrm{n}=8$, Kendall-tau-b, 0,618 $\mathrm{p}=0,034)$, "mittelschwere Demenz (MMSE 11-20 Punkte)" ( $\mathrm{n}=13$, Pearson 0,591, $\mathrm{p}=0,033$ ), "Codon129 Methionin/Valin-heterozygote Frauen" ( $\mathrm{n}=9$, Pearson $0,758, \mathrm{p}=0,018)$ sowie unter den Probanden mit rapider Progression ( $\mathrm{n}=9$, Pearson 0,717, $\mathrm{p}=0,030$ ) (Abb. 32) beobachtet werden.

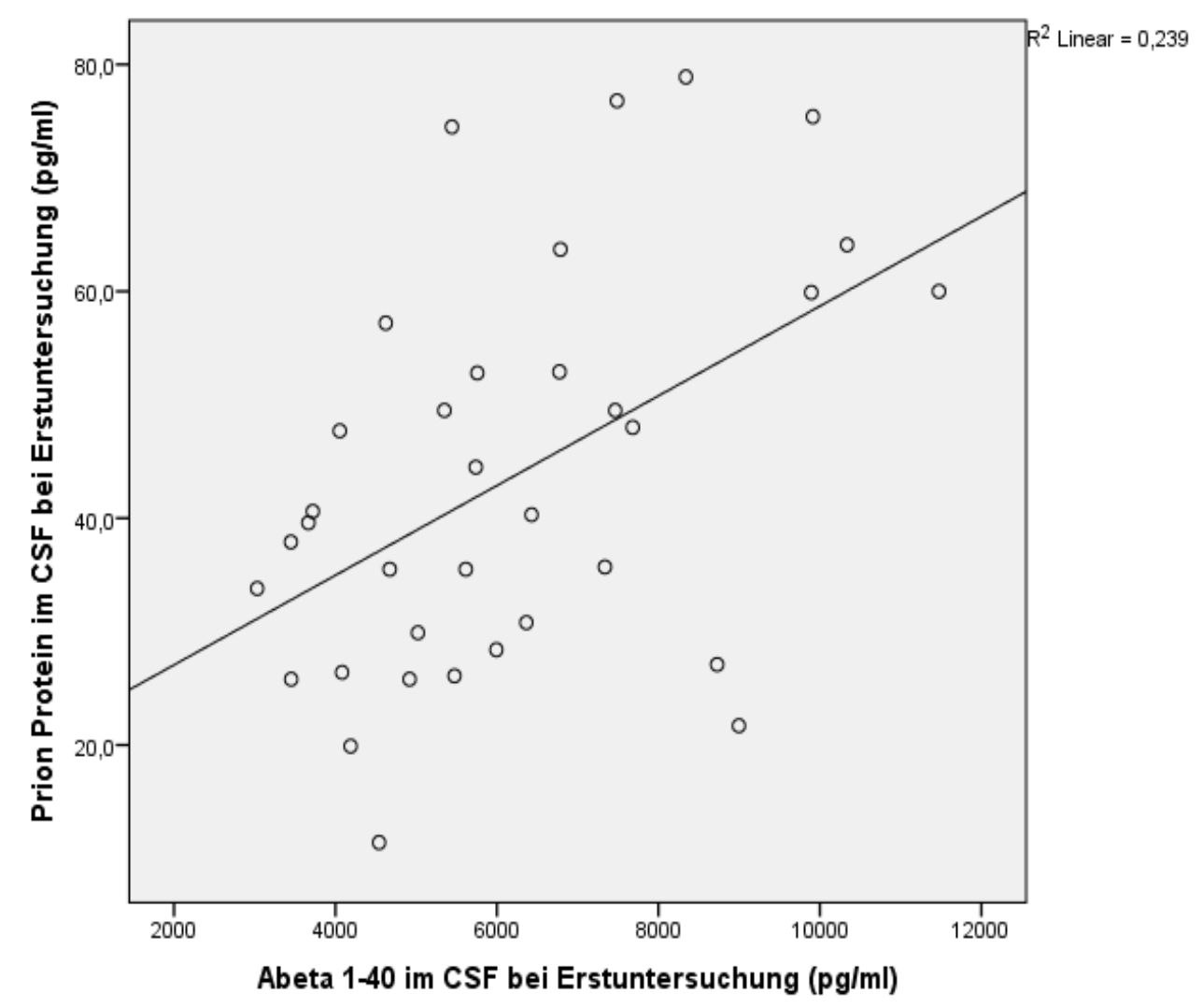

Abb. 31: Korrelation von PrPc und A $\beta 1-40$ 


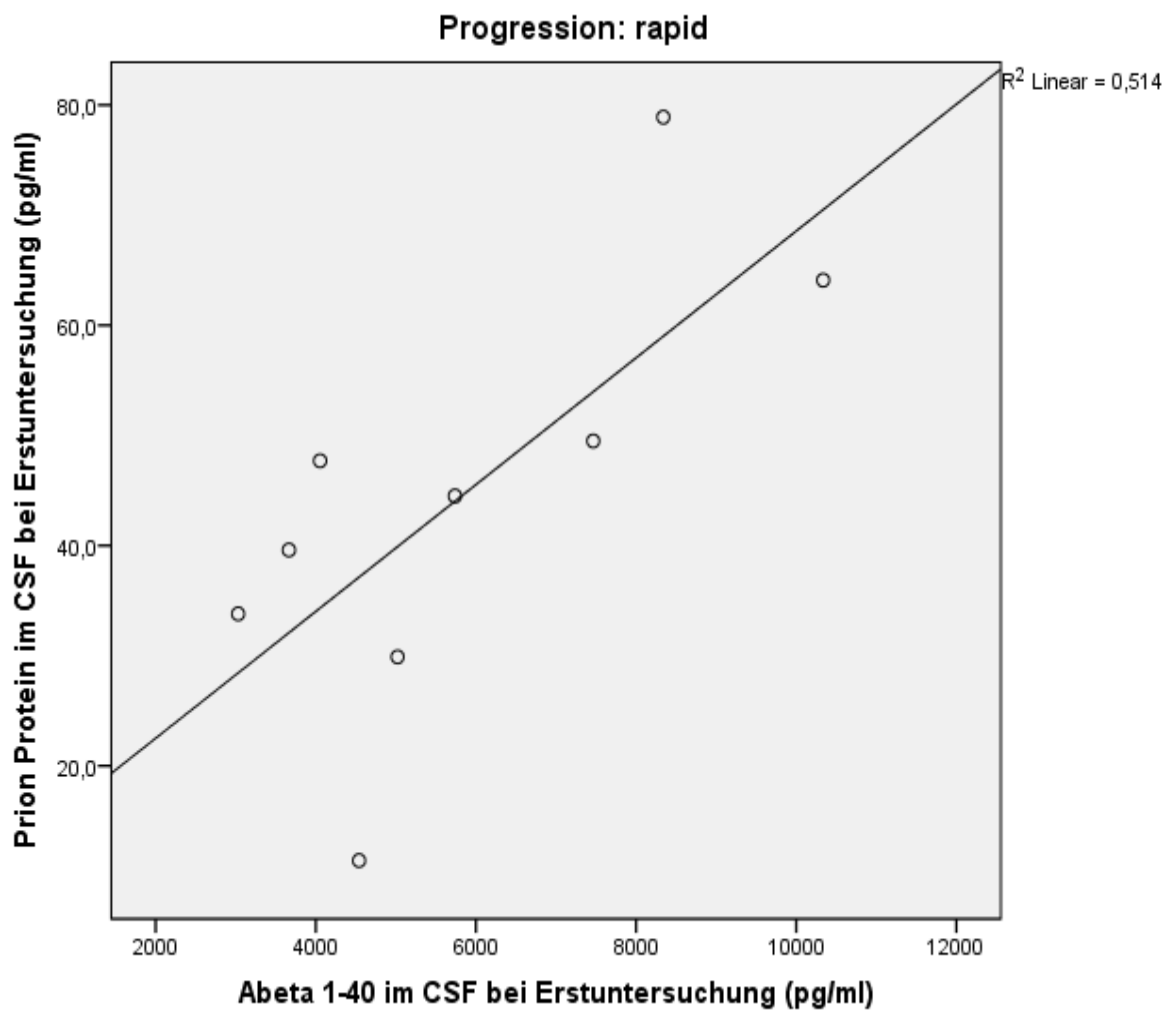

Abb. 32: Korrelation von PrPc und A $\beta 1-40$ bei rapider Progression

3.5.1.2 PrPc und $A \beta 1-42$

Zwischen PrPc und A $\beta 1-42$ konnte kein signifikanter Zusammenhang ermittelt werden.

\subsubsection{PrPc und Tau}

Zwischen PrPc und Tau zeigten sich über das Gesamtkollektiv ( $\mathrm{n}=37$, Kendall-tau-b 0,324, $\mathrm{p}=0,005$ ) (Abb. 33) sowie in den Untergruppen "Altersgruppe 66 bis 80 Jahre" ( $\mathrm{n}=16$, Kendall-tau-b 0,427, $\mathrm{p}=0,022)$, "Frauen der Altersgruppe 66 bis 80 Jahre" ( $\mathrm{n}=12$, Kendall-tau-b 0,443, $\mathrm{p}=0,046)$, "leichte Demenz (MMSE 21-30 Punkte)" ( $\mathrm{n}=21$, Kendall-tau-b 0,476, $\mathrm{p}=0,016$ ), "Männer im Stadium der leichten Demenz (MMSE 21-30 Punkte)" ( $\mathrm{n}=12$, Kendall-tau-b, 0,455, p=0,040), "langsame Progression" ( $\mathrm{n}=28$, Kendall-tau-b 0,276, p=0,040), "ApoE \&4-Allel-positiv" ( $\mathrm{n}=20$, Kendall-tau-b 0,343, $\mathrm{p}=0,035)$ sowie "Codon 129-m/v-heterozygot" ( $\mathrm{n}=14$, Kendall-tau-b 0,398, $\mathrm{p}=0,048)$ mindestens signifikante, im mittleren Bereich liegende Zusammenhänge.

Hohe bzw. sehr hohe Korrelationen waren für die Untergruppen "Männer der Altersgruppe 66 bis 80 Jahre" ( $\mathrm{n}=4$, Pearson 0,955, p=0,045), "Männer mit langsamer Progression" ( $\mathrm{n}=12$, Pearson 0,693, p=0,012, "Männern mit der Allelkombination ApoE-3/4" (n=5, Pearson 0,994, p=0,001) (Abb. 34), "ApoE ع4-Allel-positive Männer" ( $\mathrm{n}=7$, Pearson 0,914, $\mathrm{p}=0,004)$ sowie für die Codon 129-m/vheterozygoten Frauen ( $\mathrm{n}=9$, Pearson $0,732, \mathrm{p}=0,025)$ darstellbar (Abb. 35) 


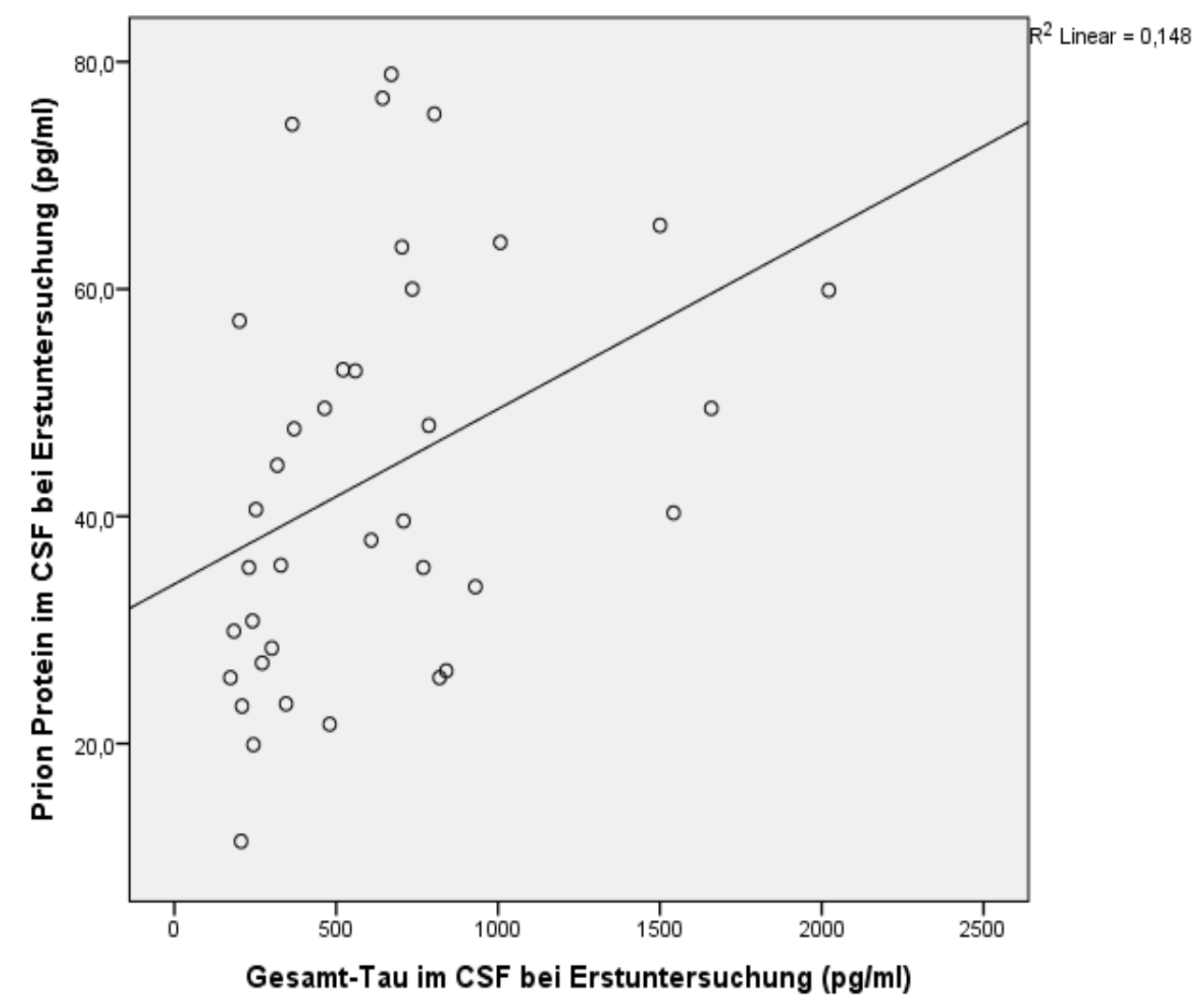

Abb. 33: Korrelation von PrPc und Tau

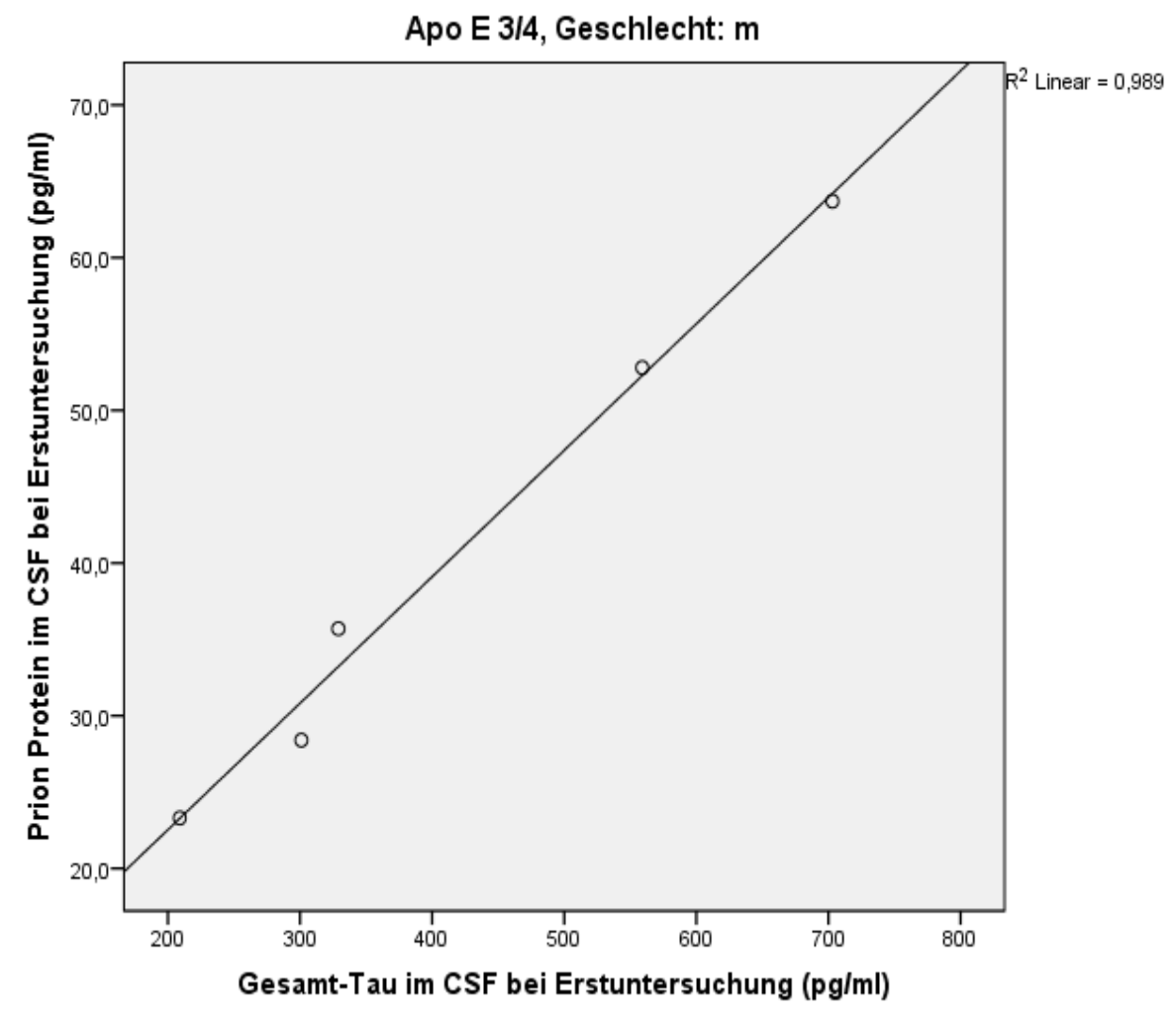

Abb. 34: Korrelation von PrPc und Tau bei Männern mit ApoE 3/4-Allel 


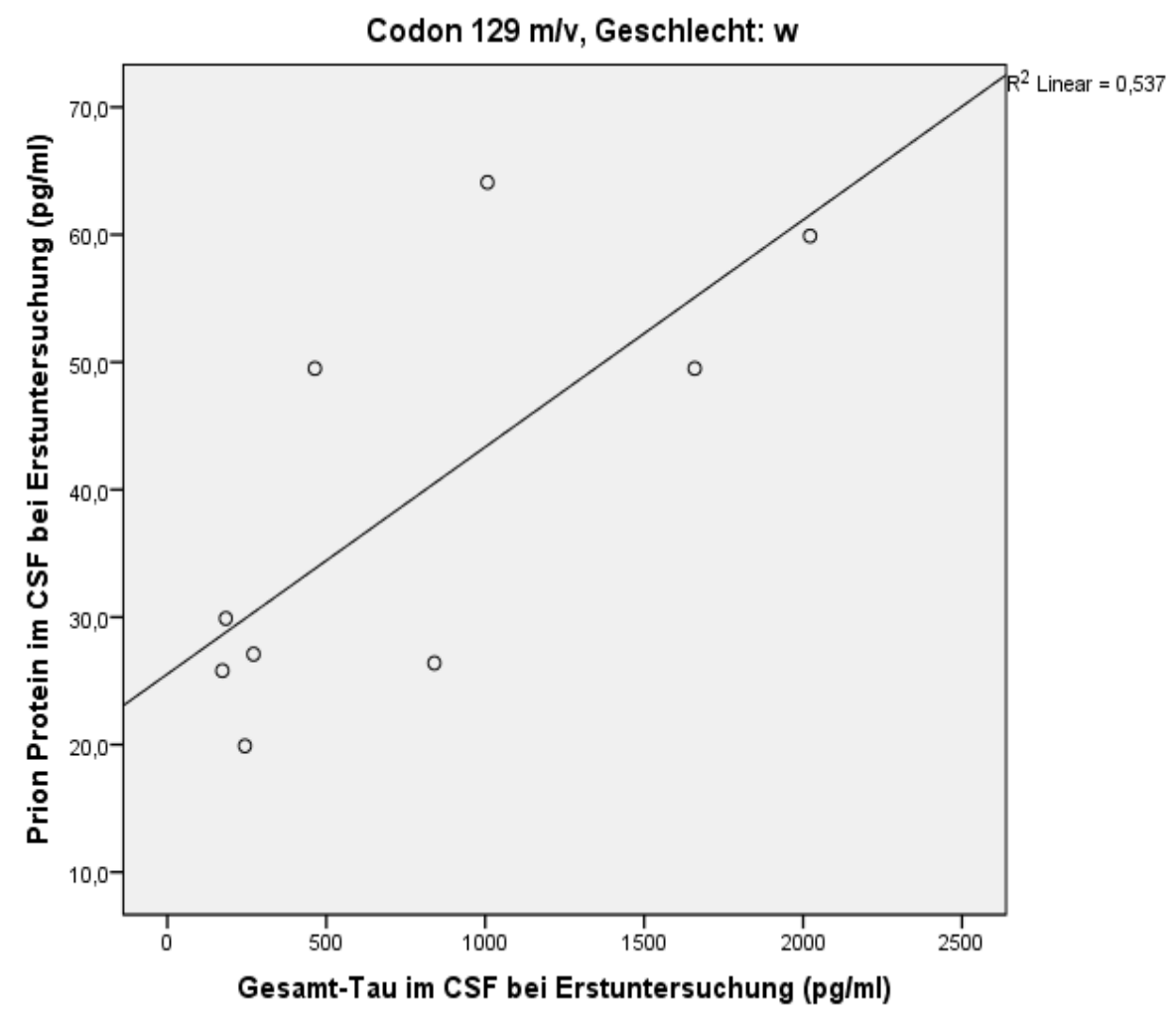

Abb. 35: Korrelation von PrPc und Tau bei Codon 129 m/v-heterozygoten Frauen

\subsubsection{PrPc und pTau}

Für die Untergruppen "66 bis 80 Jahre" ( $\mathrm{n}=16$, Kendall-tau-b 0,447, p=0,017), "leichte Demenz (MMSE 21-30 Punkte)" ( $\mathrm{n}=22$, Pearson 0,467, p=0,029), "langsame Progression" ( $\mathrm{n}=29$, Kendalltau-b 0,327, p=0,012), "ApoE 3/4-Allelträger" ( $\mathrm{n}=14$, Kendall-tau-b 0,468, $\mathrm{p}=0,021)$ sowie "ApoE ع4-Allel-positiv" ( $\mathrm{n}=20$, Kendall-tau-b 0,476, $\mathrm{p}=0,003$ ) konnten mindestens signifikante, im mittleren Bereich liegende Zusammenhänge zwischen PrPc und pTau beobachtet werden.

Hohe Zusammenhänge zwischen PrPc und pTau waren bei den Frauen der Altersgruppe "66 bis 80 Jahre" ( $\mathrm{n}=12$, Kendall-tau-b 0,595 p=0,007) (Abb. 36) sowie bei den ApoE $\varepsilon 4$-Allel-positiven Frauen $(\mathrm{n}=13$, Kendall-tau-b 0,555, $\mathrm{p}=0,009)$ (Abb. 37) darstellbar. 


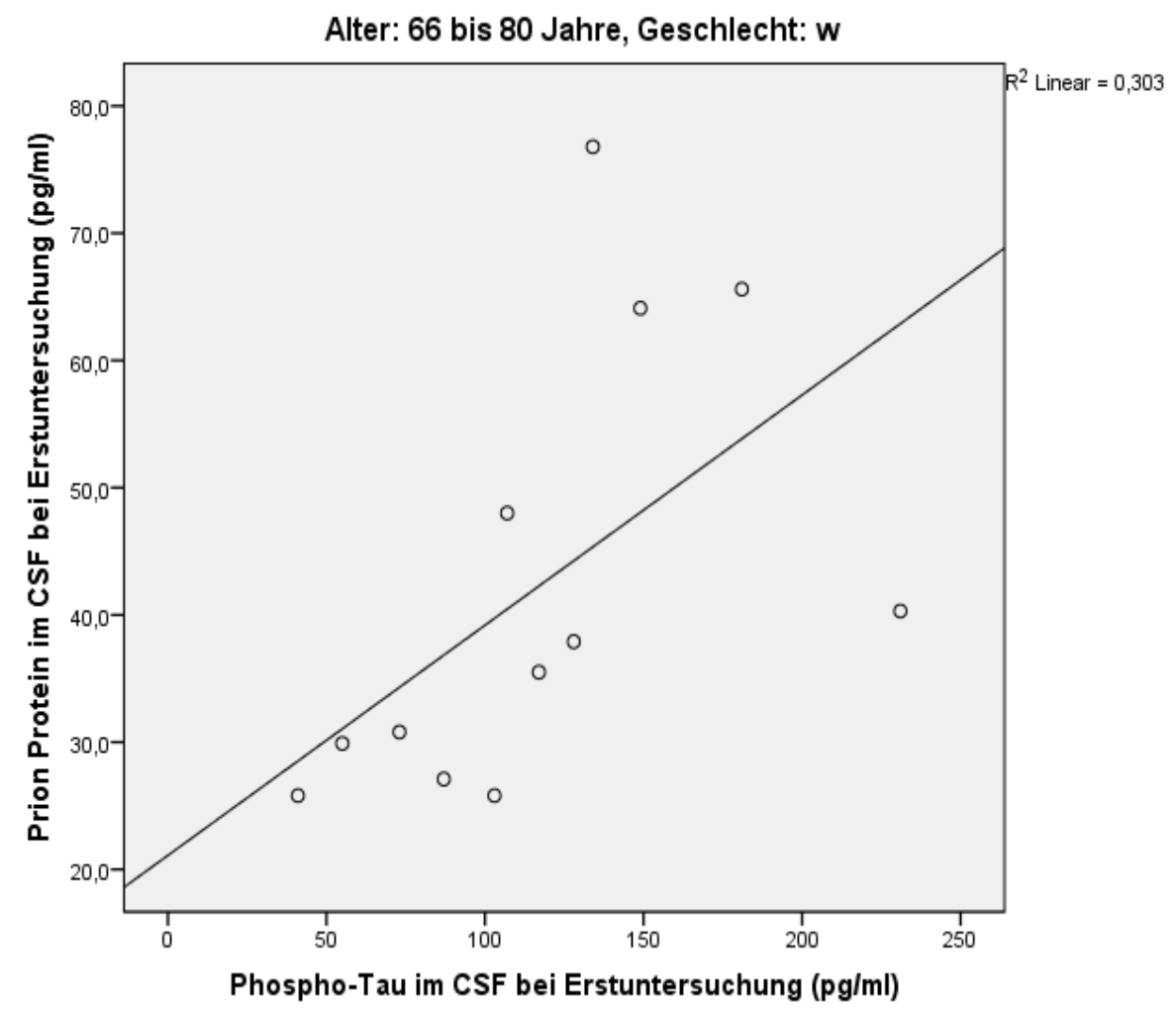

Abb. 36: Korrelation von PrPc und pTau bei Frauen der Altersgruppe "66 bis 80 Jahre"

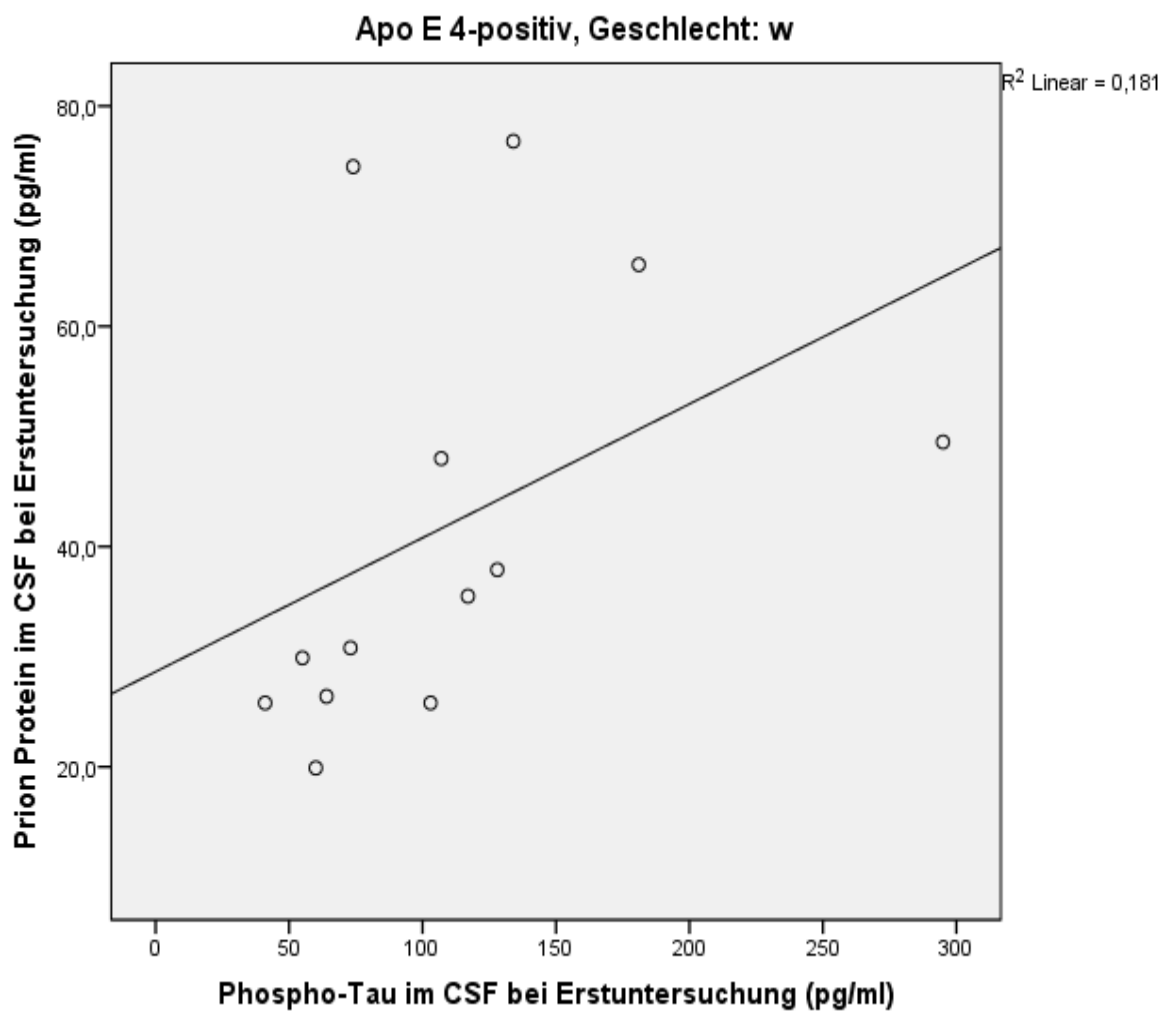

Abb. 37: Korrelation von PrPc und pTau bei ApoE \&4-positiven Frauen 3.5.1.5 PrPc und Progression 
Bei den Frauen mit der Allelkombination ApoE-3/3 konnte eine signifikante, hohe negative Korrelation zwischen Prion-Protein und der Progression dargestellt werden ( $\mathrm{n}=7$, Kendall-tau-b $0,651, \mathrm{p}=0,046)($ Abb. 38).

In der Gruppe der über 65-jährigen Frauen (LOAD) mit dieser Allelkombination scheint PrionProtein nahezu perekt mit der Progression negativ zu korrelieren, allerdings reicht die Gruppengröße $(\mathrm{n}=5)$ nicht aus, um ein Signifikanzniveau zu berechnen (Abb. 39).

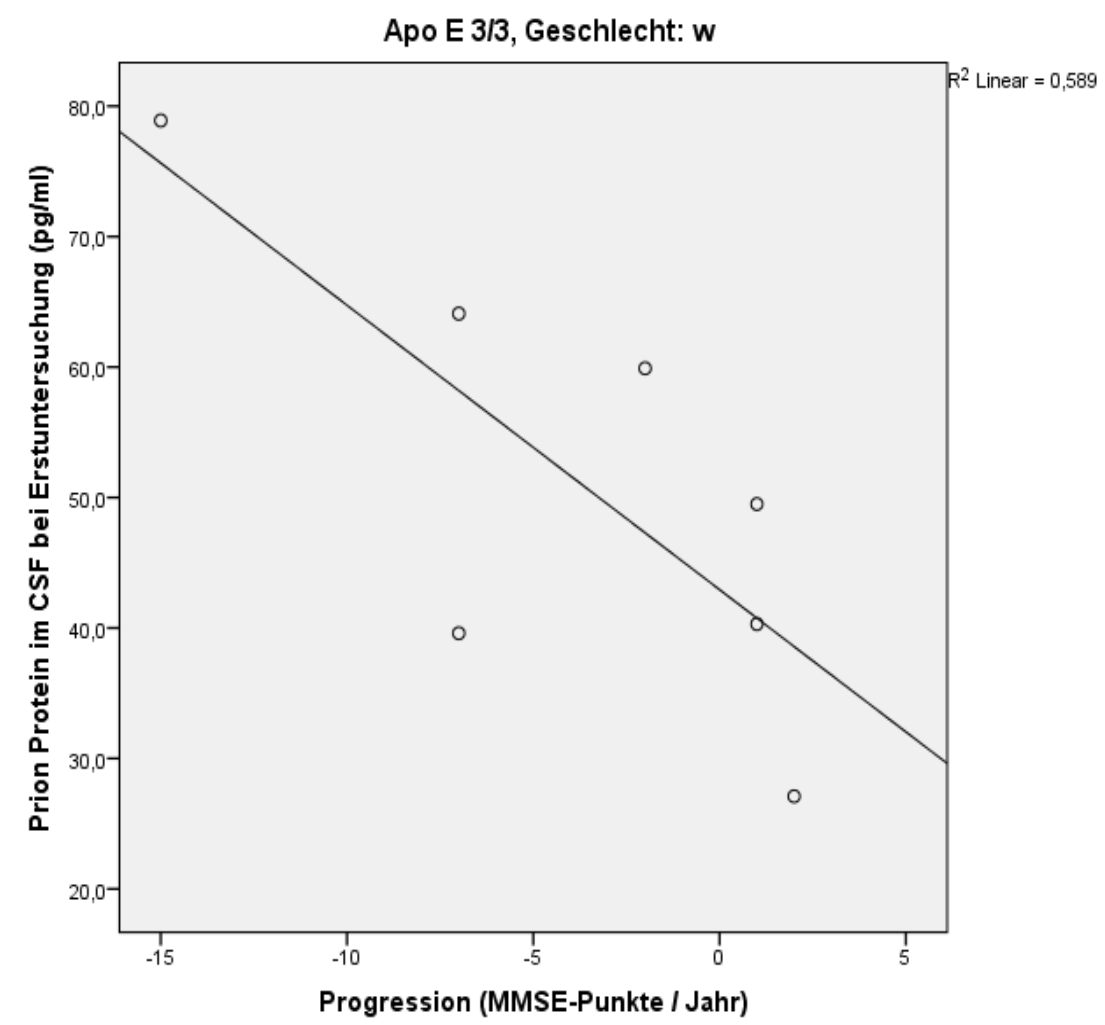

Abb. 38: Korrelation von PrPc und Progression bei Frauen mit ApoE 3/3-Allel 


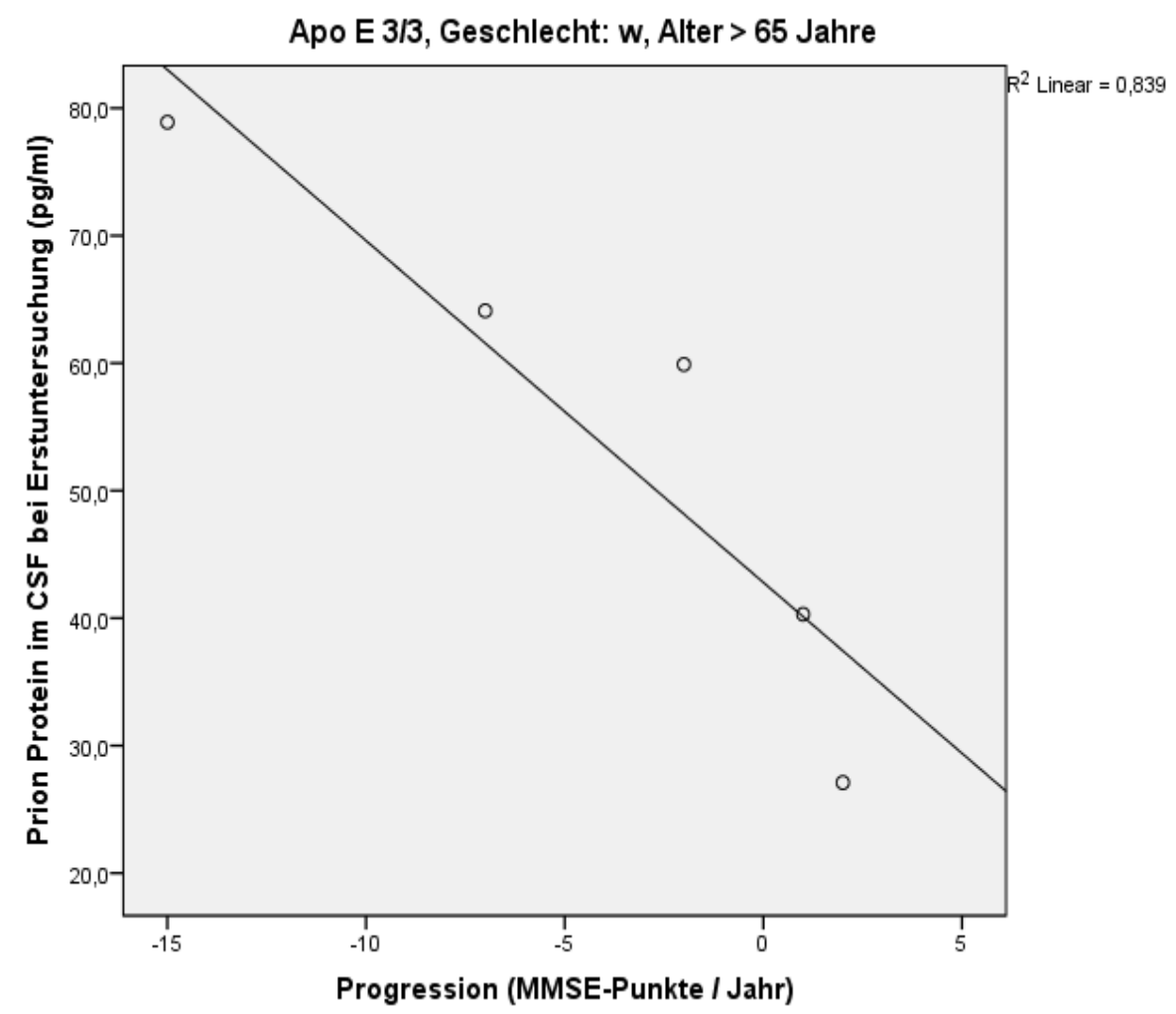

Abb. 39: Korrelation von PrPc und Progression bei Frauen mit ApoE-3/3-Allel im Alter von über 65 Jahren

\subsubsection{Weitere AD-Marker}

\subsubsection{1 $\mathrm{A} \beta 1-40$ und $\mathrm{A} \beta 1-42$}

Bezogen auf das Gesamtkollektiv zeigte sich eine hoch signifikante, hohe Korrelation zwischen A $\beta 1-40$ und A $\beta 1-42$ im CSF der Probanden (Pearson 0,557, $\mathrm{p}=0,001, \mathrm{n}=35$ ).

Weitere hohe bis sehr hohe Zusammenhänge zwischen $A \beta 1-40$ und $A \beta 1-42$ waren in den Untergruppen "Männer" ( $\mathrm{n}=15$, Pearson 0,666, p=0,007), "Altersgruppe $\leq 65$ Jahre" (n=16, Pearson 0,761, p=0,001), "Männer der Altersgruppe $\leq 65$ Jahre" $(\mathrm{n}=11$, Pearson 0,827, $\mathrm{p}=0,002)$, "Altersgruppe 66 bis 80 Jahre" (n=16, Pearson 0,541, p=0,046), "leichte Demenz" (n=20, Pearson 0,667, p=0,001), "Männer im Stadium der leichten Demenz" ( $\mathrm{n}=12$, Pearson 0,667, p=0,018), "rapide Verläufe" ( $\mathrm{n}=9$, Pearson 0,811, p=0,008), "ApoE 3/3-Allel" ( $\mathrm{n}=14$, Pearson 0,763, p=0,002), "Männer mit ApoE 3/3-Allel" (n=4, Pearson 0,917, p=0,004), "ApoE \&4-Allel-negativ" (n=15, Pearson 0,770, p=0,001), "Codon 129-m/m-homozygot" ( $\mathrm{n}=14$, Pearson 0,783, p=0,001), "Codon 129-m/m-homozygote Frauen" ( $\mathrm{n}=10$, Pearson 0,825, p=0,003), "Codon 129-m/m-homozygote Männer" ( $\mathrm{n}=4$, Pearson 0,983, p=0,017) sowie "Codon 129-v/v-homozygote Männer" ( $\mathrm{n}=4$, Pearson $0,965 \mathrm{p}=0,035)$ darstellbar.

Bei den Frauen $(n=20$, Pearson 0,469, p=0,039) sowie in der Gruppe mit langsamen Verläufen $(\mathrm{n}=26$, Pearson $0,452, \mathrm{p}=0,020)$ war der signifikante Zusammenhang zwischen $\mathrm{A} \beta 1-40$ und $\mathrm{A} \beta 1-42$ 
im mittleren Bereich liegend.

\subsubsection{A $\beta 1-40$ und Tau}

Zwischen A $\beta 1-40$ und Tau zeigten sich im Gesamtkollektiv ( $\mathrm{n}=34$, Kendall-tau-b 0,255, p=0,034) sowie in den Untergruppen "leichte Demenz" ( $n=19$, Kendall-tau-b 0,404, p=0,016), "langsame Verläufe" (n=26, Kendall-tau-b 0,287, p=0,045) und "Codon 129 -m/v-heterozygot" (n=13, Kendalltau-b 0,487, $\mathrm{p}=0,020)$ mindestens

signifikante, im mittleren Bereich liegenden Zusammenhänge.

Bei den Männern im Stadium der leichten Demenz ( $n=11$, Kendall-tau-b 0,564, p=0,016) sowie bei den Männern mit langsamen Verläufen $(n=10$, Pearson 0,783, $p=0,007)$ zeigten sich zwischen $A \beta 1$ 40 und Tau hohe bzw. sehr hohe Korrelationen.

\subsubsection{A $\beta 1-40$ und pTau}

Die Korrelation zwischen A $\beta 1-40$ und pTau lag im Gesamtkollektiv ( $n=35$, Pearson 0,366, p=0,030) sowie in den Untergruppen " leichte Demenz" ( $\mathrm{n}=22$, Pearson 0,498, p=0,025), "langsame Verläufe" ( $\mathrm{n}=26$, Kendall-tau-b 0,404, $\mathrm{p}=0,004)$ mindestens signifikant im mittleren Bereich. Hohe Zusammenhänge zwischen A $\beta 1-40$ und pTau konnten bei den Untergruppen "Männer im Stadium der leichten Demenz" ( $\mathrm{n}=12$, Pearson 0,636, p=0,026), "ApoE 3/4-Allel" ( $\mathrm{n}=12$, Kendall-tau-b 0,545, $\mathrm{p}=0,014)$, "Frauen mit der Allelkombination ApoE 3/4" (n=8, Kendall-tau-b 0,643, p=0,026), "Codon 129-m/v-heterozygot" ( $\mathrm{n}=14$, Kendall-tau-b 0,582, p=0,004) sowie "Codon 129 -m/vheterozygote Frauen" ( $n=9$, Kendall-tau-b 0,556, p=0,037) festgestellt werden.

\subsubsection{A $\beta 1-42$ und Tau}

In der Gruppe der Männer mit rapiden Verläufen zeigte sich eine signifikante, sehr hohe negative Korrelation zwischen A $\beta 1-42$ und Tau (Pearson -0,979, $\mathrm{p}=0,021, \mathrm{n}=4$ ).

3.5.2.5 A $\beta 1-42$ und pTau

Zwischen A $\beta 1-42$ und pTau konnten keine signifikanten Zusammenhänge festgestellt werden.

\subsubsection{A $\beta 1-42$ und Progression}

Bei den $A p o E$ \&4-Allel-positiven Frauen zeigte sich eine signifikante, im mittleren Bereich liegende negative Korrelation zwischen A $\beta 1-42$ und der Progression (Kendall-tau-b -0,456, p=0,039, n=13) (Abb. 40).

Bei den $A p o E$ \&4-Allel-positiven Männern zeigte sich hingegen eine signifikante, hohe positive Korrelation zwischen A $\beta 1-42$ und der Progression (Kendall-tau-b 0,651, p=0,046, n=7) (Abb. 41). 


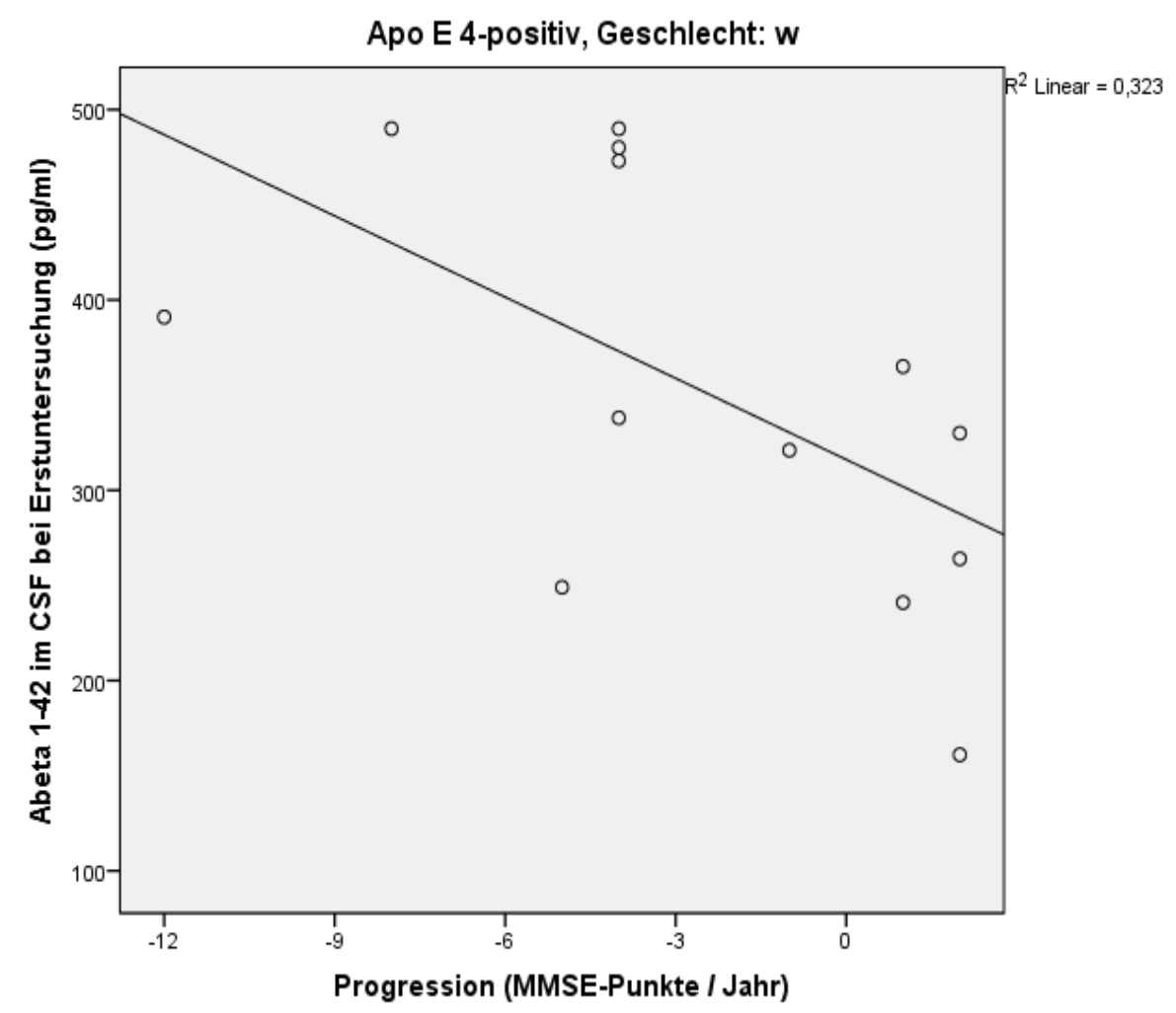

Abb. 40: Korrelation von A $\beta 1-42$ und Progression bei ApoE \&4-positiven Frauen

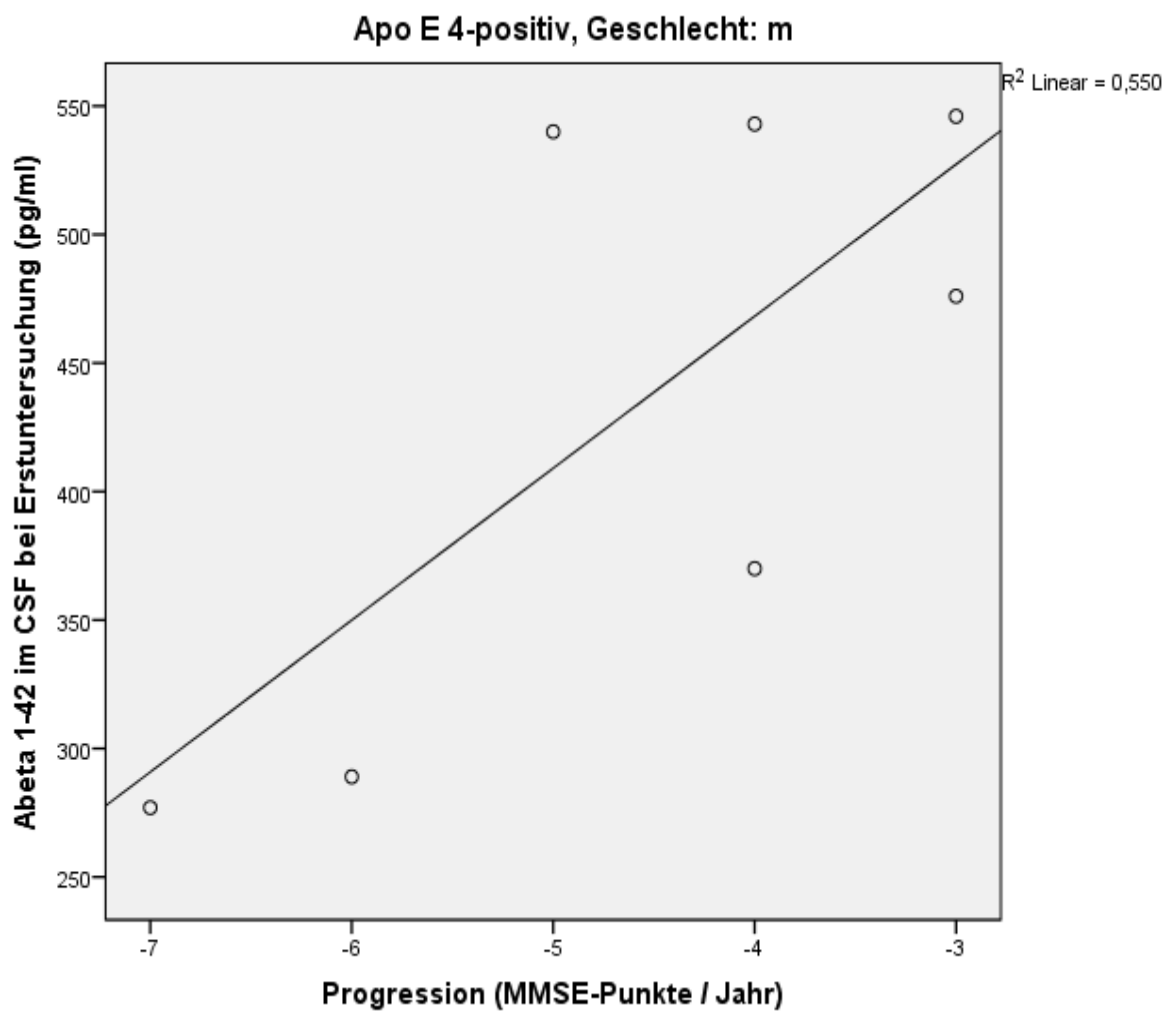

Abb. 41: Korrelation von A $\beta 1-42$ und Progression bei $A p o E$ \&4-positiven Männern 
Mindestens signifikante, im mittleren Bereich liegende Korrelationen von Tau und pTau ergaben sich im Gesamtkollektiv ( $\mathrm{n}=37$, Kendall-tau-b 0,552, $\mathrm{p}<0,001$ ) sowie bei den Untergruppen "Männer" ( $\mathrm{n}=16$, Kendall-tau-b 0,477, p=0,010), "leichte Demenz" ( $\mathrm{n}=21$, Kendall-tau-b 0,510, p=0,001), "Männer im Stadium der leichten Demenz" ( $n=12$, Kendall-tau-b 0,443, p=0,046), "langsame Verläufe" ( $\mathrm{n}=28$, Kendall-tau-b 0,488, p<0,001), "ApoE 3/3-Allel" ( $\mathrm{n}=14$, Kendall-tau-b 0,597, $\mathrm{p}=0,003$ ) sowie "Codon 129-m/m-homozygot" ( $\mathrm{n}=16$, Kendall-tau-b 0,417, $\mathrm{p}=0,005$ ).

Hohe bzw. sehr hohe Korrelationen zwischen Tau und pTau wurden in den Untergruppen "Frauen" $(\mathrm{n}=21$, Kendall-tau-b 0,600, $\mathrm{p}<0,001)$, "Altersgruppe 66 bis 80 Jahre" ( $\mathrm{n}=16$, Pearson 0,942, $\mathrm{p}<0,001)$, "Frauen der Altersgruppe 66 bis 80 Jahre" ( $n=12$, Pearson 0,937, $\mathrm{p}<0,001)$, "Männer der Altersgruppe 66 bis 80 Jahre" ( $n=4$, Pearson 0,981, p=0,019), "Frauen im Stadium der leichten Demenz" ( $\mathrm{n}=9$, Kendall-tau-b 0,611, $\mathrm{p}=0,022)$, "mittelschwere Demenz" ( $\mathrm{n}=14$, Pearson 0,877, $\mathrm{p}<0,001$ ), "Frauen im Stadium der mittelschweren Demenz" ( $\mathrm{n}=10$, Pearson 0,851, $\mathrm{p}=0,002$ ), "Frauen mit langsamen Verläufen" ( $\mathrm{n}=16$, Kendall-tau-b 0,550, $\mathrm{p}=0,003$ ), "Männer mit langsamen Verläufen" ( $\mathrm{n}=12$, Pearson 0,692, p=0,038), "rapide Verläufe" ( $\mathrm{n}=9$, Kendall-tau-b 0,704, p=0,009), "Frauen mit rapiden Verläufen" ( $\mathrm{n}=5$, Pearson 0,937, p=0,019), "Frauen mit ApoE 3/3-Allel" (n=7, Pearson 0,880, p=0,009), "Allelkombination ApoE 3/4" ( $\mathrm{n}=14$, Kendall-tau-b 0,538, p=0,007), "Frauen mit der Allelkombination ApoE 3/4" (n=9, Kendall-tau-b 0,611, p=0,022), "ApoE 4/4homozygot" ( $\mathrm{n}=5$, Pearson 0,954, $\mathrm{p}=0,012)$, "ApoE $\varepsilon 4$-Allel-negativ" ( $\mathrm{n}=15$, Kendall-tau-b 0,536, $\mathrm{p}=0,006)$, "ApoE $\varepsilon 4$-Allel-negative Frauen" (n=7, Pearson 0,880, p=0,009), "ApoE $\varepsilon 4$-Allel-positiv" ( $\mathrm{n}=20$, Kendall-tau-b 0,565, p=0,001), "ApoE $\varepsilon 4$-Allel-positive Frauen" ( $\mathrm{n}=13$, Kendall-tau-b 0,564, $\mathrm{p}=0,007$ ), "Codon 129-m/m-homozygote Frauen" ( $\mathrm{n}=11$, Pearson 0,863, p=0,001), "Codon 129-m/vheterozygot" ( $\mathrm{n}=14$, Kendall-tau-b 0,626, $\mathrm{p}=0,002)$ sowie

"Codon 129-m/v-heterozygote Frauen" ( $\mathrm{n}=9$, Kendall-tau-b 0,833, p=0,002) dargestellt.

\section{Diskussion}

Im Rahmen einer longitudinalen Studie wurde ein Kollektiv aus Probanden, welche die revidierten McKhann Kriterien zur Diagnose des M. Alzheimer, modifiziert nach DuBois, als Einschlusskriterien erfüllten, im Verlauf beobachtet. Die in der Diagnostik von $\mathrm{AD}$ etablierten CSF-Biomarker $\mathrm{A} \beta 1-40, \mathrm{~A} \beta 1-42$, Tau und pTau wurden bei Studieneinschluss bestimmt. Ebenfalls bei Studieneinschluss wurde PrPc im CSF der Probanden bestimmt. Alle oben genannten CSF-Parameter wurden auf ihre Eignung hin als Verlaufsprädiktor der Alzheimerkrankheit untersucht.

\subsection{Prion-Protein}

\subsubsection{Mittelwerte PrPc}


Die in dieser Studie ermittelten Werte für die Konzentration von PrPc im CSF sind durchschnittlich geringer, verglichen mit den Werten aus anderen Studien (Meyne et al. 2009, Roberts et al. 2010). Unterschiedliche Methoden in der Messung und die strenge Auswahl der Probanden nach den DuBois-Kriterien sind mögliche Ursachen hierfür, so dass ein Vergleich zu den vorhergehenden Studien nur bedingt zulässig ist.

PrPc wird vornehmlich in Neuronen gebildet (Linden et al. 2008), deren Anzahl bei AD infolge Neurodegeneration stark vermindert ist (Weiner et al. 2010).

Es wird daher angenommen, dass niedrige Konzentrationen von $\operatorname{PrPc}$ im CSF für einen fortgeschrittenen neuronalen Verlust sprechen (Boesenberg-Grosse et al. 2006).

Alternativ kommen auch spezifische Prozesse infrage, die bei AD eine Rolle spielen können: Interaktionen zwischen PrPc und den wesentlichen Merkmalen der Alzheimer-pathologie wie A $\beta$, dessen Vorläuferproteine, Tau, pTau sowie deren Stoffwechselwege wurden zuvor beschrieben (Parkin et al. 2007, Hooper und Turner 2008, Kellett und Hooper 2009, Vincent et al. 2009, Laurén et al. 2009, Griffiths et al. 2011, Lewis et al. 2012, Larson et al. 2012, Schmitz et al. 2013).

Allerdings wurden bislang keine Referenzwerte für die Konzentration von PrPc im CSF Gesunder oder Erkrankter festgelegt.

\subsubsection{Geschlecht}

In der vorliegenden Arbeit ist die Konzentrationen von PrPc im CSF der Probanden zwischen den Geschlechtern ausgeglichen, was sich mit den Beobachtungen von Meyne deckt (Meyne et al. 2009).

\subsubsection{Alter und Krankheitsstadium}

Ebenfalls übereinstimmend mit Meyne (Meyne et al. 2009) konnte kein signifikanter Unterschied in der CSF-Konzentration von PrPc zwischen den Altersgruppen der Probanden innerhalb des ADKollektivs erkannt werden.

Die von Meyne beschriebene Verminderung der PrPc-Konzentration mit zunehmender Erkrankungsschwere wurde nicht gesehen.

Meyne untersuchte das zelluläre Prion-Protein im Liquor cerebrospinalis von Patienten mit verschiedenen neurologischen Erkrankungen, darunter neurodegenerative Erkrankungen wie die Creutzfeldt-Jakob-Krankheit, Alzheimer-Demenz, Demenz mit Lewy-Körperchen, Normaldruckhydrozephalus und Morbus Parkinson sowie nicht-neurodegenerative Erkrankungen wie generalisierte epileptische Anfälle, Encephalomyelitis disseminata, Meningitis, Enzephalitis und ischämische Hirninsulte.

Die Auswahl von Meynes Alzheimer-Studienkollektiv erfolgte nach den Richtlinien der NINCDSADRDA, so dass auch aufgrund der abweichenden Diagnosekriterien ein Vergleich der Daten nur bedingt möglich ist.

Das physiologisch gealterte Gehirn ist gekennzeichnet durch eine Atrophie, auch bedingt durch 
einen Verlust an Neuronen (Sack et al. 2011), was zu einer geringeren Syntheseleistung von PrPc führen dürfte. Auch im (hippocampalen) Gewebe Gesunder ist der Gehalt an PrPc mit steigendem Alter reduziert (Whitehouse et al. 2010).

Obgleich die Wege der Freisetzung von PrPc in den CSF bislang nicht geklärt sind (Fevrier et al. 2004, Robertson et al. 2006, Linden et al. 2008), wird angenommen, dass die Konzentration von PrPc im CSF den Gehalt an PrPc im Gewebe verhältnismäßig widerspiegelt (Boesenberg-Grosse et al. 2006, Meyne et al. 2009).

$\mathrm{Da}$ bei $\mathrm{AD}$ voraussichtlich die Anzahl PrPc-synthetisierender Neurone mit zunehmender Erkrankungsschwere bzw. -dauer abnimmt, wäre auch hier eine Verminderung der PrPcKonzentration im Hirngewebe bzw. im CSF mit steigendem Alter und zunehmender Erkrankungsschwere denkbar.

Andererseits ist das von pathologischen Prozessen gekennzeichnete Gehirn der AD-Patienten nicht mit dem physiologisch gealterten Gehirn Gesunder vergleichbar (Akiyama 1994, Town 2010, Herrup 2010, Barber 2011).

\subsubsection{Verläufe}

Dass die Verläufe der Alzheimerkrankheit zwischen den Individuen weder homogen noch linear sind (Wilkosz et al. 2010), spricht zudem für die Schwierigkeit, einen sich kurzfristig verändernden Parameter wie PrPc als Biomarker für Stadien dieser Krankheit verwenden zu können.

\subsubsection{ApoE}

Innerhalb der Gruppe der Probanden mit der Allelkombination ApoE 3/3 konnte zwischen den Geschlechtern ein signifikanter Unterschied in den Mittelwerten der Konzentration von PrionProtein im CSF dargestellt werden (w: 51,34 $\pm 17,54 \mathrm{pg} / \mathrm{ml}, \mathrm{n}=7 ; \mathrm{m}: 31,58 \pm 14,68 \mathrm{pg} / \mathrm{ml}, \mathrm{n}=8$; $\mathrm{p}=0,033)($ Abb. 24).

Zwischen den Geschlechtern bestand in dieser Gruppe weder im durchschnittlichen Alter (w: 71,26 \pm 19,94 Jahre, $n=7 ; m: 62,32 \pm 10,37$ Jahre, $n=8 ; p=0,129$ ) noch im mittleren MMSE-Wert (w: 18,29 $\pm 5,88$ Punkte, $\mathrm{n}=7 ; \mathrm{m}: 22,0 \pm 3,38$ Punkte, $\mathrm{n}=8 ; \mathrm{p}=0,219$ ) ein signifikanter Unterschied.

Inwiefern die Faktoren Geschlecht und ApoE-Allel die Synthese von PrPc beeinflussen können, bleibt zu untersuchen und wird nochmals unter 4.1.1.6 diskutiert (s.u.).

\subsubsection{PRNP}

Auf die Stärke der Expression von PrPc scheint der PRNP-Genotyp keinen Einfluss zu haben (Saijo et al. 2011), was auch in dieser Studie gezeigt werden konnte.

Berr stellte dar, dass das Valin-Allel am Codon 129 des PRNP-Gens einen ähnlichen verschlechternden Effekt auf die kognitive Leistung älterer Menschen hat wie das \&4-Allel von ApoE (Berr et al. 1998).

Allerdings ist umstritten, ob und welchen Einfluss der PRNP-Genotyp bei AD hat. 
Einige Autoren sehen einen Einfluss des PRNP-Genotyps auf die Krankheit, doch sind auch hier die Ergebnisse widersprüchlich:

Dermaut sieht in Homozygotie auf dem Codon 129 - insbesondere für Valin - ein erhöhtes Risiko für EOAD (Dermaut et al. 2003), wohingegen Riemenschneider in Methionin-Homozygotie ein erhöhtes Risiko für EOAD sieht (Riemenschneider et al. 2004). In polnischen Populationen beschrieben Golanska und Gacia Codon 129-Homozygotie als einen AD-Risikofaktor (Golanska et al. 2004) bzw. Methionin-Homozygotie als Risikofaktor für LOAD (Gacia et al. 2006).

Del Bo sieht in Methionin-Homozygotie bzw. im M-Allel einen Risikofaktor für AD bei Europäern (Del Bo et al. 2006) und Giannattasio beschrieb das Fehlen eines ApoE \&4-Allels bei PRNP Codon 129-Heterozygotie als negativen Prädiktor für die Überlebenszeit von (weiblichen) AD-Patienten (Giannattasio et al. 2008).

In rapiden Verläufen konnten Zeitpunkt und Ausmaß klinischer Symptome in Abhängigkeit vom PRNP-Genotyp beobachtet werden (Schmidt et al. 2010).

Andere Autoren bestreiten einen Einfluss des PRNP-Genotyps auf AD oder konnten einen klaren Zusammenhang nicht darstellen (Combarros et al. 2000, Casadei et al. 2001, Ohkubo et al. 2003, Ahn et al. 2006, Poleggi et al. 2008, Schmidt et al. 2013).

$\mathrm{Ob}$ und welchen Einfluss der PRNP-Genotyp auf die Enstehung und Verläufe der Alzheimerkrankheit hat, bleibt also weiterhin näher zu untersuchen.

\subsubsection{Inflammation}

Zahlreiche Veröffentlichungen unterstützen die Vermutung, dass eine latente Infektion bzw. eine chronische Inflammation als eine mögliche Ursache für die Entstehung von AD gewertet werden müssen (Akiyama 1994, Calabrese et al. 2004, Town 2010, Herrup 2010).

Der aus einer - möglicherweise subklinischen - Inflammation resultierende oxidative Stress vermag die vermehrte Expression von PrPc als neuroprotektive Antwort zu induzierten (Voigtländer et al. 2001, De Almeida et al. 2005). Die Aktivität der Synthetisierung von PrPc könnte - der aktuellen inflammatorischen Last angepasst - individuell variieren und einen erwarteten "stadiengerechten" Unterschied in der PrPc-Konzentration verwischen. Kim beschrieb, dass die anti-inflammatorischen Eigenschaften von ApoE4 geringer sind als die von ApoE3 (Kim et al. 2009) und McClelland stellte dar, dass geschlechtsspezifische Unterschiede in der Immunantwort auf Infektionen bestehen (McClelland und Smith 2011). Hieraus folgend könnten sowohl Geschlecht als auch ApoE-Genotyp einen Einfluss auf die Synthese von PrPc haben. Da eine zerebrale Infektion jedoch als Ausschlusskriterium für diese Studie gewertet und hier keine Daten hinsichtlich einer subklinischen Inflammation erhoben wurden, können derlei Zusammenhänge aus den Ergebnissen dieser Arbeit nicht abgeleitet werden.

\subsubsection{Korrelationen}


Eine positive Korrelation von $\operatorname{PrPc}$ und $\mathrm{A} \beta$ konnte bereits zuvor beschrieben werden: Meyne zeigte eine sehr signifikante, hohe Korrelation sowohl zwischen PrPc als auch A $\beta 1-42(\beta=0.63 ; p=0.005)$ (Meyne et al. 2009).

Ein signifikanter Zusammenhang zwischen $\mathrm{PrPc}$ und $\mathrm{A} \beta 1-42$ konnte in dieser Studie nicht nachvollzogen werden, jedoch zwischen PrPc und A $1-40$ (Korrelation nach Pearson 0,489, $\mathrm{p}=0,003, \mathrm{n}=35$ ) (siehe Abb. 31).

Die Stärke des Zusammenhangs zwischen PrPc und A $\beta 1-40$ stieg in der Gruppe mit weiblichen Probanden (Korrelation nach Pearson $0,568, \mathrm{p}=0,009, \mathrm{n}=20$ ), insbesondere unter den Codon 129m/v-heterozygoten Frauen (Korrelation nach Pearson 0,758, p=0,018, n=9).

Einen sehr hohen, sehr signifikanten Zusammenhang zwischen PrPc und A $\beta 1-40$ zeigten auch die Probanden mit rapider Progression (Pearson 0,717, $\mathrm{p}=0,030, \mathrm{n}=9$ )(siehe Abb. 32).

Ausgehend davon, dass die CSF-Konzentration von A $\beta 1-40$ bei Manifestation der Alzheimerkrankheit unverändert oder erhöht (Humpel 2011) und die von $\operatorname{PrPc}$ infolge von Neurodegeneration vermindert sind (Boesenberg-Grosse et al. 2006, Meyne et al. 2009, Carnini et al. 2010), erscheint die Annahme einer positiven Korrelation dieser beiden Parameter zunächst als unwahrscheinlich. Allerdings sind die Verbindungen von $\operatorname{PrPc}$ und $\mathrm{A} \beta$ noch größtenteils unklar: Einige Autoren sehen in PrPc einen Rezeptoren, der einen toxischen Effekt von A $\beta$-Oligomeren im Sinne von einer Unterdrückung der Langzeitpotenzierung vermittelt (Laurén et al. 2009, Barry et al. 2011), allerdings wird von anderer Seite bestritten, dass PrPc ein essentieller Bestandteil der Neurotoxizität von $A \beta$ ist (Forloni und Balducci 2011). Untersucht wurde weiterhin eine zu der A $\beta$ Prozessierung möglicherweise erstaunliche Ähnlichkeit in der Prozessierung von PrPc durch Proteasen der ADAM-Familie, deren Produkte ebenfalls in Abhängigkeit vom Wirkort der Protease entweder neuroprotektive (C1-PrP) oder neurotoxische (C2-PrP) Eigenschaften aufweisen (GuillotSestier et al. 2009, Guillot-Sestier et al. 2012, Westaway und Jhamandas 2012).

Auch konnte bislang nicht geklärt werden, ob der beschriebene neurotoxische Effekt eines A $\beta$ Oligomer-PrPc-Komplexes in der Vermittlung der A $\beta$-Toxizität durch PrPc oder durch Hemmung der neuroprotektiven Eigenschaften von $\operatorname{PrPc}$ durch $\mathrm{A} \beta$ begründet ist (Biasini et al. 2012). Eine weitere Interaktion von PrPc und A $\beta$ ist die verminderte Produktion von sAPP $\beta$ und infolgedessen von AICD und $A \beta$ durch Hemmung von BACE1 durch PrPc (Parkin et al. 2007, Hooper und Turner 2008, Kellett und Hooper 2009, Griffiths et al. 2011). Eine Verminderung der Produktion von A $\beta 1-40$ durch PrPc konnte zuletzt kürzlich im Zell- und Tierversuch nachgewiesen werden (Schmitz et al. 2013). Da die Versuche anhand von NichtAlzheimer-Modellen durchgeführt wurden, können deren Ergebnisse nicht unweigerlich auf die Ergebnisse der hier vorliegenden Arbeit übertragen werden, allerdings geben sie Hinweise auf bedeutende Interaktionen zwischen PrPc und der Prozessierung von A $\beta$, die sich auch auf Alzheimermodelle übertragen lassen könnten.

Ob die Synthese von PrPc durch AICD reguliert wird, ist umstritten (Vincent et al. 2009, Lewis et 
al. 2012). Allerdings vermag $A \beta$ über verschiedene PRR (=Pattern Recognition Receptor)-vermittelte Signalwege wie TLR (=toll-like receptor), RAGE (receptor for advanced glycation endproducts) und NRL (NOD-like receptor) eine Immunantwort auszulösen (Glass et al. 2010). Eine hierdurch induzierte Synthese von PrPc könnte einen positiven Zusammenhang zwischen der CSF-Konzentration von A $\beta 1-40$ und PrPc erklären, wobei hier zahlreiche möglicherweise noch unbekannte Faktoren unberücksichtigt geblieben sind.

\subsubsection{PrPc und $A \beta 1-42$}

Für die Parameter $\mathrm{PrPc}$ und $\mathrm{A} \beta 1-42$ konnten in dieser Arbeit keine linearen Zusammenhänge ermittelt werden. Meyne beschrieb zuvor einen sehr signifikanten, hohen positiven Zusammenhang zwischen PrPc und $\mathrm{A} \beta 1-42(\beta=0.63 ; \mathrm{p}=0.005)$ (Meyne et al. 2009). Ob diese abweichenden Ergebnisse durch die unterschiedliche Kollektivauswahl (siehe 4.1.2.2) erklärt werden können, bleibt unklar; Gruppengröße und Altersstruktur der Probanden scheinen zumindest vergleichbar zu sein.

Zum einen wäre eine positive Korrelation dieser Parameter aufgrund der mit zunehmendem neuronalen Untergang verminderten Konzentration von PrPc im CSF sowie mit der durch Plaquebildung verminderten Konzentration von A $\beta 1-42$ im CSF von AD-Probanden durchaus vorstellbar.

Andererseits scheint PrPc ein recht schnell regulierbarer Faktor zu sein, der den akuellen, z.B. inflammatorischen Anforderungen zügig angepasst werden kann und bei erhöhter A $\beta$-Plaque-Last widergespiegelt durch eine verminderte Konzentration von A $\beta 1-42$ im CSF - entsprechend vermehrt exprimiert wird.

Dieses würde einen negativen Zusammenhang der CSF-Konzentration dieser beiden Parameter vermuten lassen.

Die vermehrte Expression von PrPc könnte durch die infolge von Neurodegeneration verminderte Anzahl an PrPc-synthetisierenden Neuronen quantitativ relativiert werden, was im Ergebnis keinen linearen Zusammenhang darstellen liesse.

\subsubsection{PrPc und Tau}

Eine positive Korrelation zwischen PrPc und Tau im CSF von AD-Patienten wurde zuvor von Meyne beschrieben ( $\beta=0.65 ; p=0.003)$ (Meyne et al. 2009).

Auch in der vorliegenden Arbeit konnte eine Korrelation zwischen PrPc und Tau dargestellt werden (Kendall-tau-b 0,324, $\mathrm{p}=0,005, \mathrm{n}=37$ ) (siehe Abb. 33), wenngleich nur mit einer im mittleren Bereich liegenden Stärke.

Bei den Männern der Altersgruppe "66 bis 80 Jahre" war die signifikante Korrelation dieser Parameter sehr hoch (Pearson 0,955, $\mathrm{p}=0,045, \mathrm{n}=4$ ).

Bei den Männern mit der Allelkombination ApoE-3/4 zeigte sich sogar eine hoch-signifikante, sehr hohe Korrelation zwischen Prion-Protein und Tau (Korrelation nach Pearson 0,994, p=0,001, n=5) 
(siehe Abb. 34).

Insgesamt war die sehr signifikante Korrelation zwischen PrPc und Tau bei den ApoE \&4-positiven Männern sehr hoch (Pearson 0,914, p=0,004, n=7), ebenso wie bei den Codon 129-m/vheterozygoten Frauen (Pearson 0,732, p=0,025, n=9) (Abb. 35).

Die Verbindung von Prion-Protein und Tau wurde noch nicht vollends entschlüsselt.

Allerdings kann eine pro-inflammatorische Immunantwort über MAPK-Kinase-Signalwege die Phosphorylierung von Tau und somit die Bildung von Tangles verstärken, ebenso wie Tau über denselben Signalweg eine Immunantwort zu induzieren vermag (Zilka et al. 2012). Eine hierdurch gesteigerte Synthese von PrPc wäre denkbar.

Möglicherweise sind auch die in dieser Gruppe spezifischen Eigenschaften von Geschlecht und ApoE- bzw. PRNP-Genotyp für die Darstellbarkeit eines Zusammenhanges zwischen der Konzentration von Tau und PrPc im CSF verantwortlich.

\subsubsection{PrPc und pTau}

Auch zwischen PrPc und pTau konnten in der vorliegenden Arbeit positive lineare Zusammenhänge beobachtet werden, insbesondere bei den "66 bis 80"-jährigen Frauen (Kendall-tau-b 0,595 p=0,007, $\mathrm{n}=12$ ) (siehe Abb. 36), sowie den ApoE 4-Allel-positiven Frauen (Kendall-tau-b 0,555, p=0,009, $\mathrm{n}=13$ ) (siehe Abb. 37).

Im Zell- und Tierversuch konnte ein hemmender Einfluß von PrPc auf die Bildung von pTau dargestellt werden (Larson et al. 2012, Schmitz et al. 2013). Diese Ergebnisse können als Hinweise auf eine protektive Funktion von PrPc gegenüber Tau-bedingten, pathologischen Prozessen auch bei AD interpretiert werden.

Diese Aussagen scheinen zunächst widersprüchlich zu sein, da ein hemmender Einfluß von PrPc auf die Bildung von pTau einen negativen Zusammenhang dieser Parameter vermuten lässt.

Analog zu den für PrPc und Tau (siehe 4.1.2.3) beschriebenen Mechanismen scheint eine zur pathologischen pTau-Bildung konsekutiv verstärkte Exprimierung von $\operatorname{PrPc}$ eine mögliche plausible Erklärung für die Zusammenhänge von PrPc und pTau zu sein.

\subsubsection{PrPc und Progression}

Bei den Frauen mit der Allelkombination ApoE-3/3 konnte eine signifikante, hohe negative Korrelation zwischen Prion-Protein und der Progression dargestellt werden (Kendall-tau-b -0,651, $\mathrm{p}=0,046, \mathrm{n}=7$ ) (siehe Abb. 38), d.h. je höher die CSF-Konzentration von PrPc zum Zeitpunkt der Erstuntersuchung war, desto stärker war die folgende kognitive Verschlechterung (= negative Progression).

In der Gruppe der über 65-jährigen Frauen mit dieser Allelkombination scheint Prion-Protein nahezu perfekt mit der Progression negativ zu korrelieren, allerdings reichte die Gruppengröße $(n=5)$ nicht aus, um ein Signifikanzniveau zu berechnen (siehe Abb. 39).

Da alle Probandinnen dieser Gruppe $\varepsilon 3$-homozygot waren, konnte nicht herausgearbeitet werden, ob 
das Fehlen des $\varepsilon 4$-Allels oder die bestimmten Eigenschaften des $\varepsilon 3$-Allels für dieses Ergebnis ursächlich sind - dieses sollte in folgenden Untersuchungen in einem größeren Kollektiv nachgeholt werden.

Möglicherweise wird für diese Gruppe aufgrund der spezifischen Einflüsse von Alter, Geschlecht und ApoE-Allelkombination ein Zusammenhang zwischen relativer Erhöhung der PrPcKonzentration und nachfolgender kognitiver Verschlechterung am deutlichsten darstellbar. Folglich könnte Prion-Protein dann in bestimmten Fällen als Prädiktor für eine kognitive Verschlechterung dienen.

4.2 Weitere AD-Marker

4.2.1 A $\beta 1-40$

\subsubsection{Mittelwerte}

Zwischen den Geschlechtern gab es keine signifikanten Unterschiede in den Konzentrationen von A 1-40 im CSF der Probanden.

Dieses steht im Einklang mit den Angaben aus der wissenschaftliche Literatur, die in der Demenzdiagnostik einheitliche Grenzwerte für beide Geschlechter bezüglich der CSFKonzentrationen von A $\beta$ festgelegt hat (Sjögren et al. 2001, Andreasen N 2001, Diener 2008, De Meyer et al. 2010, Vidoni et al. 2011, Toledo et al. 2012).

Unter den Männern konnte zwischen den Gruppen mit langsamen Verläufen und rapiden Verläufen ein signifikanter Unterschied in der mittleren Konzentration von A 1-40 (Mittelwert "Langsam" ( $\mathrm{n}=11): 6794,8 \pm$ 2427,6 pg/ml ; "Rapid" ( $\mathrm{n}=4): 4340,3 \pm 1124,4 \mathrm{pg} / \mathrm{ml} ; \mathrm{p}=0,021)$ festgestellt werden (siehe Tab. 3, Abb. 25).

Zwischen diesen Gruppen gab es keine signifikanten Unterschiede bezüglich Alter ("Langsam": 63,5 \pm 7,9 Jahre ; "Rapid": 60,6 \pm 8,4 Jahre, p=0,535) oder Mini-Mental-Status bei Erstuntersuchung ("Langsam": 23,4 \pm 3,8 Punkte ; "Rapid": 22,5 \pm 5,2 Punkte ; p=0,703).

Ausgehend davon, dass die CSF-Konzentration von A $\beta 1-40$ bei Manifestation der Alzheimerkrankheit unverändert oder erhöht ist (Humpel 2011), erscheint eine verminderte Konzentration von A $\beta 1-40$ im CSF von Probanden mit rapiden Verläufen zunächst überraschend. Es wird angenommen, dass die Ablagerung in Form von Plaques ein Übertreten von $\mathrm{A} \beta$ in den $\mathrm{CSF}$ erschwert und $\mathrm{A} \beta$ dort somit nur in geringeren Konzentrationen nachweisbar ist (Hampel et al. 2010, Holtzman 2011, Irwin et al. 2013). Hiervon betroffen ist überwiegend das aggregationsfreudigere $A \beta 1-42$, dass - obgleich nur ungefähr einen Zehntel der Menge von A $\beta 1-40$ betragend - mit ca. 60\% einen Großteil des in den Plaques enthaltenen $\beta$-Amyloids ausmacht (Burdick et al. 1992, Prior et al. 1996).

Es bleibt zu klären, ob eine verminderte Konzentration von A $\beta 1-40$ im CSF hiernach für eine vermehrte Ablagerung als Plaque und somit stärker fortgeschrittener Neuropathologie 
spricht, die sich durch einen schnelleren Krankheitsverlauf ausdrückt.

Insgesamt scheint $A \beta 1-40$ im Gegensatz zu $A \beta 1-42$ inzwischen als CSF-Biomarker für die ADDiagnostik an Bedeutung verloren zu haben (Holtzman 2011).

$\mathrm{Ob}$ A $\beta 1-40$ in bestimmten Fällen als prognostischer Faktor bezüglich der Progressionsgeschwindigkeit dienen kann, ist aus diesem kleinen Kollektiv nicht abzuleiten und müsste anhand größerer Probandengruppen untersucht werden.

Darüberhinaus könnten auch weitere, vielleicht auch bislang unbekannte Faktoren, die unabhängig von dem messbaren $\mathrm{A} \beta 1-40$ an der Krankheitsentwicklung beteiligt sind, die Verlaufsgeschwindigkeit beeinflussen. Übereinstimmend mit aktuellen Ergebnissen anderer Studien konnte auch hier kein Einfluß des ApoE-Genotyps auf die CSF-Konzentration von A $\beta 1-40$ erkannt werden (Engelborghs et al. 2007)

\subsubsection{Korrelationen}

\subsubsection{1 $\mathrm{A} \beta 1-40$ und $\mathrm{A} \beta 1-42$}

Im Gesamtkollektiv sowie in den meisten Untergruppen zeigten sich überwiegend hohe bis sehr hohe positive Zusämmenhänge zwischen den CSF-Parametern A $\beta 1-40$ und A $\beta 1-42$ (siehe 3.5.2.1), was in Anbetracht des zugrundeliegenden Pathomechanismus schlüssig ist.

Im Hinblick auf die Beobachtungen in der Literatur, die für A $\beta 1-40$ unverändert hohe oder leicht erhöhte CSF-Konzentrationen sowie erniedrigte Werte für A $\beta 1-42$ angibt (Shaw et al. 2009, Humpel 2011), würde man jedoch zunächst keinen positiven Zusammenhang dieser beiden Parametern erwarten.

Andererseits wurden bereits zuvor lineare Zusammenhänge dieser Parameter mit vergleichbarer Stärke und Signifikanz von Gloeckner anhand eines AD-Kollektivs beschrieben (Gloeckner 2010).

Darüberhinaus dienen die etablierten Grenzwerte in der AD-Diagnostik zur Abgrenzung Kranker gegenüber den Gesunden und machen keine Aussage über das Verhalten der Parameter zueinander innerhalb einer AD-Probandengruppe.

\subsection{A $\beta 1-40$ und Tau}

Über das Gesamtkollektiv zeigte sich ein signifikanter Zusammenhang zwischen den CSF-Parametern A $\beta 1-40$ und Tau (Kendall-tau-b 0,255, $\mathrm{p}=0,034, \mathrm{n}=34$ ), mit der stärksten Korrelation unter den Männern mit langsamen Verläufen (Pearson 0,783, $\mathrm{p}=0,007, \mathrm{n}=10$ ) (siehe 3.5.2.2). Zwischen den Geschlechtern gab es hierbei keine signifikanten Unterschiede in der mittleren CSF-Konzentration dieser beiden Parameter, obgleich man die höhere Konzentration von Tau im CSF der Frauen gegenüber den Männern als Trend werten könnte (Median: w: 670,0 \pm 606,0 pg/ml, n=21 ; m: 337,0 \pm 
432,0 pg/ml, $\mathrm{n}=16$; $\mathrm{p}=0,059$ ) (siehe Tab. 1). Allerdings wiesen Männer mit langsamen Verläufen eine signifikant höhere CSF-Konzentration von A $\beta 1-40$ auf als die Männer mit rapiden Verläufen ("Langsam" ( $\mathrm{n}=11)$ : 6794,8 \pm 2427,6 pg/ml, "Rapid" ( $\mathrm{n}=4)$ : 4340,3 $\pm 1124,4$ pg/ml ; p=0,021); bezüglich der Konzentration von Tau waren auch diese Gruppen ausgeglichen (siehe Tab. 1, Tab. 3 u. Tab. 5 sowie Abb. 25).

Auch zwischen A $\beta 1-40$ und Tau im CSF konnten lineare Zusammenhänge in einem ADKollektiv zuvor beschrieben werden (Gloeckner 2010).

Ausgehend von unverändert hohen bzw. erhöhten Konzentrationen für A $\beta 1-40$ im CSF sowie erhöhten Konzentrationen von Tau im CSF von Alzheimerkranken liegt eine positive Korrelation dieser Parameter auf der Hand.

Da A $\beta 1-40$ mit ca. 90\% den größten Anteil des gesamten gebildeten A $\beta$ ausmacht, die Amyloidplaques jedoch überwiegend (zu ca. 60\%) aus A $\beta 1-42$ bestehen (Burdick et al. 1992, Prior et al. 1996) ist es schwierig, anhand der CSF-Konzentration Rückschlüsse auf die tatsächliche Amyloidplaque-Last des Gehirns zu ziehen.

4.2.1.2.3 A $\beta 1-40$ und pTau

Auch zwischen A $\beta 1-40$ und pTau zeigten sich signifikante Korrelationen im mittleren bis hohen Bereich (siehe 3.5.2.3), die analog zu den Zusammenhängen von A $\beta 1-40$ und Tau bewertet werden müssen.

Darüberhinaus ist beschrieben worden, dass $\mathrm{A} \beta$ über die Aktivierung der Glykogensynthase-Kinase 3 (GSK3) zur Tau-Hyperphosphorylierung beitragen kann (Jin et al. 2011, Mines et al. 2011), womit bereits experimentell direkte Zusammenhänge dieser Parameter dargestellt wurden.

\subsubsection{A $\beta 1-42$}

\subsubsection{Mittelwerte}

Bei den Männern zeigten sich signifikante Unterschiede der mittleren Konzentration an A $\beta 1-42$ im CSF zwischen den Altersgruppen " $\leq 65$ Jahre" und "66 bis 80 Jahre"

(Mittelwert " $\leq 65$ Jahre" ( $\mathrm{n}=12): 427,0 \pm 140,9$ pg/ml ; "66 bis 80 Jahre": $(\mathrm{n}=4): 310,3 \pm 51,9$ pg/ml ; p=0,030) (siehe Tab. 4 u. Abb. 26), wobei es keine signifikanten Mittelwertunterschiede bezüglich des MMSE-Wertes gab (" $\leq 65$ Jahre" (n=12): 23,1 \pm 4,6 Punkte ; "66 bis 80 Jahre": (n=4): 23,3 $\pm 2,8$ Punkte ; $\mathrm{p}=0,770)$.

Unter den Männern konnte weiterhin zwischen den Gruppen mit langsamen Verläufen und rapiden Verläufen ein signifikanter Unterschied in der mittleren Konzentration von A $\beta 1-42$ (Mittelwert 
"Langsam" (n=13): 443,3 \pm 112,2 pg/ml ; "Rapid" (n=4): 264,8 \pm 85,7 pg/ml ; p=0,011) dargestellt werden (siehe Tab. 4 und Abb. 27). Zwischen diesen Gruppen gab es keine signifikanten Unterschiede bezüglich Alter ("Langsam": 63,5 \pm 7,9 Jahre ; "Rapid": 60,6 \pm 8,4 Jahre, p=0,535) oder MMSE bei Erstuntersuchung ("Langsam": 23,4 \pm 3,8 Punkte ; "Rapid": 22,5 \pm 5,2 Punkte ; $\mathrm{p}=0,703)$.

Es wurde beschrieben, dass erniedrigte Werte für A $\beta 1-42$ im CSF eine negative Korrelation mit der Alzheimerpathologie aufweisen (Strozyk et al. 2003, Tapiola et al. 2009, Bendlin et al. 2012). Weiterhin wird angenommen, dass Veränderungen der CSF-Konzentrationen von $A \beta$ den kognitiven Veränderungen vorausgehen, so dass erniedrigte Werte für $A \beta 1-42$ im CSF als prognostischer Faktor für den Krankheitsverlauf gelten können - zumindest für die Konversion von MCI zur AD bzw. in frühen Krankheitsstadien (Snider et al. 2009, Henneman et al. 2009, Kester et al. 2009, Davatzikos et al. 2011, Ewers et al. 2012).

Insofern sind die signifikant geringeren Konzentrationen von A $\beta 1-42$ im CSF der älteren Probanden bzw. von denjenigen mit schnelleren Verläufen durchaus schlüssig.

Warum diese Unterschiede nur anhand der männlichen und nicht der weiblichen Probanden beobachtet werden konnten, bleibt zunächst unklar.

Zwischen den Geschlechtern konnten signifikante Mittlelwertunterschiede bezüglich der CSFKonzentration von A $1-42$ sowohl in der Gruppe mit langsamen Verläufen

(w: 349,7 $\pm 97,6 \mathrm{pg} / \mathrm{ml}, \mathrm{n}=16 ; \mathrm{m}: 443,3 \pm 112,2 \mathrm{pg} / \mathrm{ml}, \mathrm{n}=13 ; \mathrm{p}=0,023$ ) als auch in der Gruppe der ApoE 3/4-Allelträger (w: $371,8 \pm 90,0 \mathrm{pg} / \mathrm{ml}, \mathrm{n}=9 ; \mathrm{m}: 495,0 \pm 75,7 \mathrm{pg} / \mathrm{ml}, \mathrm{n}=5 ; \mathrm{p}=0,029$ ) beobachtet werden (siehe Abb. 28 und Abb. 29).

Allerdings wiesen die Frauen in der Gruppe mit langsamer Progression einen signifikant geringeren MMSE-Wert gegenüber dem der Männer auf (w: 16,8 \pm 6,1 Punkte, n=16; m: 23,4 \pm 3,8 Punkte, $\mathrm{n}=13 ; \mathrm{p}=0,001$ ). Bezüglich des Alters waren diese Gruppen ausgeglichen (w: 69,7 $\pm 9,2$ Jahre, $\mathrm{n}=16$ ; m: 63,5 \pm 7,9 Jahre, $\mathrm{n}=13 ; \mathrm{p}=0,065)$.

In der Gruppe der ApoE 3/4-Allelträger konnten keine signifikanten Unterschiede bezüglich Alter (w: 67, $2 \pm 8,9$ Jahre, $n=9$; m: 61,5 \pm 4,8 Jahre, $n=5 ; p=0,211$ ) bzw. MMSE-Wert (w: 16,0 $\pm 12,0$ Punkte, $n=9$; m: 25,0 \pm 7,0 Punkte, $n=5 ; p=0,180$ ) beobachtet werden. Der signifikant geringere MMSE-Wert der Frauen gegenüber den Männern könnte auf eine stärker fortgeschrittene Erkrankung hinweisen, wodurch sich die signifikant geringere CSF-Konzentration von A $\beta 1-42$ begründen ließe.

Obgleich auf der einen Seite kein signifikanter Einfluss von Alter oder Geschlecht auf die Konzentration von A $\beta$ im CSF beschrieben wird (Glodzik-Sobanska et al. 2009), wird auf der anderen Seite ein bedeutender Einfluss von Sexualhormonen auf den A $\beta$-Stoffwechsel postuliert (Barron und Pike 2012).

Bezogen auf das Gesamtkollektiv konnte eine gleichmäßige Verteilung von A $\beta 1-42$ im CSF der Probanden auch in dieser Studie nachvollzogen werden (siehe Tab. 1, Abb. 9).

Inwiefern in früheren Studien eine Unterteilung der Probanden nach Progressionstypen bzw. ApoEGenetik erfolgte, kann oftmals nicht nachvollzogen werden.

Möglicherweise werden bei diesen kleinen Probandengruppen verstärkt individuelle Aspekte der 
multifaktoriellen Alzheimerkrankheit dargestellt.

Dennoch sollte auch hier ein geschlechtsspezifisches Merkmal dieses Parameters in Erwägung gezogen und in größeren Gruppen untersucht werden.

\subsubsection{Korrelationen}

Die Zusammenhänge zwischen $\mathrm{A} \beta 1-42$ und $\mathrm{A} \beta 1-40$ wurden unter 4.2.1.2.1 diskutiert.

\subsection{A $\beta 1-42$ und Tau}

In der Gruppe der Männer mit rapiden Verläufen konnte eine signifikante, sehr hohe negative Korrelation zwischen den CSF-Parametern A $\beta 1-42$ und Tau beschrieben werden (Pearson -0,979, $\mathrm{p}=0,021, \mathrm{n}=4)$.

Ein negativer Zusammenhang zwischen A $\beta 1-42$ und Tau ist schlüssig, da sowohl vermindertes $A \beta 1$ 42 im CSF als auch erhöhtes Tau im CSF Rückschlüsse auf die Alzheimerpathologie bzw. neuronale Schädigung bieten können.

Warum sich dieses auschließlich in der Gruppe der Männer mit rapiden Verläufen darstellen ließ, bleibt unklar. Ob dieses Ergebnis aufgrund der geringen Gruppengröße $(n=4)$ verallgemeinert werden kann, ist zumindest fraglich.

\subsection{A $\beta 1-42$ und pTau}

Zwischen A $\beta 1-42$ und pTau ließen sich keine signifikanten Zusammenhänge darstellen.

Dieses Ergebnis überrascht zunächst, da sowohl vermindertes A $\beta 1-42$ als auch erhöhtes pTau im CSF als Indikatoren für die Alzheimerpathologie gelten.

Andererseits wurde beschrieben, dass die Tau-Hyperphosphorylierung über eine Aktivierung der Glycogen Synthase Kinase-3 (GSK3) durch lösliches A $\beta$ erfolgt (Jin et al. 2011, Mines et al. 2011) - in Bezug auf A $\beta 1-42$ ist der lösliche Anteil allerdings durch hohe Aggregationsneigung und Plaquebildung deutlich vermindert, was sich auch in den geringeren CSF-Konzentrationen widerspiegelt. Daher ist es schwierig, eine direkte Beziehung dieser beiden CSF-Parameter zueinander abzuleiten.

\subsection{A $\beta 1-42$ und Progression}

Bei den ApoE \&4-Allel-positiven Frauen zeigte sich eine signifikante, im mittleren Bereich liegende negative Korrelation zwischen A $\beta 1-42$ und der Progression (Kendall-tau-b -0,456, p=0,039, n=13) (siehe Abb. 40), wohingegen sich den ApoE \&4-Allel-positiven Männern eine signifikante, hohe positive Korrelation zwischen A $\beta 1-42$ und der Progression ergab (Kendall-tau-b 0,651, p=0,046, 
$\mathrm{n}=7$ ) (siehe Abb. 41).

Zwischen diesen Gruppen gab es keine signifikanten Unterschiede bezüglich der Konzentration von Aß1-42 im CSF (w: 353,3 $\pm 107,9 \mathrm{pg} / \mathrm{ml}, \mathrm{n}=13 ; \mathrm{m}: 434,4 \pm 120,6 \mathrm{pg} / \mathrm{ml}, \mathrm{n}=7 ; \mathrm{p}=0,141$ ) beziehungsweise des Alters der Probanden (w: 69,6 \pm 8,5 Jahre, $n=13$; m: 62,8 \pm 5,5 Jahre, $n=7$; $\mathrm{p}=0,074)$.

Allerdings wiesen die Frauen einen signifikant geringeren MMSE-Wert gegenüber den Männern auf (w: 16,0 $\pm 11,0$ Punkte, $n=13 ; m: 25,0 \pm 6,0$ Punkte, $n=7 ; p=0,046$ ).

Obgleich diese Gruppen aufgrund der signifikant geringeren MMSE-Werte bei den Frauen als Hinweis auf einen stärkeren Fortschritt der Krankheit nicht direkt miteinander verglichen werden können, stellt sich Frage, warum die ApoE \&4-Allelpositiven Männer einen positiven Zusammenhang zwischen der Konzentration von A $\beta 1-42$ im CSF und der Progression aufweisen. Möglicherweise zeigt sich auch insbesondere an diesem Beispiel, dass die Alzheimerkrankheit eine multifaktorielle Erkrankung ist (Blennow et al. 2006), die eine zunehmend individuelle Betrachtungsweise erforderlich macht. Ob sich die Ergebnisse anhand eines größeren Studienkollektivs reproduzieren lassen, bleibt zu überprüfen.

\subsubsection{Tau}

\subsubsection{Mittelwerte}

Auch die Konzentrationen von Tau im CSF waren zwischen den Geschlechtern ausgeglichen. Allerdings scheint die Konzentration von Tau im CSF der Frauen tendenziell höher zu sein als die der Männer, wobei das Signifikanzniveau von 5\% verfehlt wurde (Median: w: 670,0 \pm 606,0 pg/ml, $\mathrm{n}=21 ; \mathrm{m}: 337,0 \pm 432,0 \mathrm{pg} / \mathrm{ml}, \mathrm{n}=16 ; \mathrm{p}=0,059$ ) (siehe Tab. 1, Abb. 6).

Möglicherweise können das durchschnittlich höhere Alter der Frauen (w: 69,3 \pm 9,8 Jahre, n=21 ; m: 62,8 $\pm 7,8$ Jahre, $n=17$; $\mathrm{p}=0,031)$ und der niedrigere MMSE-Wert (w: 17,6 $\pm 6,4$ Punkte, $n=21 ; m: 23,2 \pm 4,0$ Punkte, $n=17 ; p=0,004$ ) als eine Ursache für diesen Trend gewertet werden.

Zwischen den Geschlechtern konnte in der Altersgruppe " $\leq 65$ Jahre" ein signifikanter Mittelwertunterschied bezüglich der CSF-Konzentration von Tau festgestellt werden (w: 838,4 $\pm 482,5 \mathrm{pg} / \mathrm{ml}, \mathrm{n}=5 ; \mathrm{m}: 449,0 \pm 236,0 \mathrm{pg} / \mathrm{ml}, \mathrm{n}=12 ; \mathrm{p}=0,038$ )(siehe Abb. 30).

In diesen Gruppen konnten keine signifikanten Untschiede bezüglich des Alters dargestellt werden (w: 56,4 $\pm 5,2$ Jahre, $n=5 ; m: 58,8 \pm 4,1$ Jahre, $n=12 ; p=0,754$ ),

allerdings wiesen die Frauen eine signifikant geringeren MMSE-Wert gegenüber den Männer auf (w: 13,0 $\pm 8,8$ Punkte, $\mathrm{n}=5 ; \mathrm{m}: 23,1 \pm 4,6$ Punkte, $\mathrm{n}=12 ; \mathrm{p}=0,037$ ).

Tau im CSF gilt als Indikator neuronaler Schädigung (Irwin et al. 2013), was die höheren CSFKonzentrationen bei den Frauen mit den geringen MMSE-Werten als Zeichen einer verstärkt fortgeschrittenen Erkrankung gut erklären könnte. 
Darüberhinaus wird Tau in Verbindung mit pTau und $A \beta$ von manchen Autoren als verlaufsprognostischer Faktor bei prä-dementiellen oder frühen Krankeitsstadien gewertet (Snider et al. 2009, Henneman et al. 2009, Kester et al. 2009, Davatzikos et al. 2011, Ewers et al. 2012). Dieses konnte in der vorliegenden Arbeit nicht dargestellt werden. Ansonsten stehen diese Ergebnisse im Einklang mit den Angaben in der Literatur, die für Tau im CSF von einheitlichen Grenzwerten zwischen den Geschlechtern ausgehen (Sjögren et al. 2001, Andreasen N 2001, Diener 2008, De Meyer et al. 2010, Vidoni et al. 2011, Toledo et al. 2012), jedoch mit höheren CSF-Konzentrationen bei steigendem Lebensalter (Sjögren et al. 2001, Vemuri et al. 2010).

\subsubsection{Korrelationen Tau und pTau}

Die Zusammenhänge zwischen Tau und $A \beta 1-40$ sowie $A \beta 1-42$ wurden unter 4.2.1.2.2 und 4.2.2.2.1 beschrieben (siehe dort).

Über das gesamte Kollektiv zeigten sich signifikante, im mittleren Bereich liegende Korrelationen der Parameter Tau und pTau. In den meisten Untergruppen waren die Zusammenhänge sogar hoch bis sehr hoch, insbesondere mit fortschreitendem Alter oder Demenzstadium der Probanden.

Da pTau die hyperphosphorylierte Form von Tau darstellt, sind die beschriebenen Korrelationen schlüssig und entsprechen den Erwartungen.

\subsection{4 pTau}

\subsubsection{Mittelwerte}

Im Gesamtkollektiv sowie in den einzelnen Untergruppen konnte kein signifikanter Unterschied bezüglich der mittleren Konzentration an pTau im CSF der Probanden festgestellt werden (siehe Tab. 6).

Dieses entspricht grundsätzlich den Angaben in der Literatur, die im Verlauf der Alzheimerkrankheit weitgehend stabile CSF-Konzentrationen von Tau bzw. pTau angibt (Sunderland et al. 1999, Blennow et al. 2007, De Leon et al. 2007, Vemuri et al. 2010, Rosen et al. 2013).

\subsubsection{Korrelationen}

Die Zusammenhänge zwischen pTau und $A \beta 1-40$, $A \beta 1-42$ sowie Tau wurden unter 4.2.1.2.2, 4.2.2.2.1 und 4.2.3.2 diskutiert (siehe dort).

\subsection{Methodenkritik}

Die vorliegende Arbeit hat folgende Stärken und Schwächen:

Ein großer Vorteil ist die Prospektivität der Studie (siehe 2.1), was eine der Fragestellung (siehe 1.7) entsprechend zielgerichtete Datensammlung und -auswertung möglich machte. Durch die strenge 
Auswahl der Probanden nach den DuBois-Kriterien (siehe 1.3 und 2.1) konnte ein gut selektiertes Kollektiv an Probanden, die zum Zeitpunkt der Diagnosestellung an einer Alzheimerdemenz erkrankt waren, geschaffen werden. Als besondere Stärke dieser Arbeit ist somit die hieraus resultierende, hohe Datenqualität zu nennen. Aufgrund von Kollinearität im Datenmaterial, d.h. der Korrelation unabhängiger Variablen untereinander, wurde sich in der statistischen Auswertung letztlich für die Stratifizierung anstatt für die multivariate Analyse der Parameter entschieden. Ob es hierbei gelungen ist, alle Confounder zu kontrollieren oder - trotz sorgfältiger Auswahl der angewandten Tests (siehe 2.3) - in allen Analysen eine ausreichend hohe Teststärke zu erzielen, bleibt mitunter fraglich, womit das statistische Vorgehen sowohl als Stärke als auch als Schwäche dieser Arbeit zu werten sein kann. Ein dem Design als prospektive Studie sowie den strengen Auswahlkriterien geschuldeter Nachteil dieser Arbeit ist die geringe Größe des Probandenkollektivs, was die Ergebnisse insgesamt anfälliger z.B. für Ausreißer macht. Darüberhinaus fielen, wie im Rahmen prospektiver Studien üblich und ebenfalls als Nachteil des Designs zu werten, ein Teil der Probanden im Verlauf aus der weiteren Beobachtung und Auswertung heraus. Hierdurch entstanden nach mehrfacher Stratifizierung teilweise nur sehr kleine Untergruppen, die weiterführende und sinnvolle statistische Auswertungen nicht möglich machten, was als weitere Schwäche der Arbeit betrachtet werden kann.

5. Zusammenfassung

Morbus Alzheimer ist eine neurodegenerative Erkrankung, deren Ursachen trotz intensiver Forschung weitgehend unklar sind.

Die Verläufe dieser Krankheit sind sehr heterogen, und es wurden rapide Subtypen beschrieben, zu deren Prädiktoren die Datenlage bislang widersprüchlich ist.

Zahlreiche Risikofaktoren für die Erkrankung an einer Demenz vom Alzheimer-Typ wurden bisher beschrieben, darunter auch genetische Faktoren wie das ApoE-Allel $\varepsilon 4$.

Zelluläres Prion-Protein ist ein Zelloberflächeneiweiß insbesondere des Nervengewebes.

Interaktionen von Prion-Protein mit wesentlichen Merkmalen der Alzheimer-Pathologie wie A $\beta$ und dessen Vorläuferproteinen sowie Tau, pTau und deren Stoffwechselwege wurden jüngst beschrieben.

In dieser Studie wurde untersucht, ob zelluläres Prion-Protein im CSF von Probanden mit Alzheimerdemenz als Prädiktor für die Verlaufsgeschwindigkeit dieser Erkrankung geeignet sein kann. Hierzu wurden Probanden mit einer wahrscheinlichen Alzheimerdemenz über mindestens ein Jahr lang engmaschig beobachtet und in Bezug auf die Konzentration des zellulären Prion-Proteins im Liquor cerebrospinalis analysiert.

Es konnte gezeigt werden, dass zelluläres Prion-Protein bei Probanden mit einer bestimmten Kombination von Geschlecht und ApoE-Allel eine deutliche Korrelation mit der Progressionsgeschwindigkeit aufweist.

Bei den weiblichen Probanden mit der Allelkombination ApoE-3/3 konnte eine signifikante, hohe negative Korrelation zwischen Prion-Protein und der Progression dargestellt werden. Insbesondere 
in der Gruppe der über 65-jährigen Frauen (LOAD) mit dieser Allelkombination korreliert PrionProtein negativ mit der Progression.

Obgleich noch weitere Untersuchungen mit größeren Probandengruppen notwendig sind, könnte zelluläres Prion-Protein in bestimmten Fällen als ein möglicher Prädiktor für schnelle Verläufe der Alzheimerkrankheit dienen.

Darüberhinaus konnten zwischen zellulärem Prion-Protein im CSF und den etablierten CSFBiomarkern zahlreiche Zusammenhänge beschrieben werden, deren Interaktionen auf zellulärer Ebene geprüft werden müssen.

\section{Anhang}

6.1 Kriterien McKhann (McKhann et al. 1984)

I. The criteria for the clinical diagnosis of PROBABLE Alzheimer's disease include:

dementia established by clinical examination and documented by the Mini-Mental Test, 'Blessed Dementia Scale', or some similar examination,

and confirmed by neuropsychological tests:

deficits in two or more areas of cognition:

progressive worsening of memory and other cognitive functions;

no disturbance of consciousness;

onset between ages 40 and 90, most often after age 65 ;

and absence of systemic disorders or other brain diseases that in and of themselves could account for the progressive deficits in memory and cognition.

II. The diagnosis of PROBABLE Alzheimer's disease is supported by:

progressive deterioration of specific cognitive functions such as

language (aphasia), motor skills (apraxia), and perception (agnosia);

impaired activities of daily living and altered patterns of behavior;

family history of similar disorders, particularly if confirmed neuropathologically;

and laboratory results of:

normal lumbar puncture as evaluated by standard techniques,

normal pattern or nonspecific changes in EEG such asincreased slow-wave activity;

and evidence of cerebral atrophy on CT with progression documented by serial observation.

III. Other clinical features consistent with the diagnosis of PROBABLE Alzheimer's disease, after exclusion of causes of dementia other than Alzheimer's disease, include:

plateaus in the course of progression of the illness:

associated symptoms of depression, insomnia, incontinence, delusions, illusions, hallucinations, catastrophic verbal. emotional, or physical outbursts, sexual disorders, and weight loss;

other neurologic abnormalities in some patients, especially with more advanced disease and 
including motor signs such as increased muscle tone, myoclonus, or gait disorder;

seizures in advanced disease;

and CT normal for age.

IV. Features that make the diagnosis of PROBABLE Alzheimer's disease uncertain or unlikely include:

sudden, apoplectic onset;

focal neurologic findings such as hemiparesis, sensory loss, visual field deficits, and incoordination early in the course of the illness;

and seizures or gait disturbances at the onset or very early in the course of the illness.

\section{Clinical diagnosis of POSSIBLE Alzheimer's disease:}

may be made on the basis of the dementia syndrome, in the absence of other neurologic, psychiatric, or systemic disorders sufficient to cause dementia, and in the presence of variatims in the onset, in the presentation, or in the clinical course;

may be made in the presence of a second systemic or brain disorder sufficient to produce dementia, which is not considered to he the cause of the dementia;

and should be used in research studies when a single, gradually progressive severe cognitive deficit is identified in the absence of other identifiable cause.

VI. Criteria for diagnosis of DEFINITE Alzheimer's disease are:

the clinical criteria for probable Alzheimer's disease and histopathologic evidence obtained from a biopsy or autopsy.

VII. Classification of Alzheimer's disease for research purposes should specify features that may differentiate subtypes of the disorder, such as:

familial occurrence;

onset before age of 65 ;

presence of trisomy-21;

and coexistence of other relevant conditions such as Parkinson's disease.

6.2 Kriterien DuBois (Dubois et al. 2007)

Probable AD: A plus one or more supportive features B, C, D, or E

Core diagnostic criteria 
A. Presence of an early and significant episodic memory impairment that includes the following features:

1. Gradual and progressive change in memory function reported by patients or informants over more than 6 months

2. Objective evidence of significantly impaired episodic memory on testing: this generally consists of recall deficit that does not improve significantly or does not normalise with cueing or recognition testing and after effective encoding of information has been previously controlled

3. The episodic memory impairment can be isolated or associated with other cognitive changes at the onset of $\mathrm{AD}$ or as $\mathrm{AD}$ advances

\section{Supportive features}

B. Presence of medial temporal lobe atrophy

- Volume loss of hippocampi, entorhinal cortex, amygdala evidenced on MRI with qualitative ratings using visual scoring (referenced to well characterised population with age norms) or quantitative volumetry of regions of interest (referenced to well characterised population with age norms)

C. Abnormal cerebrospinal fluid biomarker

- Low amyloid $\beta 1-42$ concentrations, increased total tau concentrations, or increased phospho-tau concentrations, or combinations of the three

- Other well validated markers to be discovered in the future

D. Specific pattern on functional neuroimaging with PET

- Reduced glucose metabolism in bilateral temporal parietal regions

- Other well validated ligands, including those that foreseeably will emerge such as Pittsburg compound B or FDDNP

E. Proven AD autosomal dominant mutation within the immediate family

Exclusion criteria

\section{History}

- Sudden onset

- Early occurrence of the following symptoms: gait disturbances, seizures, behavioural changes

Clinical features

- Focal neurological features including hemiparesis, sensory loss, visual field deficits

- Early extrapyramidal signs

Other medical disorders severe enough to account for memory and related symptoms 
- Non-AD dementia

- Major depression

- Cerebrovascular disease

- Toxic and metabolic abnormalities, all of which may require specific

investigations

- MRI FLAIR or T2 signal abnormalities in the medial temporal lobe that are

consistent with infectious or vascular insults

Criteria for definite $\mathrm{AD}$

$\mathrm{AD}$ is considered definite if the following are present:

- Both clinical and histopathological (brain biopsy or autopsy) evidence of the disease, as required by the NIA-Reagan criteria for the post-mortem diagnosis of $\mathrm{AD}$; criteria must both be present 139

- Both clinical and genetic evidence (mutation on chromosome 1, 14, or 21) of AD; criteria must both be present

\section{Literaturverzeichnis}

Aebi C: Validierung der neuropsychologischen Testbatterie CERAD-NP : eine MultiCenter Studie. 2002, http://edoc.unibas.ch/diss/DissB_6279

Ahn K, Kim E, Kwon Y-A, Kim DK, Lee J-E, Jo SA (2006): No association of prion protein gene polymorphisms with Alzheimer's disease in Korean population. Exp Mol Med $\underline{38}, 727-731$

Akiyama H (1994): Inflammatory Response in Alzheimer's Disease. The Tohoku Journal of Experimental Medicine 174, 295-303

Akiyama H, Kondo H, Ikeda K, Kato M, McGeer PL (2001): Immunohistochemical localization of neprilysin in the human cerebral cortex: inverse association with vulnerability to amyloid beta-protein (Abeta) deposition. Brain Res 902, 277281

Allinson TMJ, Parkin ET, Turner AJ, Hooper NM (2003): ADAMs family members as amyloid precursor protein alpha-secretases. J Neurosci Res $\underline{74}, 342-352$

De Almeida CJG, Chiarini LB, Da Silva JP, E Silva PM, Martins MA, Linden R (2005): The cellular prion protein modulates phagocytosis and inflammatory response. $\mathrm{J}$ 
Leukoc Biol 77, $238-246$

Alonso AC, Zaidi T, Grundke-Iqbal I, Iqbal K (1994): Role of abnormally phosphorylated tau in the breakdown of microtubules in Alzheimer disease. Proc Natl Acad Sci USA 91, 5562-5566

Alonso AC, Grundke-Iqbal I, Iqbal K (1996): Alzheimer's disease hyperphosphorylated tau sequesters normal tau into tangles of filaments and disassembles microtubules. Nat Med $\underline{2}, 783-787$

Alzheimer A (1907): Über eine eigenartige Erkrankung der Hirnrinde. Allgemeine Zeitschrift für Psychiatrie und psychisch-gerichtliche Medizin 64, 146 -148

Amieva H, Phillips LH, Della Sala S, Henry JD (2004): Inhibitory functioning in Alzheimer's disease. Brain 127, 949-964

Andreasen N ML (2001): EValuation of csf-tau and csf-aß42 as diagnostic markers for alzheimer disease in clinical practice. Arch Neurol $\underline{58}, 373-379$

Arriagada PV, Growdon JH, Hedley-Whyte ET, Hyman BT (1992): Neurofibrillary tangles but not senile plaques parallel duration and severity of Alzheimer's disease. Neurology $\underline{42}, 631-639$

Bäckman L, Small BJ, Fratiglioni L (2001): Stability of the preclinical episodic memory deficit in Alzheimer's disease. Brain $\underline{124}$, 96-102

Balducci C, Beeg M, Stravalaci M, Bastone A, Sclip A, Biasini E, Tapella L, Colombo L, Manzoni C, Borsello T, et al. (2010): Synthetic amyloid- $\beta$ oligomers impair long-term memory independently of cellular prion protein. Proc Natl Acad Sci U S A $\underline{107}, 2295-2300$

Ballard C, Corbett A (2011): Screening for dementia: an opportunity for debate. Expert Review of Neurotherapeutics $\underline{11}, 1347-1349$

Barber R (2011): Inflammatory signaling in Alzheimer disease and depression. Cleveland Clinic Journal of Medicine 78, S47-S49

Barron AM, Pike CJ (2012): Sex hormones, aging, and Alzheimer's disease. Front Biosci (Elite Ed) 4, 976-997

Barry AE, Klyubin I, Mc Donald JM, Mably AJ, Farrell MA, Scott M, Walsh DM, Rowan MJ (2011): Alzheimer's Disease Brain-Derived Amyloid-B-Mediated Inhibition of LTP In Vivo Is Prevented by Immunotargeting Cellular Prion Protein. J Neurosci 31, 7259-7263

Basi G, Frigon N, Barbour R, Doan T, Gordon G, McConlogue L, Sinha S, Zeller M (2003): Antagonistic effects of beta-site amyloid precursor protein-cleaving enzymes 1 and 2 on beta-amyloid peptide production in cells. J Biol Chem $\underline{278}$, $31512-31520$

Bayles KA, Tomoeda CK (1983): Confrontation naming impairment in dementia. Brain Lang $\underline{19}, 98-114$

Beekman AT (2011): Neuropathological correlates of late-life depression. Expert 
Review of Neurotherapeutics 11, 947-949

Bell KFS, Zheng L, Fahrenholz F, Cuello AC (2008): ADAM-10 over-expression increases cortical synaptogenesis. Neurobiol Aging 29, 554-565

Belyaev ND, Nalivaeva NN, Makova NZ, Turner AJ (2009): Neprilysin gene expression requires binding of the amyloid precursor protein intracellular domain to its promoter: implications for Alzheimer disease. EMBO Rep 10, 94-100

Bendlin BB, Carlsson CM, Johnson SC, Zetterberg H, Blennow K, Willette AA, Okonkwo OC, Sodhi A, Ries ML, Birdsill AC, et al. (2012): CSF T-Tau/A?42 Predicts White Matter Microstructure in Healthy Adults at Risk for Alzheimer's Disease. PLoS One 7, http://www.ncbi.nlm.nih.gov/pmc/articles/PMC3368882/ [29.03.2013]

Bennett BD, Babu-Khan S, Loeloff R, Louis JC, Curran E, Citron M, Vassar R (2000): Expression analysis of BACE2 in brain and peripheral tissues. J Biol Chem 275, 20647-20651

Berr C, Richard F, Dufouil C, Amant C, Alperovitch A, Amouyel P (1998): Polymorphism of the prion protein is associated with cognitive impairment in the elderly: the EVA study. Neurology $\underline{51}, 734-737$

Biasini E, Turnbaugh J, Unterberger U, Harris DA (2012): Prion Protein at the crossroads of physiology and disease. Trends Neurosci $\underline{35}, 92-103$

Bird TD: Alzheimer Disease Overview; in: GeneReviews(®); hrsg. v. Pagon RA, Adam MP, Ardinger HH, Wallace SE, Amemiya A, Bean LJ, Bird TD, Dolan CR, Fong C-T, Smith RJ, Stephens K; University of Washington, Seattle, Seattle (WA) 1993, http://www.ncbi.nlm.nih.gov/books/NBK1161/ [25.06.2015]

Blacker D, Lee H, Muzikansky A, Martin EC, Tanzi R, McArdle JJ, Moss M, Albert M (2007): Neuropsychological measures in normal individuals that predict subsequent cognitive decline. Arch Neurol 64, 862-871

Blennow K, De Leon MJ, Zetterberg H (2006): Alzheimer's disease. Lancet 368, 387403

Blennow K, Zetterberg H, Minthon L, Lannfelt L, Strid S, Annas P, Basun H, Andreasen N (2007): Longitudinal stability of CSF biomarkers in Alzheimer's disease. Neurosci Lett $\underline{419}, 18-22$

Del Bo R, Scarlato M, Ghezzi S, Martinelli-Boneschi F, Fenoglio C, Galimberti G, Galbiati S, Virgilio R, Galimberti D, Ferrarese C, et al. (2006): Is M129V of PRNP gene associated with Alzheimer's disease? A case-control study and a meta-analysis. Neurobiol Aging 27, 770.e1-770.e5

Boesenberg-Grosse C, Schulz-Schaeffer WJ, Bodemer M, Ciesielczyk B, Meissner B, Krasnianski A, Bartl M, Heinemann U, Varges D, Eigenbrod S, et al. (2006): Brain-derived proteins in the CSF, do they correlate with brain pathology in CJD? BMC Neurol $\underline{6}, 35-35$

Boyles JK, Notterpek LM, Anderson LJ (1990): Accumulation of apolipoproteins in the regenerating and remyelinating mammalian peripheral nerve. Identification of 
apolipoprotein D, apolipoprotein A-IV, apolipoprotein E, and apolipoprotein A-I. J Biol Chem 265, 17805-17815

Braak H, Braak E (1991): Neuropathological stageing of Alzheimer-related changes. Acta Neuropathol 2, 239-259

Braak H, Braak E (1995): Staging of Alzheimer's disease-related neurofibrillary changes. Neurobiol Aging 16, 271-278; discussion 278-284

Bruscoli M, Lovestone S (2004): Is MCI really just early dementia? A systematic review of conversion studies. Int Psychogeriatr $\underline{16}$, 129-140

Bu G (2009): Apolipoprotein E and its receptors in Alzheimer's disease: pathways, pathogenesis and therapy. Nat Rev Neurosci 10, 333-344

Buée L, Bussière T, Buée-Scherrer V, Delacourte A, Hof PR (2000): Tau protein isoforms, phosphorylation and role in neurodegenerative disorders. Brain Res Brain Res Rev $\underline{33}$, 95-130

Buerger K, Ewers M, Pirttilä T, Zinkowski R, Alafuzoff I, Teipel SJ, DeBernardis J, Kerkman D, McCulloch C, Soininen H, Hampel H (2006): CSF phosphorylated tau protein correlates with neocortical neurofibrillary pathology in Alzheimer's disease. Brain 129, 3035-3041

Burdick D, Soreghan B, Kwon M, Kosmoski J, Knauer M, Henschen A, Yates J, Cotman C, Glabe C (1992): Assembly and aggregation properties of synthetic Alzheimer's A4/beta amyloid peptide analogs. J Biol Chem 267, 546-554

Busse A, Bischkopf J, Riedel-Heller SG, Angermeyer MC (2003): Subclassifications for mild cognitive impairment: prevalence and predictive validity. Psychol Med 33, 1029-1038

Butters N, Albert MS, Sax DS, Miliotis P, Nagode J, Sterste A (1983): The effect of verbal mediators on the pictorial memory of brain-damaged patients. Neuropsychologia 21, 307-323

Butters N, Granholm E, Salmon DP, Grant I, Wolfe J (1987): Episodic and semantic memory: a comparison of amnesic and demented patients. J Clin Exp Neuropsychol $\underline{9}, 479-497$

Cai H, Wang Y, McCarthy D, Wen H, Borchelt DR, Price DL, Wong PC (2001): BACE1 is the major beta-secretase for generation of Abeta peptides by neurons. Nat Neurosci 4, 233-234

Caillé I, Allinquant B, Dupont E, Bouillot C, Langer A, Müller U, Prochiantz A (2004): Soluble form of amyloid precursor protein regulates proliferation of progenitors in the adult subventricular zone. Development 131, 2173-2181

Caine D, Hodges JR (2001): Heterogeneity of semantic and visuospatial deficits in early Alzheimer's disease. Neuropsychology 15, 155-164

Calabrese V, Boyd-Kimball D, Scapagnini G, Butterfield DA (2004): Nitric oxide and cellular stress response in brain aging and neurodegenerative disorders: the role of vitagenes. In Vivo $\underline{18}, 245-267$ 
Campion D, Dumanchin C, Hannequin D, Dubois B, Belliard S, Puel M, ThomasAnterion C, Michon A, Martin C, Charbonnier F, et al. (1999): Early-onset autosomal dominant Alzheimer disease: prevalence, genetic heterogeneity, and mutation spectrum. Am J Hum Genet $\underline{65}$, 664-670

Carnini A, Casha S, Yong VW, Hurlbert RJ, Braun JE. (2010): Reduction of PrPC in human cerebrospinal fluid after spinal cord injury. Prion $\underline{4}, 80-86$

Carson JA, Turner AJ (2002): Beta-amyloid catabolism: roles for neprilysin (NEP) and other metallopeptidases? J Neurochem $\underline{81}, 1-8$

Casadei V, Ferri C, Calabrese E, Grimaldi L, Franceschi M, Veglia F, Licastro F, Mariani C (2001): Prion protein gene polymorphism and Alzheimer's disease: one modulatory trait of cognitive decline? J Neurol Neurosurg Psychiatry $\underline{71}$, 279-280

Catalano SM, Dodson EC, Henze DA, Joyce JG, Krafft GA, Kinney GG (2006): The role of amyloid-beta derived diffusible ligands (ADDLs) in Alzheimer's disease. Curr Top Med Chem $\underline{6}, 597-608$

Chang K-A, Suh Y-H (2005): Pathophysiological roles of amyloidogenic carboxyterminal fragments of the beta-amyloid precursor protein in Alzheimer's disease. J Pharmacol Sci 97, 461-471

Chang K-A, Suh Y-H (2010): Possible roles of amyloid intracellular domain of amyloid precursor protein. BMB Rep $\underline{43}$, 656-663

Christensen H, Kopelman MD, Stanhope N, Lorentz L, Owen P (1998): Rates of forgetting in Alzheimer dementia. Neuropsychologia 36, 547-557

Clague F, Dudas RB, Thompson SA, Graham KS, Hodges JR (2005): Multidimensional measures of person knowledge and spatial associative learning: can these be applied to the differentiation of Alzheimer's disease from frontotemporal and vascular dementia? Neuropsychologia $\underline{43}, 1338-1350$

Collinge J, Whittington MA, Sidle KC, Smith CJ, Palmer MS, Clarke AR, Jefferys JG (1994): Prion protein is necessary for normal synaptic function. Nature $\underline{370}$, 295-297

Combarros O, Sánchez-Guerra M, Llorca J, Alvarez-Arcaya A, Berciano J, Peña N, Fernández-Viadero C (2000): Polymorphism at codon 129 of the prion protein gene is not associated with sporadic AD. Neurology 55, 593-595

Cook DG, Leverenz JB, McMillan PJ, Kulstad JJ, Ericksen S, Roth RA, Schellenberg GD, Jin L-W, Kovacina KS, Craft S (2003): Reduced hippocampal insulindegrading enzyme in late-onset Alzheimer's disease is associated with the apolipoprotein E-epsilon4 allele. Am J Pathol 162, 313-319

Coon KD, Myers AJ, Craig DW, Webster JA, Pearson JV, Lince DH, Zismann VL, Beach TG, Leung D, Bryden L, et al. (2007): A high-density whole-genome association study reveals that APOE is the major susceptibility gene for sporadic late-onset Alzheimer's disease. J Clin Psychiatry $\underline{68}$, 613-618

Corder EH, Saunders AM, Risch NJ, Strittmatter WJ, Schmechel DE, Gaskell PC Jr, 
Rimmler JB, Locke PA, Conneally PM, Schmader KE (1994): Protective effect of apolipoprotein E type 2 allele for late onset Alzheimer disease. Nat Genet $\underline{7}$, 180-184

Criado JR, Sánchez-Alavez M, Conti B, Giacchino JL, Wills DN, Henriksen SJ, Race R, Manson JC, Chesebro B, Oldstone MBA (2005): Mice devoid of prion protein have cognitive deficits that are rescued by reconstitution of $\operatorname{PrP}$ in neurons. Neurobiol Dis $\underline{19}, 255-265$

Cupers P, Orlans I, Craessaerts K, Annaert W, De Strooper B (2001): The amyloid precursor protein (APP)-cytoplasmic fragment generated by gamma-secretase is rapidly degraded but distributes partially in a nuclear fraction of neurones in culture. J Neurochem $\underline{78}, 1168-1178$

Davatzikos C, Bhatt P, Shaw LM, Batmanghelich KN, Trojanowski JQ (2011): Prediction of MCI to AD conversion, via MRI, CSF biomarkers, pattern classification. Neurobiol Aging $\underline{32}$, 2322.e19-2322.e27

Davies L, Wolska B, Hilbich C, Multhaup G, Martins R, Simms G, Beyreuther K, Masters CL (1988): A4 amyloid protein deposition and the diagnosis of Alzheimer's disease: prevalence in aged brains determined by immunocytochemistry compared with conventional neuropathologic techniques. Neurology $\underline{38}, 1688-1693$

Deane R, Sagare A, Hamm K, Parisi M, Lane S, Finn MB, Holtzman DM, Zlokovic BV (2008): apoE isoform-specific disruption of amyloid $\beta$ peptide clearance from mouse brain. J Clin Invest $\underline{118}$, 4002-4013

Delobel P, Lavenir I, Fraser G, Ingram E, Holzer M, Ghetti B, Spillantini MG, Crowther RA, Goedert M (2008): Analysis of tau phosphorylation and truncation in a mouse model of human tauopathy. Am J Pathol 172, 123-131

Dermaut B, Croes EA, Rademakers R, Van den Broeck M, Cruts M, Hofman A, Van Duijn CM, Van Broeckhoven C (2003): PRNP Val129 homozygosity increases risk for early-onset Alzheimer's disease. Ann Neurol 53, 409-412

Deshpande A, Mina E, Glabe C, Busciglio J (2006): Different conformations of amyloid beta induce neurotoxicity by distinct mechanisms in human cortical neurons. $\mathrm{J}$ Neurosci 26, 6011-6018

Dickson DW (1997): The pathogenesis of senile plaques. J Neuropathol Exp Neurol $\underline{56}$, 321-339

Diener H-C: Leitlinie Diagnostik und Therapie degenerativer Demenzen : (Morbus Alzheimer, Frontotemporale Demenz, Lewy-Körperchen-Demenz, Neurodegenerative Demenz); Sonderauszugsausgabe aus Leitlinien für Diagnostik und Therapie in der Neurologie, 4., überarbeitete und erweiterte Auflage; hrsg. von H. C. Diener, N. Putzki und der Kommission Leitlinien der Deutschen Gesellschaft für Neurologie. Thieme, Stuttgart 2008

Drewes G (2004): MARKing tau for tangles and toxicity. Trends Biochem Sci $\underline{29}, 548$ 555

Drewes G, Mandelkow EM, Baumann K, Goris J, Merlevede W, Mandelkow E (1993): 
Dephosphorylation of tau protein and Alzheimer paired helical filaments by calcineurin and phosphatase-2A. FEBS Lett $\underline{336}$, 425-432

Dubois B, Feldman HH, Jacova C, Dekosky ST, Barberger-Gateau P, Cummings J, Delacourte A, Galasko D, Gauthier S, Jicha G, et al. (2007): Research criteria for the diagnosis of Alzheimer's disease: revising the NINCDS-ADRDA criteria. Lancet Neurol $\underline{6}, 734-746$

Duce JA, Tsatsanis A, Cater MA, James SA, Robb E, Wikhe K, Leong SL, Perez K, Johanssen T, Greenough MA, et al. (2010): Iron-export ferroxidase activity of $\beta$ amyloid precursor protein is inhibited by zinc in Alzheimer's disease. Cell $\underline{142}$, 857-867

Duyckaerts C, Delatour B, Potier M-C (2009): Classification and basic pathology of Alzheimer disease. Acta Neuropathol 118, 5-36

Edbauer D, Willem M, Lammich S, Steiner H, Haass C (2002): Insulin-degrading enzyme rapidly removes the beta-amyloid precursor protein intracellular domain (AICD). J Biol Chem 277, 13389-13393

Engelborghs S, Sleegers K, Cras P, Brouwers N, Serneels S, Leenheir ED, Martin J-J, Vanmechelen E, Broeckhoven CV, Deyn PPD (2007): No association of CSF biomarkers with APOE 4 , plaque and tangle burden in definite Alzheimer's disease. Brain 130, 2320-2326

Erkinjuntti T, Ostbye T, Steenhuis R, Hachinski V (1997): The effect of different diagnostic criteria on the prevalence of dementia. N Engl J Med 337, 1667-1674

Ewers M, Walsh C, Trojanowski JQ, Shaw LM, Petersen RC, Jack CR, Feldman HH, Bokde ALW, Alexander GE, Scheltens P, et al. (2012): Prediction of conversion from mild cognitive impairment to Alzheimer's disease dementia based upon biomarkers and neuropsychological test performance. Neurobiol Aging $\underline{33}$, 1203-1214.e2

Fabrigoule C, Rouch I, Taberly A, Letenneur L, Commenges D, Mazaux JM, Orgogozo JM, Dartigues JF (1998): Cognitive process in preclinical phase of dementia. Brain 121 ( Pt 1), 135-141

Fahn S, Marsden C, Goldstein M (1987): Recent Developments in Parkinson's Disease, vol. 2. Macmillan Healthcare Information 153-163, 293-304

Feijoo C, Campbell DG, Jakes R, Goedert M, Cuenda A (2005): Evidence that phosphorylation of the microtubule-associated protein Tau by SAPK4/p38delta at Thr50 promotes microtubule assembly. J Cell Sci $\underline{118}$, 397-408

Ferri CP, Prince M, Brayne C, Brodaty H, Fratiglioni L, Ganguli M, Hall K, Hasegawa K, Hendrie H, Huang Y, et al. (2005): Global prevalence of dementia: a Delphi consensus study. Lancet $\underline{366}, 2112-2117$

Fevrier B, Vilette D, Archer F, Loew D, Faigle W, Vidal M, Laude H, Raposo G (2004): Cells release prions in association with exosomes. Proc Natl Acad Sci U S A $\underline{101}, 9683-9688$

Fischer P, Jungwirth S, Zehetmayer S, Weissgram S, Hoenigschnabl S, Gelpi E, 
Krampla W, Tragl KH (2007): Conversion from subtypes of mild cognitive impairment to Alzheimer dementia. Neurology 68, 288-291

Forloni G, Balducci C (2011): $\beta$-amyloid oligomers and prion protein: Fatal attraction? Prion $\underline{5}, 10-15$

Fox NC, Warrington EK, Seiffer AL, Agnew SK, Rossor MN (1998): Presymptomatic cognitive deficits in individuals at risk of familial Alzheimer's disease. A

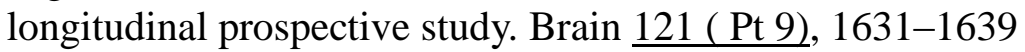

Freude KK, Penjwini M, Davis JL, Laferla FM, Blurton-Jones M (2011): Soluble amyloid precursor protein induces rapid neural differentiation of human embryonic stem cells. J Biol Chem 286, 24264-24274

Frisoni GB, Fox NC, Jack CR, Scheltens P, Thompson PM (2010): The clinical use of structural MRI in Alzheimer disease. Nat Rev Neurol $\underline{6}, 67-77$

Gacia M, Safranow K, Styczyńska M, Jakubowska K, Pepłońska B, ChodakowskaZebrowska M, Przekop I, Słowik A, Golańska E, Hułas-Bigoszewska K, et al. (2006): Prion protein gene M129 allele is a risk factor for Alzheimer's disease. J Neural Transm $\underline{113}, 1747-1751$

Gadotti VM, Zamponi GW (2011): Cellular prion protein protects from inflammatory and neuropathic pain. Mol Pain $\underline{7}, 59$

Gadotti VM, Bonfield SP, Zamponi GW (2012): Depressive-like behaviour of mice lacking cellular prion protein. Behav Brain Res 227, 319-323

Gambetti P, Cali I, Notari S, Kong Q, Zou W-Q, Surewicz WK (2011): Molecular biology and pathology of prion strains in sporadic human prion diseases. Acta Neuropathol $\underline{121}, 79-90$

Gendron TF, Petrucelli L (2009): The role of tau in neurodegeneration. Mol Neurodegener $\underline{4}, 13$

Geschwind MD, Haman A, Miller BL (2007): Rapidly Progressive Dementia. Neurol Clin $\underline{25}, 783-$ vii

Geslani DM, Tierney MC, Herrmann N, Szalai JP (2005): Mild cognitive impairment: an operational definition and its conversion rate to Alzheimer's disease. Dement Geriatr Cogn Disord 19, 383-389

Giannakopoulos P, Herrmann FR, Bussière T, Bouras C, Kövari E, Perl DP, Morrison JH, Gold G, Hof PR (2003): Tangle and neuron numbers, but not amyloid load, predict cognitive status in Alzheimer's disease. Neurology $\underline{60}, 1495-1500$

Giannattasio C, Poleggi A, Puopolo M, Pocchiari M, Antuono P, Dal Forno G, Wekstein DR, Matera MG, Seripa D, Acciarri A, et al. (2008): Survival in Alzheimer's disease is shorter in women carrying heterozygosity at codon 129 of the PRNP gene and no APOE epsilon 4 allele. Dement Geriatr Cogn Disord 25, 354-358

Giunta B, Fernandez F, Nikolic WV, Obregon D, Rrapo E, Town T, Tan J (2008): Inflammaging as a prodrome to Alzheimer's disease. J Neuroinflammation 5, 51 
Glass CK, Saijo K, Winner B, Marchetto MC, Gage FH (2010): Mechanisms Underlying Inflammation in Neurodegeneration. Cell 140, 918-934

Glodzik-Sobanska L, Pirraglia E, Brys M, De Santi S, Mosconi L, Rich KE, Switalski R, Saint Louis L, Sadowski MJ, Martiniuk F, et al. (2009): The effects of normal aging and ApoE genotype on the levels of CSF biomarkers for Alzheimer's disease. Neurobiol Aging $\underline{30}, 672-681$

Gloeckner SF (2010): Transthyretin-, Aß 1-40- und Aß 1-42- und Tau-ProteinKonzentrationen im Liquor cerebrospinalis bei demenziellen Erkrankungen., https://ediss.uni-goettingen.de/handle/11858/00-1735-0000-0006-AFE5-D [11.10.2013]

Goedert M, Spillantini MG, Jakes R, Rutherford D, Crowther RA (1989): Multiple isoforms of human microtubule-associated protein tau: sequences and localization in neurofibrillary tangles of Alzheimer's disease. Neuron $\underline{3}, 519$ 526

Goedert M, Spillantini MG, Cairns NJ, Crowther RA (1992): Tau proteins of Alzheimer paired helical filaments: abnormal phosphorylation of all six brain isoforms. Neuron $\underline{8}, 159-168$

Golanska E, Hulas-Bigoszewska K, Rutkiewicz E, Styczynska M, Peplonska B, Barcikowska M, Bratosiewicz-Wasik J, Liberski PP (2004): Polymorphisms within the prion (PrP) and prion-like protein (Doppel) genes in AD. Neurology $\underline{62}, 313-315$

Goldberg RJ (2007): Alzheimer's disease. Compr Ther 33, 58-64

Gómez-Ramos A, Smith MA, Perry G, Avila J (2004): Tau phosphorylation and assembly. Acta Neurobiol Exp (Wars) $\underline{64}, 33-39$

Gong CX, Singh TJ, Grundke-Iqbal I, Iqbal K (1993): Phosphoprotein phosphatase activities in Alzheimer disease brain. J Neurochem $\underline{61}$, 921-927

Gong CX, Shaikh S, Wang JZ, Zaidi T, Grundke-Iqbal I, Iqbal K (1995): Phosphatase activity toward abnormally phosphorylated tau: decrease in Alzheimer disease brain. J Neurochem $\underline{65}, 732-738$

Gong CX, Lidsky T, Wegiel J, Zuck L, Grundke-Iqbal I, Iqbal K (2000): Phosphorylation of microtubule-associated protein tau is regulated by protein phosphatase $2 \mathrm{~A}$ in mammalian brain. Implications for neurofibrillary degeneration in Alzheimer's disease. J Biol Chem 275, 5535-5544

Gralle M, Ferreira ST (2007): Structure and functions of the human amyloid precursor protein: the whole is more than the sum of its parts. Prog Neurobiol $\underline{82}, 11-32$

Greene JD, Hodges JR (1996): Identification of famous faces and famous names in early Alzheimer's disease. Relationship to anterograde episodic and general semantic memory. Brain 119 ( Pt 1), 111-128

Greene JD, Baddeley AD, Hodges JR (1996): Analysis of the episodic memory deficit in early Alzheimer's disease: evidence from the doors and people test. Neuropsychologia 34, 537-551 
Griffiths HH, Whitehouse IJ, Baybutt H, Brown D, Kellett KAB, Jackson CD, Turner AJ, Piccardo P, Manson JC, Hooper NM (2011): Prion Protein Interacts with BACE1 Protein and Differentially Regulates Its Activity toward Wild Type and Swedish Mutant Amyloid Precursor Protein. J Biol Chem 286, 33489-33500

Grundke-Iqbal I, Iqbal K, Quinlan M, Tung YC, Zaidi MS, Wisniewski HM (1986): Microtubule-associated protein tau. A component of Alzheimer paired helical filaments. J Biol Chem 261, 6084-6089

Guillot-Sestier M-V, Sunyach C, Druon C, Scarzello S, Checler F (2009): The ?Secretase-derived N-terminal Product of Cellular Prion, N1, Displays Neuroprotective Function in Vitro and in Vivo. J Biol Chem 284, 35973-35986

Guillot-Sestier M-V, Sunyach C, Ferreira ST, Marzolo M-P, Bauer C, Thevenet A, Checler F (2012): ?-Secretase-derived Fragment of Cellular Prion, N1, Protects against Monomeric and Oligomeric Amyloid? (A?)-associated Cell Death. J Biol Chem 287, 5021-5032

Hampel H, Shen Y, Walsh DM, Aisen P, Shaw LM, Zetterberg H, Trojanowski JQ, Blennow K (2010): Biological markers of amyloid ?-related mechanisms in Alzheimer's disease. Exp Neurol 223, 334-346

Han W, Ji T, Mei B, Su J (2011): Peptide p3 may play a neuroprotective role in the brain. Med Hypotheses $\underline{76}$, 543-546

Hardy J (2006): Has the amyloid cascade hypothesis for Alzheimer's disease been proved? Curr Alzheimer Res $\underline{3}, 71-73$

Hardy JA, Higgins GA (1992): Alzheimer's disease: the amyloid cascade hypothesis. Science 256, 184-185

Hayashi H (2011): Lipid metabolism and glial lipoproteins in the central nervous system. Biol Pharm Bull 34, 453-461

Hayashi H, Campenot RB, Vance DE, Vance JE (2009): Protection of Neurons from Apoptosis by Apolipoprotein E-containing Lipoproteins Does Not Require Lipoprotein Uptake and Involves Activation of Phospholipase $\mathrm{C} \gamma 1$ and Inhibition of Calcineurin. J Biol Chem 284, 29605-29613

Heindel WC, Salmon DP, Shults CW, Walicke PA, Butters N (1989): Neuropsychological evidence for multiple implicit memory systems: a comparison of Alzheimer's, Huntington's, and Parkinson's disease patients. J Neurosci $\underline{9}, 582-587$

Henneman WJP, Vrenken H, Barnes J, Sluimer IC, Verwey NA, Blankenstein MA, Klein M, Fox NC, Scheltens P, Barkhof F, Van der Flier WM (2009): Baseline CSF p-tau levels independently predict progression of hippocampal atrophy in Alzheimer disease. Neurology $\underline{73}, 935-940$

Henry JD, Crawford JR, Phillips LH (2004): Verbal fluency performance in dementia of the Alzheimer's type: a meta-analysis. Neuropsychologia 42, 1212-1222

Herrup K (2010): Reimagining Alzheimer's Disease-An Age-Based Hypothesis. The Journal of Neuroscience $\underline{30}, 16755-16762$ 
Higgins LS, Murphy GM Jr, Forno LS, Catalano R, Cordell B (1996): P3 beta-amyloid peptide has a unique and potentially pathogenic immunohistochemical profile in Alzheimer's disease brain. Am J Pathol 149, 585-596

Himmler A, Drechsel D, Kirschner MW, Martin DW Jr (1989): Tau consists of a set of proteins with repeated $\mathrm{C}$-terminal microtubule-binding domains and variable $\mathrm{N}$ terminal domains. Mol Cell Biol $\underline{9}, 1381-1388$

Hodges J (1998): The amnestic prodrome of Alzheimer's disease. Brain 121 ( Pt 9), $1601-1602$

Hodges JR (2006): Alzheimer's centennial legacy: origins, landmarks and the current status of knowledge concerning cognitive aspects. Brain 129, 2811-2822

Holtzman DM (2011): CSF biomarkers for Alzheimer's disease: Current utility and potential future use. Neurobiol Aging $\underline{32}$, S4-S9

Hooper NM, Turner AJ (2008): A new take on prions: preventing Alzheimer's disease. Trends Biochem Sci $\underline{33}, 151-155$

Huey ED, Mirza N, Putnam KT, Soares H, Csako G, Levy JA, Copenhaver B, Cohen RM, Sunderland T (2006): Stability of CSF beta-amyloid(1-42) and tau levels by APOE genotype in Alzheimer patients. Dement Geriatr Cogn Disord 22, 48-53

Humpel C (2011): Identifying and validating biomarkers for Alzheimer's disease. Trends Biotechnol 29, 26-32

Hyman BT, Van Hoesen GW, Damasio AR, Barnes CL (1984): Alzheimer's disease: cell-specific pathology isolates the hippocampal formation. Science $\underline{225}, 1168$ 1170

Ignatius MJ, Gebicke-Härter PJ, Skene JH, Schilling JW, Weisgraber KH, Mahley RW, Shooter EM (1986): Expression of apolipoprotein E during nerve degeneration and regeneration. Proc Natl Acad Sci U S A $\underline{83}, 1125-1129$

Iqbal K, Grundke-Iqbal I, Zaidi T, Merz PA, Wen GY, Shaikh SS, Wisniewski HM, Alafuzoff I, Winblad B (1986): Defective brain microtubule assembly in Alzheimer's disease. Lancet $\underline{2}, 421-426$

Iqbal K, Grundke-Iqbal I, Smith AJ, George L, Tung YC, Zaidi T (1989): Identification and localization of a tau peptide to paired helical filaments of Alzheimer disease. Proc Natl Acad Sci USA $\underline{86}, 5646-5650$

Iqbal K, Liu F, Gong C-X, Grundke-Iqbal I (2010): Tau in Alzheimer disease and related tauopathies. Curr Alzheimer Res $\underline{7}$, 656-664

Irwin DJ, Trojanowski JQ, Grossman M (2013): Cerebrospinal fluid biomarkers for differentiation of frontotemporal lobar degeneration from Alzheimer's disease. Front Aging Neurosci $\underline{5}$, http://www.ncbi.nlm.nih.gov/pmc/articles/PMC3578350/ [29.03.2013]

Jin M, Shepardson N, Yang T, Chen G, Walsh D, Selkoe DJ (2011): Soluble amyloid beta-protein dimers isolated from Alzheimer cortex directly induce Tau hyperphosphorylation and neuritic degeneration. Proc Natl Acad Sci USA $\underline{108}$, 
$5819-5824$

Johnson GVW, Stoothoff WH (2004): Tau phosphorylation in neuronal cell function and dysfunction. J Cell Sci 117, 5721-5729

Josephs KA, Ahlskog JE, Parisi JE, Boeve BF, Crum BA, Giannini C, Petersen RC (2009): Rapidly Progressive Neurodegenerative Dementias. Arch Neurol $\underline{66}$, 201-207

Kar S, Slowikowski SPM, Westaway D, Mount HTJ (2004): Interactions between betaamyloid and central cholinergic neurons: implications for Alzheimer's disease. J Psychiatry Neurosci $\underline{29}, 427-441$

Kellett KAB, Hooper NM (2009): Prion protein and Alzheimer disease. Prion $\underline{3}$, 190194

Kester MI, Van der Vlies AE, Blankenstein MA, Pijnenburg YAL, Van Elk EJ, Scheltens P, Van der Flier WM (2009): CSF biomarkers predict rate of cognitive decline in Alzheimer disease. Neurology $\underline{73}, 1353-1358$

Kim J, Basak JM, Holtzman DM (2009): The Role of Apolipoprotein E in Alzheimer's Disease. Neuron $\underline{63}, 287-303$

Kimberly WT, LaVoie MJ, Ostaszewski BL, Ye W, Wolfe MS, Selkoe DJ (2003): Gamma-secretase is a membrane protein complex comprised of presenilin, nicastrin, Aph-1, and Pen-2. Proc Natl Acad Sci USA 100, 6382-6387

Klein AM, Kowall NW, Ferrante RJ (1999): Neurotoxicity and oxidative damage of beta amyloid 1-42 versus beta amyloid 1-40 in the mouse cerebral cortex. Ann N Y Acad Sci $\underline{893}, 314-320$

Klein WL (2006): Synaptic targeting by A beta oligomers (ADDLS) as a basis for memory loss in early Alzheimer's disease. Alzheimers Dement 2 , 43-55

Klein WL, Stine WB Jr, Teplow DB (2004): Small assemblies of unmodified amyloid beta-protein are the proximate neurotoxin in Alzheimer's disease. Neurobiol Aging 25, 569-580

Komarova NL, Thalhauser CJ (2011): High Degree of Heterogeneity in Alzheimer's Disease Progression Patterns. PLoS Comput Biol $\underline{7}$, http://www.ncbi.nlm.nih.gov/pmc/articles/PMC3207941/ [09.03.2013]

Kopelman MD (1985): Rates of forgetting in Alzheimer-type dementia and Korsakoff's syndrome. Neuropsychologia $\underline{23}, 623-638$

Kopelman MD (1991): Frontal dysfunction and memory deficits in the alcoholic

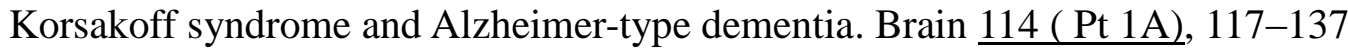

Köpke E, Tung YC, Shaikh S, Alonso AC, Iqbal K, Grundke-Iqbal I (1993): Microtubule-associated protein tau. Abnormal phosphorylation of a non-paired helical filament pool in Alzheimer disease. J Biol Chem 268, 24374-24384

Lacor PN, Buniel MC, Chang L, Fernandez SJ, Gong Y, Viola KL, Lambert MP, Velasco PT, Bigio EH, Finch CE, et al. (2004): Synaptic targeting by 
Alzheimer's-related amyloid beta oligomers. J Neurosci 24, 10191-10200

LaDu MJ, Shah JA, Reardon CA, Getz GS, Bu G, Hu J, Guo L, Van Eldik LJ (2001): Apolipoprotein $\mathrm{E}$ and apolipoprotein $\mathrm{E}$ receptors modulate A beta-induced glial neuroinflammatory responses. Neurochem Int $\underline{39}, 427-434$

Landau SM, Harvey D, Madison CM, Reiman EM, Foster NL, Aisen PS, Petersen RC, Shaw LM, Trojanowski JQ, Jack CR Jr, et al. (2010): Comparing predictors of conversion and decline in mild cognitive impairment. Neurology $\underline{75}, 230-238$

LaPointe NE, Morfini G, Pigino G, Gaisina IN, Kozikowski AP, Binder LI, Brady ST (2009): The amino terminus of tau inhibits kinesin-dependent axonal transport: implications for filament toxicity. J Neurosci Res $\underline{87}$, 440-451

Larson M, Sherman MA, Amar F, Nuvolone M, Schneider JA, Bennett DA, Aguzzi A, Lesne SE (2012): The complex PrPc-Fyn couples human oligomeric A? with pathological tau changes in Alzheimer's disease. J Neurosci $\underline{32}, 16857-1671$ a

Laurén J, Gimbel DA, Nygaard HB, Gilbert JW, Strittmatter SM (2009): Cellular Prion Protein Mediates Impairment of Synaptic Plasticity by Amyloid- $\beta$ Oligomers. Nature $\underline{457}, 1128-1132$

Lawton MP, Brody EM (1969): Assessment of older people: self-maintaining and instrumental activities of daily living. Gerontologist $\underline{9}$, 179-186

Lee VM, Balin BJ, Otvos L Jr, Trojanowski JQ (1991): A68: a major subunit of paired helical filaments and derivatized forms of normal Tau. Science 251, 675-678

De Leon MJ, Mosconi L, Blennow K, DeSanti S, Zinkowski R, Mehta PD, Pratico D, Tsui W, Louis LAS, Sobanska L, et al. (2007): Imaging and CSF Studies in the Preclinical Diagnosis of Alzheimer's Disease. Annals of the New York Academy of Sciences 1097, 114-145

Leoni V, Solomon A, Kivipelto M (2010): Links between ApoE, brain cholesterol metabolism, tau and amyloid beta-peptide in patients with cognitive impairment. Biochem Soc Trans $\underline{38}, 1021-1025$

Levy-Lahad E, Wasco W, Poorkaj P, Romano DM, Oshima J, Pettingell WH, Yu CE, Jondro PD, Schmidt SD, Wang K (1995): Candidate gene for the chromosome 1 familial Alzheimer's disease locus. Science 269, 973-977

Lewis V, Whitehouse IJ, Baybutt H, Manson JC, Collins SJ, Hooper NM (2012): Cellular Prion Protein Expression Is Not Regulated by the Alzheimer's Amyloid Precursor Protein Intracellular Domain. PLoS One $\underline{7}$

Li B, Chohan MO, Grundke-Iqbal I, Iqbal K (2007): Disruption of microtubule network by Alzheimer abnormally hyperphosphorylated tau. Acta Neuropathol $\underline{113}, 501-$ 511

Li H, Wang B, Wang Z, Guo Q, Tabuchi K, Hammer RE, Südhof TC, Zheng H (2010): Soluble amyloid precursor protein (APP) regulates transthyretin and Klotho gene expression without rescuing the essential function of APP. Proc Natl Acad Sci USA $107,17362-17367$ 
Liang Z, Liu F, Iqbal K, Grundke-Iqbal I, Wegiel J, Gong C-X (2008): Decrease of protein phosphatase $2 \mathrm{~A}$ and its association with accumulation and hyperphosphorylation of tau in Down syndrome. J Alzheimers Dis 13, 295-302

Linden R, Martins VR, Prado MAM, Cammarota M, Izquierdo I, Brentani RR (2008): Physiology of the prion protein. Physiol Rev $\underline{88}, 673-728$

Lindwall G, Cole RD (1984): Phosphorylation affects the ability of tau protein to promote microtubule assembly. J Biol Chem 259, 5301-5305

Liu F, Grundke-Iqbal I, Iqbal K, Gong C-X (2005): Contributions of protein phosphatases PP1, PP2A, PP2B and PP5 to the regulation of tau phosphorylation. Eur J Neurosci 22, 1942-1950

Locascio JJ, Growdon JH, Corkin S (1995): Cognitive test performance in detecting, staging, and tracking Alzheimer's disease. Arch Neurol 52, 1087-1099

Löffler J, Huber G (1992): Beta-amyloid precursor protein isoforms in various rat brain regions and during brain development. J Neurochem 59, 1316-1324

Lue LF, Kuo YM, Roher AE, Brachova L, Shen Y, Sue L, Beach T, Kurth JH, Rydel RE, Rogers J (1999): Soluble amyloid beta peptide concentration as a predictor of synaptic change in Alzheimer's disease. Am J Pathol 155, 853-862

Luo Y, Bolon B, Kahn S, Bennett BD, Babu-Khan S, Denis P, Fan W, Kha H, Zhang J, Gong Y, et al. (2001): Mice deficient in BACE1, the Alzheimer's beta-secretase, have normal phenotype and abolished beta-amyloid generation. Nat Neurosci $\underline{4}$, $231-232$

Maeda S, Sahara N, Saito Y, Murayama S, Ikai A, Takashima A (2006): Increased levels of granular tau oligomers: an early sign of brain aging and Alzheimer's disease. Neurosci Res $\underline{54}, 197-201$

Maglio LE, Perez MF, Martins VR, Brentani RR, Ramirez OA (2004): Hippocampal synaptic plasticity in mice devoid of cellular prion protein. Brain Res Mol Brain Res $\underline{131}, 58-64$

Maglio LE, Martins VR, Izquierdo I, Ramirez OA (2006): Role of cellular prion protein on LTP expression in aged mice. Brain Res 1097, 11-18

Manzoni C, Colombo L, Bigini P, Diana V, Cagnotto A, Messa M, Lupi M, Bonetto V, Pignataro M, Airoldi C, et al. (2011): The Molecular Assembly of Amyloid A $\beta$ Controls Its Neurotoxicity and Binding to Cellular Proteins. PLoS One $\underline{6}$

Marcinkiewicz M, Seidah NG (2000): Coordinated expression of beta-amyloid precursor protein and the putative beta-secretase BACE and alpha-secretase ADAM10 in mouse and human brain. J Neurochem $\underline{75}, 2133-2143$

Markesbery WR, Schmitt FA, Kryscio RJ, Davis DG, Smith CD, Wekstein DR (2006): Neuropathologic substrate of mild cognitive impairment. Arch Neurol $\underline{63}, 38-46$

Martin A, Fedio P (1983): Word production and comprehension in Alzheimer's disease: the breakdown of semantic knowledge. Brain Lang 19, 124-141 
Mattson MP (1997): Cellular actions of beta-amyloid precursor protein and its soluble and fibrillogenic derivatives. Physiol Rev $\underline{77}, 1081-1132$

McClelland EE, Smith JM (2011): Gender specific differences in the immune response to infection. Arch Immunol Ther Exp (Warsz) 59, 203-213

McKhann G, Drachman D, Folstein M, Katzman R, Price D, Stadlan EM (1984): Clinical diagnosis of Alzheimer's disease: report of the NINCDS-ADRDA Work Group under the auspices of Department of Health and Human Services Task Force on Alzheimer's Disease. Neurology $\underline{34}$, 939-944

McLean CA, Cherny RA, Fraser FW, Fuller SJ, Smith MJ, Beyreuther K, Bush AI, Masters CL (1999): Soluble pool of Abeta amyloid as a determinant of severity of neurodegeneration in Alzheimer's disease. Ann Neurol 46, 860-866

McLennan NF, Brennan PM, McNeill A, Davies I, Fotheringham A, Rennison KA, Ritchie D, Brannan F, Head MW, Ironside JW, et al. (2004): Prion protein accumulation and neuroprotection in hypoxic brain damage. Am J Pathol $\underline{165}$, 227-235

Mead S (2006): Prion disease genetics. Eur J Hum Genet 14, 273-281

Metcalfe MJ, Figueiredo-Pereira ME (2010): Relationship between tau pathology and neuroinflammation in Alzheimer's disease. Mt Sinai J Med 77, 50-58

De Meyer G, Shapiro F, Vanderstichele H, Vanmechelen E, Engelborghs S, De Deyn PP, Coart E, Hansson O, Minthon L, Zetterberg H, et al. (2010): DiagnosisIndependent Alzheimer Disease Biomarker Signature in Cognitively Normal Elderly People. Arch Neurol 67, 949-956

Meyne F, Gloeckner SF, Ciesielczyk B, Heinemann U, Krasnianski A, Meissner B, Zerr I (2009): Total prion protein levels in the cerebrospinal fluid are reduced in patients with various neurological disorders. J Alzheimers Dis $\underline{17}, 863-873$

Mines MA, Beurel E, Jope RS (2011): Regulation of Cell Survival Mechanisms in Alzheimer's Disease by Glycogen Synthase Kinase-3. Int J Alzheimers Dis 2011

Mitchell AJ, Shiri-Feshki M (2009): Rate of progression of mild cognitive impairment to dementia--meta-analysis of 41 robust inception cohort studies. Acta Psychiatr Scand $\underline{119}, 252-265$

Mitsios N, Saka M, Krupinski J, Pennucci R, Sanfeliu C, Miguel Turu M, Gaffney J, Kumar P, Kumar S, Sullivan M, Slevin M (2007): Cellular prion protein is increased in the plasma and peri-infarcted brain tissue after acute stroke. J Neurosci Res $\underline{85}, 602-611$

Morishima-Kawashima M, Hasegawa M, Takio K, Suzuki M, Yoshida H, Titani K, Ihara Y (1995): Proline-directed and non-proline-directed phosphorylation of PHF-tau. J Biol Chem 270, 823-829

Moss MB, Albert MS, Butters N, Payne M (1986): Differential patterns of memory loss among patients with Alzheimer's disease, Huntington's disease, and alcoholic Korsakoff's syndrome. Arch Neurol $\underline{43}$, 239-246 
Neniskyte U, Neher JJ, Brown GC (2011): Neuronal Death Induced by Nanomolar Amyloid $\beta$ Is Mediated by Primary Phagocytosis of Neurons by Microglia. J Biol Chem 286, 39904-39913

Newkirk LA, Kim JM, Thompson JM, Tinklenberg JR, Yesavage JA, Taylor JL (2004): Validation of a 26-point telephone version of the Mini-Mental State Examination. J Geriatr Psychiatry Neurol 17, 81-87

Nunan J, Shearman MS, Checler F, Cappai R, Evin G, Beyreuther K, Masters CL, Small DH (2001): The C-terminal fragment of the Alzheimer's disease amyloid protein precursor is degraded by a proteasome-dependent mechanism distinct from gamma-secretase. Eur J Biochem 268, 5329-5336

Nunan J, Williamson NA, Hill AF, Sernee MF, Masters CL, Small DH (2003): Proteasome-mediated degradation of the C-terminus of the Alzheimer's disease beta-amyloid protein precursor: effect of C-terminal truncation on production of beta-amyloid protein. J Neurosci Res $\underline{74}, 378-385$

Ohkubo T, Sakasegawa Y, Asada T, Kinoshita T, Goto Y, Kimura H, Mizusawa H, Hachiya NS, Kaneko K (2003): Absence of association between codon 129/219 polymorphisms of the prion protein gene and Alzheimer's disease in Japan. Ann Neurol 54, 553-554; author reply 555

Ohsawa I, Takamura C, Morimoto T, Ishiguro M, Kohsaka S (1999): Amino-terminal region of secreted form of amyloid precursor protein stimulates proliferation of neural stem cells. Eur J Neurosci 11, 1907-1913

Pardossi-Piquard R, Petit A, Kawarai T, Sunyach C, Alves da Costa C, Vincent B, Ring S, D’Adamio L, Shen J, Müller U, et al. (2005): Presenilin-dependent transcriptional control of the Abeta-degrading enzyme neprilysin by intracellular domains of betaAPP and APLP. Neuron $\underline{46}, 541-554$

Park SA, Shaked GM, Bredesen DE, Koo EH (2009): Mechanism of cytotoxicity mediated by the $\mathrm{C} 31$ fragment of the amyloid precursor protein. Biochem Biophys Res Commun $\underline{388}$, 450-455

Parkin ET, Watt NT, Hussain I, Eckman EA, Eckman CB, Manson JC, Baybutt HN, Turner AJ, Hooper NM (2007): Cellular prion protein regulates beta-secretase cleavage of the Alzheimer's amyloid precursor protein. Proc Natl Acad Sci USA $\underline{104}, 11062-11067$

Pearson HA, Peers C (2006): Physiological roles for amyloid $\beta$ peptides. The Journal of Physiology $\underline{575}, 5-10$

Perry RJ, Hodges JR (1999): Attention and executive deficits in Alzheimer's disease. A

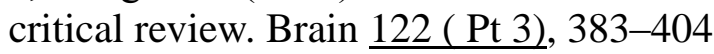

Perry RJ, Hodges JR (2000): Differentiating frontal and temporal variant frontotemporal dementia from Alzheimer's disease. Neurology $\underline{54}, 2277-2284$

Perry RJ, Watson P, Hodges JR (2000): The nature and staging of attention dysfunction in early (minimal and mild) Alzheimer's disease: relationship to episodic and semantic memory impairment. Neuropsychologia $\underline{38}, 252-271$ 
Petersen RC (2004): Mild cognitive impairment as a diagnostic entity. J Intern Med 256, 183-194

Petersen RC, Negash S (2008): Mild cognitive impairment: an overview. CNS Spectr $\underline{13}, 45-53$

Petersen RC, Smith GE, Ivnik RJ, Kokmen E, Tangalos EG (1994): Memory function in very early Alzheimer's disease. Neurology $\underline{44}, 867-872$

Petersen RC, Stevens JC, Ganguli M, Tangalos EG, Cummings JL, DeKosky ST (2001): Practice parameter: early detection of dementia: mild cognitive impairment (an evidence-based review). Report of the Quality Standards Subcommittee of the American Academy of Neurology. Neurology $\underline{56}, 1133-1142$

Pignatti R, Rabuffetti M, Imbornone E, Mantovani F, Alberoni M, Farina E, Canal N (2005): Specific impairments of selective attention in mild Alzheimer's disease. J Clin Exp Neuropsychol 27, 436-448

Pike CJ, Walencewicz AJ, Glabe CG, Cotman CW (1991): In vitro aging of betaamyloid protein causes peptide aggregation and neurotoxicity. Brain Res $\underline{563}$, 311-314

Pike CJ, Burdick D, Walencewicz AJ, Glabe CG, Cotman CW (1993):

Neurodegeneration induced by beta-amyloid peptides in vitro: the role of peptide assembly state. J Neurosci $\underline{13}, 1676-1687$

Pike CJ, Overman MJ, Cotman CW (1995): Amino-terminal deletions enhance aggregation of beta-amyloid peptides in vitro. J Biol Chem 270, 23895-23898

Poleggi A, Bizzarro A, Acciarri A, Antuono P, Bagnoli S, Cellini E, Forno GD, Giannattasio C, Lauria A, Matera MG, et al. (2008): Codon 129 polymorphism of prion protein gene in sporadic Alzheimer's disease. Eur J Neurol 15, 173-178

Priller C, Bauer T, Mitteregger G, Krebs B, Kretzschmar HA, Herms J (2006): Synapse formation and function is modulated by the amyloid precursor protein. $\mathrm{J}$ Neurosci 26, 7212-7221

Prior R, D’Urso D, Frank R, Prikulis I, Cleven S, Ihl R, Pavlakovic G (1996): Selective binding of soluble Abeta1-40 and Abeta1-42 to a subset of senile plaques. Am J Pathol 148, 1749-1756

Puckett C, Concannon P, Casey C, Hood L (1991): Genomic structure of the human prion protein gene. Am J Hum Genet $\underline{49}, 320-329$

Qiu C, De Ronchi D, Fratiglioni L (2007): The epidemiology of the dementias: an update. Curr Opin Psychiatry 20, 380-385

Reiman EM, Chen K, Liu X, Bandy D, Yu M, Lee W, Ayutyanont N, Keppler J, Reeder SA, Langbaum JBS, et al. (2009): Fibrillar amyloid- $\beta$ burden in cognitively normal people at 3 levels of genetic risk for Alzheimer's disease. Proc Natl Acad Sci U S A $\underline{106}$, 6820-6825

Reisberg B, Ferris SH, De Leon MJ, Crook T (1988): Global Deterioration Scale (GDS). Psychopharmacol Bull 24, 661-663 
Reynolds CH, Garwood CJ, Wray S, Price C, Kellie S, Perera T, Zvelebil M, Yang A, Sheppard PW, Varndell IM, et al. (2008): Phosphorylation regulates tau interactions with Src homology 3 domains of phosphatidylinositol 3-kinase, phospholipase Cgamma1, Grb2, and Src family kinases. J Biol Chem $\underline{283}$, 18177-18186

Rezaie P, Pontikis CC, Hudson L, Cairns NJ, Lantos PL (2005): Expression of cellular prion protein in the frontal and occipital lobe in Alzheimer's disease, diffuse Lewy body disease, and in normal brain: an immunohistochemical study. J Histochem Cytochem 53, 929-940

Riemenschneider M, Klopp N, Xiang W, Wagenpfeil S, Vollmert C, Müller U, Förstl H, Illig T, Kretzschmar H, Kurz A (2004): Prion protein codon 129 polymorphism and risk of Alzheimer disease. Neurology $\underline{63}, 364-366$

Robert M, Mathuranath PS (2007): Tau and tauopathies. Neurol India 55, 11-16

Roberts TK, Eugenin EA, Morgello S, Clements JE, Zink MC, Berman JW (2010): PrPC, the Cellular Isoform of the Human Prion Protein, Is a Novel Biomarker of HIV-Associated Neurocognitive Impairment and Mediates Neuroinflammation. Am J Pathol 177, 1848-1860

Robertson C, Booth SA, Beniac DR, Coulthart MB, Booth TF, McNicol A (2006): Cellular prion protein is released on exosomes from activated platelets. Blood $\underline{107}, 3907-3911$

Rogaev EI, Sherrington R, Rogaeva EA, Levesque G, Ikeda M, Liang Y, Chi H, Lin C, Holman K, Tsuda T (1995): Familial Alzheimer's disease in kindreds with missense mutations in a gene on chromosome 1 related to the Alzheimer's disease type 3 gene. Nature $\underline{376}, 775-778$

Rosen C, Hansson O, Blennow K, Zetterberg H (2013): Fluid biomarkers in Alzheimer's disease - current concepts. Mol Neurodegener $\underline{8}, 20$

Rosser A, Hodges JR (1994): Initial letter and semantic category fluency in Alzheimer's disease, Huntington's disease, and progressive supranuclear palsy. J Neurol Neurosurg Psychiatr 57, 1389-1394

Sack I, Streitberger K-J, Krefting D, Paul F, Braun J (2011): The Influence of Physiological Aging and Atrophy on Brain Viscoelastic Properties in Humans. PLoS One $\underline{6}$

Sahakian BJ, Morris RG, Evenden JL, Heald A, Levy R, Philpot M, Robbins TW (1988): A comparative study of visuospatial memory and learning in Alzheimertype dementia and Parkinson's disease. Brain 111 ( Pt 3), 695-718

Saijo E, Scheff SW, Telling GC (2011): Unaltered prion protein expression in Alzheimer disease patients. Prion $\underline{5}, 109-116$

Salbaum JM, Ruddle FH (1994): Embryonic expression pattern of amyloid protein precursor suggests a role in differentiation of specific subsets of neurons. J Exp Zool 269, 116-127

Sarazin M, Berr C, De Rotrou J, Fabrigoule C, Pasquier F, Legrain S, Michel B, Puel M, 
Volteau M, Touchon J, et al. (2007): Amnestic syndrome of the medial temporal type identifies prodromal AD: a longitudinal study. Neurology $\underline{69}, 1859-1867$

Sastre M, Walter J, Gentleman SM (2008): Interactions between APP secretases and inflammatory mediators. J Neuroinflammation $\underline{5}, 25$

Scarmeas N, Hadjigeorgiou GM, Papadimitriou A, Dubois B, Sarazin M, Brandt J, Albert M, Marder K, Bell K, Honig LS, et al. (2004): Motor signs during the course of Alzheimer disease. Neurology $\underline{63}, 975-982$

Schmechel DE, Saunders AM, Strittmatter WJ, Crain BJ, Hulette CM, Joo SH, PericakVance MA, Goldgaber D, Roses AD (1993): Increased amyloid beta-peptide deposition in cerebral cortex as a consequence of apolipoprotein $\mathrm{E}$ genotype in late-onset Alzheimer disease. Proc Natl Acad Sci USA 90, 9649-9653

Schmidt C, Redyk K, Meissner B, Krack L, Von Ahsen N, Roeber S, Kretzschmar H, Zerr I (2010): Clinical features of rapidly progressive Alzheimer's disease. Dement Geriatr Cogn Disord 29, 371-378

Schmidt C, Wolff M, Weitz M, Bartlau T, Korth C, Zerr I (2011): Rapidly progressive Alzheimer disease. Arch Neurol 68, 1124-1130

Schmidt C, Artjomova S, Hoeschel M, Zerr I (2013): CSF prion protein concentration and cognition in patients with Alzheimer disease. Prion $\underline{7}, 229-234$

Schmidtke K, Hermeneit S (2008): High rate of conversion to Alzheimer's disease in a cohort of amnestic MCI patients. Int Psychogeriatr 20, 96-108

Schmitz G: Biomarker: Bedeutung für medizinischen Fortschritt und Nutzenbewertung ; mit 14 Tabellen. Schattauer Verlag 2008

Schmitz M, Wulf K, Signore SC, Schulz-Schaeffer WJ, Kermer P, Bähr M, Wouters FS, Zafar S, Zerr I (2013): Impact of the Cellular Prion Protein on Amyloid- $\beta$ and 3PO-Tau Processing. J Alzheimers Dis $\underline{38}, 551-65$

Selkoe DJ (2008): Soluble Oligomers of the Amyloid $\beta$-Protein Impair Synaptic Plasticity and Behavior. Behav Brain Res $\underline{192}$, 106-113

Shaw LM, Vanderstichele H, Knapik-Czajka M, Clark CM, Aisen PS, Petersen RC, Blennow K, Soares H, Simon A, Lewczuk P, et al. (2009): Cerebrospinal Fluid Biomarker Signature in Alzheimer's Disease Neuroimaging Initiative Subjects. Ann Neurol 65, 403-413

Sherrington R, Rogaev EI, Liang Y, Rogaeva EA, Levesque G, Ikeda M, Chi H, Lin C, Li G, Holman K, et al. (1995): Cloning of a gene bearing missense mutations in early-onset familial Alzheimer's disease. Nature 375, 754-760

Sjögren M, Vanderstichele H, Ågren H, Zachrisson O, Edsbagge M, Wikkelsø C, Skoog I, Wallin A, Wahlund L-O, Marcusson J, et al. (2001): Tau and A $\beta 42$ in Cerebrospinal Fluid from Healthy Adults 21-93 Years of Age: Establishment of Reference Values. Clinical Chemistry 47, 1776-1781

Small DH, Klaver DW, Foa L (2010): Presenilins and the gamma-secretase: still a complex problem. Mol Brain $\underline{3}, 7$ 
Smid J, Landemberger MC, Bahia VS, Martins VR, Nitrini R, Smid J, Landemberger MC, Bahia VS, Martins VR, Nitrini R (2013): Codon 129 polymorphism of prion protein gene in is not a risk factor for Alzheimer's disease. Arquivos de Neuro-Psiquiatria $\underline{71}, 423-427$

Snider BJ, Fagan AM, Roe CM, Shah AR, Grant EA, Xiong C, Morris JC, Holtzman DM (2009): Cerebrospinal fluid biomarkers and rate of cognitive decline in very mild dementia of the Alzheimer's type. Arch Neurol 66, 638-645

Snipes GJ, McGuire CB, Norden JJ, Freeman JA (1986): Nerve injury stimulates the secretion of apolipoprotein E by nonneuronal cells. Proc Natl Acad Sci U S A $\underline{83}, 1130-1134$

Sontag E, Luangpirom A, Hladik C, Mudrak I, Ogris E, Speciale S, White CL 3rd (2004): Altered expression levels of the protein phosphatase $2 \mathrm{~A} \mathrm{ABalphaC}$ enzyme are associated with Alzheimer disease pathology. J Neuropathol Exp Neurol $\underline{63}, 287-301$

Soscia SJ, Kirby JE, Washicosky KJ, Tucker SM, Ingelsson M, Hyman B, Burton MA, Goldstein LE, Duong S, Tanzi RE, Moir RD (2010): The Alzheimer's DiseaseAssociated Amyloid $\beta$-Protein Is an Antimicrobial Peptide. PLoS One $\underline{5}$

Starkstein SE, Jorge R, Mizrahi R, Robinson RG (2006): A prospective longitudinal study of apathy in Alzheimer's disease. J Neurol Neurosurg Psychiatr $\underline{77}$, 8-11

Stefanacci RG (2011): The costs of Alzheimer's disease and the value of effective therapies. Am J Manag Care 17 Suppl 13, S356-362

Strozyk D, Blennow K, White LR, Launer LJ (2003): CSF Abeta 42 levels correlate with amyloid-neuropathology in a population-based autopsy study. Neurology $\underline{60}, 652-656$

Sunderland T, Wolozin B, Galasko D, Levy J, Dukoff R, Bahro M, Lasser R, Motter R, Lehtimäki T, Seubert P (1999): Longitudinal stability of CSF tau levels in Alzheimer patients. Biol Psychiatry $\underline{46}, 750-755$

Szigeti K, Doody RS (2011): Should EOAD patients be included in clinical trials? Alzheimers Res Ther $\underline{3}, 4$

Takada L, Geschwind M (2013): Prion Diseases. Seminars in Neurology 33, 348-356

Takasugi N, Tomita T, Hayashi I, Tsuruoka M, Niimura M, Takahashi Y, Thinakaran G, Iwatsubo T (2003): The role of presenilin cofactors in the gamma-secretase complex. Nature $\underline{422}, 438-441$

Tapiola T, Alafuzoff I, Herukka S-K, Parkkinen L, Hartikainen P, Soininen H, Pirttilä T (2009): Cerebrospinal fluid \{beta\}-amyloid 42 and tau proteins as biomarkers of Alzheimer-type pathologic changes in the brain. Arch Neurol $\underline{66}, 382-389$

Taylor CJ, Ireland DR, Ballagh I, Bourne K, Marechal NM, Turner PR, Bilkey DK, Tate WP, Abraham WC (2008): Endogenous secreted amyloid precursor proteinalpha regulates hippocampal NMDA receptor function, long-term potentiation and spatial memory. Neurobiol Dis $\underline{31}, 250-260$ 
Thinakaran G, Koo EH (2008): Amyloid Precursor Protein Trafficking, Processing, and Function. Journal of Biological Chemistry 283, 29615 -29619

Thompson SA, Graham KS, Patterson K, Sahakian BJ, Hodges JR (2002): Is knowledge of famous people disproportionately impaired in patients with early and questionable Alzheimer's disease? Neuropsychology 16, 344-358

Toledo JB, Brettschneider J, Grossman M, Arnold SE, Hu WT, Xie SX, Lee VM-Y, Shaw LM, Trojanowski JQ (2012): CSF biomarkers cutoffs: the importance of coincident neuropathological diseases. Acta Neuropathol 124, 23-35

Town T (2010): Inflammation, Immunity, and Alzheimer's Disease. CNS Neurol Disord Drug Targets $\underline{9}, 129-131$

Turner PR, O'Connor K, Tate WP, Abraham WC (2003): Roles of amyloid precursor protein and its fragments in regulating neural activity, plasticity and memory. Prog Neurobiol $\underline{70}, 1-32$

Vassar R (2001): The beta-secretase, BACE: a prime drug target for Alzheimer's disease. J Mol Neurosci 17, 157-170

Vassar R, Bennett BD, Babu-Khan S, Kahn S, Mendiaz EA, Denis P, Teplow DB, Ross S, Amarante P, Loeloff R, et al. (1999): Beta-secretase cleavage of Alzheimer's amyloid precursor protein by the transmembrane aspartic protease BACE. Science 286, 735-741

Velayos JL, Irujo A, Cuadrado-Tejedor M, Paternain B, Moleres FJ, Ferrer V (2009): The cellular prion protein and its role in Alzheimer disease. Prion $\underline{3}, 110-117$

Vemuri P, Wiste HJ, Weigand SD, Knopman DS, Trojanowski JQ, Shaw LM, Bernstein MA, Aisen PS, Weiner M, Petersen R., Jack C. (2010): Serial MRI and CSF biomarkers in normal aging, MCI, and AD. Neurology $\underline{75}, 143-151$

Verbeek MM, Kremer BPH, Rikkert MO, Van Domburg PHMF, Skehan ME, Greenberg SM (2009): Cerebrospinal fluid amyloid beta(40) is decreased in cerebral amyloid angiopathy. Ann Neurol $\underline{66}, 245-249$

Vidoni ED, Townley RA, Honea RA, Burns JM (2011): Alzheimer disease biomarkers are associated with body mass index. Neurology $\underline{77}, 1913-1920$

Vincent B, Sunyach C, Orzechowski H-D, St George-Hyslop P, Checler F (2009): p53Dependent transcriptional control of cellular prion by presenilins. J Neurosci $\underline{29}$, $6752-6760$

Vlad SC, Miller DR, Kowall NW, Felson DT (2008): Protective effects of NSAIDs on the development of Alzheimer disease. Neurology $\underline{70}, 1672-1677$

Vogelsberg-Ragaglia V, Schuck T, Trojanowski JQ, Lee VM (2001): PP2A mRNA expression is quantitatively decreased in Alzheimer's disease hippocampus. Exp Neurol $\underline{168}, 402-412$

Voigtländer T, Klöppel S, Birner P, Jarius C, Flicker H, Verghese-Nikolakaki S, Sklaviadis T, Guentchev M, Budka H (2001): Marked increase of neuronal prion protein immunoreactivity in Alzheimer's disease and human prion diseases. Acta 
Neuropathol $\underline{101}, 417-423$

Weiner MW, Aisen PS, Jack CR, Jagust WJ, Trojanowski JQ, Shaw L, Saykin AJ, Morris JC, Cairns N, Beckett LA, et al. (2010): The Alzheimer's Disease Neuroimaging Initiative: Progress report and future plans. Alzheimers Dement $\underline{6}$, 202-11.e7

Weingarten MD, Lockwood AH, Hwo SY, Kirschner MW (1975): A protein factor essential for microtubule assembly. Proc Natl Acad Sci USA $\underline{72}$, 1858-1862

Weise J, Sandau R, Schwarting S, Crome O, Wrede A, Schulz-Schaeffer W, Zerr I, Bähr M (2006): Deletion of cellular prion protein results in reduced Akt activation, enhanced postischemic caspase-3 activation, and exacerbation of ischemic brain injury. Stroke $\underline{37}, 1296-1300$

Westaway D, Jhamandas JH (2012): The P's and Q's of cellular PrP-A? interactions. Prion $\underline{6}, 359-363$

Whitehouse IJ, Jackson C, Turner AJ, Hooper NM (2010): Prion protein is reduced in aging and in sporadic but not in familial Alzheimer's disease. J Alzheimers Dis $22,1023-1031$

Wilkosz PA, Seltman HJ, Devlin B, Weamer EA, Lopez OL, DeKosky ST, Sweet RA (2010): Trajectories of Cognitive Decline in Alzheimer's Disease. Int Psychogeriatr $\underline{22}, 281-290$

Wint D (2011): Depression: A shared risk factor for cardiovascular and Alzheimer disease. Cleveland Clinic Journal of Medicine 78, S44-S46

Yan R, Munzner JB, Shuck ME, Bienkowski MJ (2001): BACE2 functions as an alternative alpha-secretase in cells. J Biol Chem $\underline{276}$, 34019-34027

Zhang Y, Thompson R, Zhang H, Xu H (2011): APP processing in Alzheimer's disease. Mol Brain $\underline{4}, 3$

Zilka N, Kazmerova Z, Jadhav S, Neradil P, Madari A, Obetkova D, Bugos O, Novak M (2012): Who fans the flames of Alzheimer's disease brains? Misfolded tau on the crossroad of neurodegenerative and inflammatory pathways. Journal of Neuroinflammation $\underline{9}, 47$ 
8. Abkürzungen

$\mathrm{AD}=$ Alzheimer's disease (Alzheimer-Krankeit)

$\mathrm{ADAM}=$ a disintegrin and metalloproteinase

$\mathrm{AICD}=\mathrm{APP}$ intracellular domain

AMP = antimikrobielles Peptid

ANOVA $=$ analysis of variance

APLP2 = Amyloid beta (A4) precursor-like protein 2

ApoE $=$ Apolipoprotein E

APP $=$ amyloid precursor protein (Amyloid-Vorläuferprotein)

ATP $=$ Adenosintriphosphat

$\mathrm{A} \beta=\beta$-Amyloid

$\mathrm{BACE}=\beta$-site APP cleaving enzyme

CERAD $=$ Consortium to Establish a Registry for Alzheimer's Disease

$\mathrm{CJD}=$ Creutzfeldt-Jakob disease

$\mathrm{CSF}=$ cerebrospinal fluid (Liquor cerebrospinalis)

$\mathrm{CTF}=$ carboxyl terminal fragment

$\mathrm{EOAD}=$ early-onset Alzheimer's disease

GPI $=$ Glycosylphosphatidylinositol

ICD = International Statistical Classification of Diseases and Related Health Problems

IDE = insulin degrading enzyme (Insulysin)

$\mathrm{IFN}=$ Interferon

$\mathrm{IQR}=$ interquartile range

$\mathrm{kDa}=$ Kilodalton

Leu $=$ Leucin

LOAD = late-onset Alzheimer's disease

Lys $=$ Lysin

M bzw. $\mathrm{m}=$ Methionin

$\mathrm{MAP}=$ microtubule-associated protein

$\mathrm{MAP}=$ mitogen-activated protein

MCI = mild cognitve impairment

MMSE $=$ mini-mental state examination, Mini-Mental-Status-Test

MRI = magnetic resonance imaging

$\mathrm{mRNA}=$ messenger ribonucleic acid

n.a. $=$ nicht angegeben

$\mathrm{NFT}=$ neurofibrillary tangle

NINCDS-ADRDA = National Institute of Neurological and Communicative Disorders and Stroke / 
Alzheimer's Disease and Related Disorders Association

NMDA $=$ N-Methyl-D-Aspartat

NPDPK $=$ non-proline directed protein kinases

$\mathrm{NRL}=$ NOD-like receptor

$\mathrm{NRZ}=$ Nationales Referenzzentrum

n.s. $=$ nicht signifikant

NSAID = nonsteroidal anti-inflammatory drug

PDPK $=$ proline-directed protein kinases

PET $=$ Positronenemissionstomografie

$\mathrm{PHF}=$ paired helical filament

$\operatorname{PrPc}=$ prion protein cellular

$\operatorname{PrPsc}=$ prion protein scrapie

$\mathrm{PRR}=$ pattern recognition receptor

$\mathrm{pTau}=\mathrm{p}-\mathrm{tau}=$ phosphorylated tau protein

RAGE $=$ receptor for advanced glycation endproducts

rpAD $=$ rapidly progressive Alzheimer's disease

$\mathrm{SD}=$ standard deviation

TACE $=$ tumour necrosis factor- $\alpha$ converting enzyme

$\mathrm{TLR}=$ toll-like receptor

$\mathrm{V}$ bzw. $\mathrm{v}=$ Valin

WHO = World Health Organization (Weltgesundheitsorganisation)

ZNS = Zentralnervensystem 


\section{Danksagung}

Ich danke Frau Professor Inga Zerr für die Überlassung des Dissertationsthemas und Herrn Doktor Christian Schmidt für die Betreuung der vorliegenden Arbeit, sowie allen Mitarbeitern der NRZ, insbesondere Herrn Doktor Martin Wolff, für die fruchtbare Zusammenarbeit. 
Lebenslauf

Ich wurde am 24. Januar 1979 als zweiter Sohn von Dr. Ulrich Bartlau und Ulrike Bartlau, geb. Buhmann, in Göttingen geboren. Von 1985 bis 1989 besuchte ich die Grundschule Bovenden, hiernach von 1990 bis 1991 die Orientierungsstufe Bovenden. Anschließend war ich von 1991 an Schüler des Max-Planck-Gymnasiums in Göttingen, wo ich 1998 das Abitur ablegte. Meinen Wehrdienst leistete ich von 1998 bis 2000 bei der Panzerpionierkompanie 10 in Holzminden.

Von 2001 bis 2009 studierte ich Humanmedizin an der Georg-August-Universität in Göttingen und erlangte die ärztliche Approbation im Dezember 2009.

Im Jahr 2010 konnte ich Rahmen eines einjährigen Forschungsstipendiums am Nationalen Referenzzentrum für die Surveillance Transmissibler Spongiformer Enzephalopathien in Göttingen eine bundesweite klinische Studie über schnell verlaufende Alzheimererkrankungen betreuen und war seit 2011 Promotionsstudent der Universität Göttingen.

Als Assistenzarzt der Abteilung "Anästhesie, Intensiv- und Schmerzmedizin" arbeitete ich von 2012 bis 2014 im Eichsfeld-Klinikum, Heilbad Heiligenstadt.

Seit September 2014 bin ich als Assistenzarzt in der Klinik für Anästhesiologie der Universitätsmedizin Göttingen tätig.

Derzeit lebe ich mit meiner Frau Franziska und meinen Kindern Justus (7 Jahre) und Marlene (5 Jahre) im Heilbad Heiligenstadt, Thüringen. 